\title{
Radiation-Neutralization of Stored Biological Warfare Agents with Low-Yield Nuclear Warheads
}

\author{
H. Kruger
}

August 21, 2000

Lawrence

Livermore

National

Laboratory 


\section{DISCLAIMER}

This document was prepared as an account of work sponsored by an agency of the United States Government. Neither the United States Government nor the University of California nor any of their employees, makes any warranty, express or implied, or assumes any legal liability or responsibility for the accuracy, completeness, or usefulness of any information, apparatus, product, or process disclosed, or represents that its use would not infringe privately owned rights. Reference herein to any specific commercial product, process, or service by trade name, trademark, manufacturer, or otherwise, does not necessarily constitute or imply its endorsement, recommendation, or favoring by the United States Government or the University of California. The views and opinions of authors expressed herein do not necessarily state or reflect those of the United States Government or the University of California, and -shall not be used for advertising or product endorsement purposes.

Work performed under the auspices of the U.S. Department of Energy by the University of California Lawrence Livermore National Laboratory under Contract W-7405-Eng-48.

This report has been reproduced directly from the best available copy.

Available to DOE and DOE contractors from the Office of Scientific and Technical Information P.O. Box 62, Oak Ridge, TN 37831

Prices available from (423) 576-8401 http://apollo.osti.gov/bridge/

Available to the public from the National Technical Information Service

U.S. Department of Commerce 5285 Port Royal Rd., Springfield, VA 22161 http://www.ntis.gov/

$\mathrm{OR}$ Lawrence Livermore National Laboratory Technical Information Department's Digital Library http://www.llnl.gov/tid/Library.html 


\title{
Radiation-Neutralization of Stored Biological Warfare Agents with Low-Yield Nuclear Warheads
}

\author{
Hans Kruger \\ Q Division
}

August 2000

Approved for public release.

Further dissemination unlimited. 


\begin{abstract}
MCNP Monte Carlo radiation transport computations were performed exploring the capability of low-yield nuclear fusion and fission warheads to neutralize biological warfare agents with the radiation dose deposited in the agent by the prompt neutron output. The calculations were done for various typical storage configurations on the ground in the open air or in a warehouse building.

This application of nuclear weapons is motivated by the observation that, for some military scenarios, the nuclear collateral effects area is much smaller than the area covered with unacceptable concentrations of biological agent dispersed by the use of conventional high explosive warheads.

These calculations show that biological agents can be radiation-neutralized by low-yield nuclear warheads over areas that are sufficiently large to be useful for military strikes. This report provides the calculated doses within the stored agent for various ground ranges and heights-of-burst.
\end{abstract}

\title{
Introduction
}

Storage tanks containing biological warfare agents that are located in buildings or open areas are relatively easy to damage with conventional high explosive warheads. However, this is likely to cause dispersal of the agents. Under some conditions this dispersal can cover very large areas with unacceptable concentrations of biological agent. These biological hazard areas can be very much larger than the collateral damage areas due to the various prompt effects and the radioactive fallout produced by a low-yield nuclear explosion. For this reason, the use of nuclear weapons for neutralization of stored biological warfare agents is sometimes considered.

Nuclear explosions produce many effects that can potentially destroy a biological agent. These effects include blast overpressure, prompt radiation dose, fireball heat, and radiation dose from the delayed gammas and neutrons emitted by the fission debris cloud. The extent to which fireball heat and delayed fission debris radiation will affect the agent depends on the details of how the agent-filled containers are broken open by the blast and other explosion effects, and on the details of the subsequent dispersal of the spilled agent and its mixing with the rising fireball and fission debris cloud. All this is very difficult to treat in sufficient detail with available computer codes. On the other hand, the radiation dose deposited in the agent can be accurately computed given a particular storage configuration. This makes agent neutralization by the prompt radiation output a potentially attractive kill mechanism of nuclear warheads.

It is the purpose of this report to summarize the results of our Monte Carlo computations exploring the capability of low-yield nuclear fusion or fission warheads to neutralize biological agents via the radiation dose deposited in the agent by the prompt neutron output. Since the incremental dose from the prompt gamma output can be shown to be relatively small, it has not been included in these Monte Carlo computations. 
Biological agent is typically stored in barrels or larger storage containers. Aggregates of such barrels or containers can be arranged in a variety of storage configurations. Our Monte Carlo calculations treated several configurations which we believe to be representative of typical storage practices.

We used the MCNP coupled neutron-photon Monte Carlo code for our radiation transport computations [1].

\section{Nuclear Warhead Neutron Outputs}

For the nuclear warhead, we used the same generic fission and fusion types described in our previous reports $[2,3]$.

Our neutron spectra and total neutron emissions per unit of yield are those described by Loewe [4] in the open literature:

Fission type - Army Pulsed Radiation Facility (APRF) reactor leakage spectrum and 0.4 mols of neutrons per kiloton.

Fusion type - Mono-energetic $14 \mathrm{Mev}$ neutrons from the deuterium-tritium reaction and 2.5 mols of neutrons per kiloton.

For the APRF spectrum, we used calculations performed by Kaul et al [5], which we plot in Fig.1.

\section{Radiation Neutralization Criterion}

The current U.S. standard for commercial radiation sterilization of medical products to be used inside the human body is a minimum dose of 2.5 Megarad [6]. Such sterilization is usually done with electron beams or gamma sources.

The total dose in the agent in our calculations consists of energy deposited by neutron interactions and energy deposited by neutron-induced gamma interactions. It will be shown in the remainder of this report, that for the typical agent storage configurations examined here, the total radiation dose in the agent on top of the barrel or container stack is dominated by the neutron dose for the fusion warhead. For the fission warhead, neutrons and gammas contribute approximately equally to the total dose at the top of the stack. For agent located at the bottom of the stack, most of the dose is due to gammas for both warhead type. 
A given dose produced by neutrons is known to be much more damaging to biological systems than the same dose due to gamma or electron interactions, based e.g. on the incidence of cancer among survivors of the Hiroshima and Nagasaki nuclear explosions. However, there appear to be no data published in the open literature addressing the relative effectiveness of neutrons and gammas for neutralization of biological warfare agents.

The author of this paper has used, in his past reports, a radiation neutralization criterion of one Megarad for biological agent such as anthrax [2,3]. Until neutron and gamma exposure data for various potential biological warfare agents become available, a total combined neutron and gamma dose of 1 Megarad continues to be a useful zero-order criterion for assessing the agent neutralization capability of nuclear warheads. This criterion will be used in this report.

\section{MCNP Monte Carlo Code Problem Geometries}

Five different problem geometries were set up for the MCNP computations:

1. A 500 meter radius, 2 meter thick layer consisting of a homogeneous mixture of agent and steel barrels, located on the ground in open air (Fig. 2). This layer represents a large area covered by densely stacked agent-filled barrels.

2. A pyramid stack of ten 200-liter steel barrels filled with agent, on the ground in open air or in a concrete block building with a concrete roof (Fig. 20).

3. A single-layer running stack of six one-ton steel containers filled with agent, on the ground in open air or in a concrete block building with a concrete roof (Fig. 25 with the upper layer of containers removed).

4. A double-layer running stack of eleven one-ton steel containers filled with agent, on the ground in open air or in a concrete block building with a concrete roof (Fig. 25).

5. A cylindrical concrete block building with a steel roof, with a radius varying between 15 and 85 meters, densely packed with double-layer running stacks of 200-liter agent-filled steel barrels to within 3.5 meters from the concrete block wall (Fig. 30).

For all geometries, the soil was 5 meters thick with a radius of $4 \mathrm{~km}$ for the first geometry and $1 \mathrm{~km}$ for the other four geometries. The composition of the soil was dense mixedgrain sand $\left(\mathrm{SiO}_{2}\right)$ with 16 weight percent water and its density was $2.16 \mathrm{~g} / \mathrm{cc}$. On top of the soil was a sealevel-density hemisphere of air with a radius equal to that of the soil. The composition used for the concrete block walls and the concrete roof was that of ordinary Portland-cement based concrete [7]. The density of the concrete block was $1.2 \mathrm{~g} / \mathrm{cc}$ and that of the light-weight concrete roof was $1.5 \mathrm{~g} / \mathrm{cc}$. The agent was modeled as water with a density of $1.0 \mathrm{~g} / \mathrm{cc}$. The agent/barrel mixture used in the first geometry modeled densely stacked 330-liter agent-filled barrels. This mixture had a density of $0.993 \mathrm{~g} / \mathrm{cc}$ with 16.6 percent of the mixture mass consisting of iron. The agent/barrel mixture used at the center of the fifth geometry modeled densely stacked 200-liter agent-filled barrels. The density of this mixture was $1.02 \mathrm{~g} / \mathrm{cc}$ and it contained 13.8 weight percent iron. 
For the pyramid barrel stack and the one- and two-layer running container stacks, i.e. the second, third, and fourth problem geometries, the stack consisted of cylindrical barrels and containers when the burst point was directly above the stack (zero ground range). When the burst point was offset from the stack by a finite ground range, the stack consisted of toroidal barrels or containers centered on ground zero. This shape was chosen in order to increase the probability of neutrons interacting with the agent and thus improving the Monte Carlo statistics of the computed agent radiation dose. This toroidal configuration is shown in the figures.

The outside dimensions of our 200-liter barrel are $50 \mathrm{~cm}$ diameter and $100 \mathrm{~cm}$ height; those of our one-ton container are $80 \mathrm{~cm}$ diameter and $200 \mathrm{~cm}$ height. These barrel and container volumes are nominal values.

For the zero-ground-range cases, the cylindrical barrels had a $300 \mathrm{~cm}$ axial dimension, representing three closely spaced 200-liter barrel stacks lying on the ground with their end surfaces touching. The agent zones, in which the energy deposition was tallied, were $50 \mathrm{~cm}$ long. They were centered on the midpoint of the barrel. The cylindrical containers had a $200 \mathrm{~cm}$ axial dimension with $100 \mathrm{~cm}$ long tally zones centered on the container midpoint.

The toroidal stacks thus actually represent a closely spaced linear array of stacks of cylindrical barrels or containers. The adjacent stacks provide some shielding at the ends of the cylinders. Thus the radiation dose inside an isolated single stack of barrels or containers will be somewhat higher than computed here with the toroidal shapes.

\section{Computed Radiation Doses}

The computed total radiation doses due to neutron and neutron-induced gamma interactions will now be summarized and discussed for each of the five geometries. The summaries for the barrel and container stacks will only deal with the lowest dose found in the stacks. In most geometries, this lowest dose is found in the bottom zone, i.e. the zone in contact with the ground, in that barrel that is just downrange from the vertical centerline of the stack. This is the zone of interest if the purpose of the explosion is to raise the dose in all the agent within the stack above some neutralization criterion.

The radiation doses for all the stack zones for all MCNP computations reported here are tabulated in the Appendix. All radiation doses are normalized to a ten kiloton yield. They can be linearly scaled to other yields of interest.

The total number of source neutrons used in each MCNP computation ranged between about 5 million to about 20 million. In most computational runs this number was sufficient to reduce the statistical uncertainty in the zone with the lowest dose to less than ten percent. The statistical uncertainty for each of the bottom zones is shown in the tabulations contained in the Appendix. The statistical uncertainty for the other zones in the stack is smaller by a factor that is roughly inversely proportional to the square root of the total dose. 


\section{Homogeneous agent/barrel mixture layer}

In Fig. 3 the radiation dose due a $10 \mathrm{kT}$ burst is plotted versus height-of-burst (HOB) for agent zones that had an average depth from the layer's surface ranging from 10 to $190 \mathrm{~cm}$ and an average ground range of $2.5 \mathrm{~m}$. These are the cylindrical zones directly under the burst point. Figs. $4-10$ are similar plots for annular zones at ground ranges from 10 to $450 \mathrm{~m}$. Figs. $11-18$ show such plots for a $10 \mathrm{kT}$ fusion burst.

It can be seen from these figures that there is a particular HOB that maximizes the radiation dose in agent that is located at a given ground range from the burst point. A HOB that is lower or higher than this optimum HOB will result in a lower dose. For example, for a fission warhead the optimum HOB is about $10 \mathrm{~m}$ for a ground range of $10 \mathrm{~m}$, and about $50 \mathrm{~m}$ for a ground range of $70 \mathrm{~m}$. For a fusion warhead, the optimum HOB is similar. This information is useful for selecting a HOB that will maximize the area over which an area-like agent target, such as a storage yard filled with agent containing barrels, will receive a neutralizing dose.

These figures are also useful for making zero-order estimates of dose deposited at the bottom of a barrel stack of some effective average height at some ground range. Based on such a use of these figures, the HOB was chosen as $10 \mathrm{~m}$ for most of the following MCNP computations involving more detailed agent storage configurations. However, some additional MCNP calculations exploring sensitivity to HOB were also done for some of these configurations.

The neutron-to-total-dose ratio versus agent depth is shown in Fig. 19 for a subset of the computations plotted in Figs. 3 - 18 (10 $\mathrm{m}$ average ground range; $10 \mathrm{~m} \mathrm{HOB}$ ). It can be seen that neutron interactions account for a large fraction of the dose in the zone near the surface for both the fission and fusion warhead. The fractional neutron dose from the fission warhead falls off much more rapidly with depth than that from the fusion warhead.

\section{Pyramid stack of 200-liter barrels}

The lowest radiation dose in the pyramid barrel stack versus ground range is plotted in Fig. 21 for both $10 \mathrm{kT}$ fission and fusion yields at $10 \mathrm{~m}$ HOB. This figure shows the dose for the stack both in the open air and in a concrete block building. It can be seen that the concrete building has little effect on the zone with the lowest dose on the bottom of the stack. Examination of the detailed dose distribution tables for the entire stack, contained in the Appendix, shows that the dose at the top of the stack is lowered by about a factor of two by the presence of the building. However, it is the lowest dose at the bottom of the stack that really matters when the purpose of the explosion is to neutralize all the agent in the stack.

For a $10 \mathrm{kT}$ explosion at $10 \mathrm{~m} \mathrm{HOB}$, it follows from Fig. 21 that our radiation neutralization criterion of 1 Megarad total dose is met or exceeded in all parts of the pyramid barrel stack for the fusion weapon at ground ranges less than about $70 \mathrm{~m}$ and for the fission weapon at ranges less than about $10 \mathrm{~m}$. 
Fig. 22 shows the fractional neutron dose versus ground range for this pyramid stack for a $10 \mathrm{~m}$ burst height. This neutron dose is plotted for two tally zones within the stack: the upper zone of the top barrel and the bottom zone of that barrel on the ground with the lowest total dose. The fractional neutron doses for this stack are consistent with those computed for the agent/barrel mixture layer. The neutron dose fraction in the top zone of the top barrel is about $80 \%$ for the fusion and about $60 \%$ for the fission warhead. For the bottom zone of the lowestdose barrel, the neutron fraction is about $20 \%$ for the fusion warhead and negligibly small for the fission warhead.

The HOB dependence of the lowest radiation dose at the bottom of the barrel stack is plotted in Fig. 23 for the stack in the open air or in a concrete block building. The ground ranges for this figure were chosen so that the dose for $10 \mathrm{~m} \mathrm{HOB}$ was near $1 \mathrm{Megarad}$, viz. a range of $80 \mathrm{~m}$ for the fusion and $20 \mathrm{~m}$ for the fission warhead. For this isolated pyramid stack, we do not observe the optimum HOB that the calculations for the agent/barrel layer indicate. Instead, the dose stays constant over a range of burst heights near the ground and it then decreases monotonically for larger burst heights.

In order to examine the sensitivity of the dose to details of the neutron output spectrum, we performed a series of computations using mono-energetic neutron sources in the range from $20 \mathrm{Mev}$ to $10 \mathrm{ev}$. Fig. 24 shows the lowest radiation dose per mol of neutrons in the pyramid stack at a $10 \mathrm{~m}$ ground range and a $10 \mathrm{~m} \mathrm{HOB}$, as a function of neutron energy. We note that the dose per neutron is approximately constant for neutron energies between $6 \mathrm{Mev}$ and $10 \mathrm{ev}$. Thus for warheads, like our generic fission warhead, that produce neutrons in this energy range, all that matters is the total number of neutrons produced in the explosion and not the details of their energy spectrum. For neutrons with energy above $6 \mathrm{Mev}$, the dose per neutron rises significantly with increasing neutron energy - approximately proportional to the 1.5 power of the energy.

\section{Single- and double-layer running stack of one-ton containers}

The lowest radiation dose versus ground range in the single-layer running container stack in open air or in a concrete block building is shown in Fig. 26 for the two warhead types. Fig. 28 shows the same data for the double-layer running container stack.

These two figures show again very little effect of the building on the lowest dose in the stack. It follows from Fig. 26 that, for a $10 \mathrm{kT}$ explosion at $10 \mathrm{~m} \mathrm{HOB}$, our $1 \mathrm{Megarad}$ neutralization criterion is met or exceeded in all parts of the single-layer running container stack for the fusion warhead at ground ranges less than about $70 \mathrm{~m}$ and for the fission warhead at ranges less than about $20 \mathrm{~m}$. For the double-layer running container stack, these ranges are about 15 and $5 \mathrm{~m}$, respectively, as can be seen from Fig. 28 .

The fractional neutron dose versus ground range for a $10 \mathrm{~m}$ HOB for fission and fusion warheads is shown for the single-layer running container stack in Fig. 27 and for the doublelayer stack in Fig. 29. The results are similar to those observed for the pyramid stack, except that the fractional neutron dose for the bottom zone in the two-layer stack also becomes negligible for ground ranges above about 20 meters. 


\section{Building filled with double-layer running barrel stacks}

The lowest radiation dose versus ground range in the double-layer running 200-liter barrel stacks filling the steel-roofed concrete block building is shown in Fig. 31 for the two warhead types. It can be seen that our 1 Megarad neutralization criterion is met or exceeded, for $10 \mathrm{kT}$ at $10 \mathrm{~m} \mathrm{HOB}$, for the fusion warhead at ground ranges less than about $50 \mathrm{~m}$ and for the fission warhead at ground ranges less than about $10 \mathrm{~m}$.

The fractional neutron dose versus ground range, shown in Fig. 32, is similar to that observed for the single-layer running container stack discussed above.

The dependence of the lowest radiation dose in this running stack on HOB is plotted in Fig. 33 for a ground range of $20 \mathrm{~m}$. It shows an optimum HOB similar to that observed for the homogeneous agent/barrel mixture layer, i.e. about $20 \mathrm{~m}$ for the fusion warhead and about 10 to $20 \mathrm{~m}$ for the fission warhead.

\section{Summary and Conclusions}

The prompt neutron output of low-yield nuclear warheads can neutralize biological warfare agents, in typical surface storage configurations, over areas that are sufficient large to be useful for military strikes. For $10 \mathrm{kT}$, the yield used in this report, and a height-of-burst (HOB) of $10 \mathrm{~m}$, a fusion warhead has a neutralization area with a radius of about 50 meters. This radius is about 10 meters for a $10 \mathrm{kT}$ fission warhead. These radii are based on our one Megarad neutralization criterion.

The neutralization areas are approximately the same for agents stored on the ground in open air and for those stored in a typical one-story concrete block warehouse building.

For typical extended, densely packed storage configurations, such as running barrel stacks, there is a particular HOB that maximizes the area over which agent is neutralized. For HOB's either lower or higher than this optimum height, the neutralization area decreases. The optimum $\mathrm{HOB}$ depends on the ground range for which the neutralization criterion is satisfied. This, in turn, depends on the yield and warhead type. For $10 \mathrm{kT}$, the optimum HOB is approximately 40 meters for the fusion and 10 meters for the fission warhead.

The largest fraction of the dose deposited at the top of the storage stack is due to neutron interactions. The dose at the bottom of the stack is mostly deposited by gammas produced in neutron interactions in the upper region of the stack. Neutron doses are expected to be significantly more effective in neutralizing biological warfare agents than gamma doses. However, this higher neutron dose effectiveness does not enhance the neutralization area for the storage configurations used in this report since we found the lowest dose in the stack, which determines the neutralization radius, to be mostly due to gammas. 
For neutron energies below about $6 \mathrm{Mev}$, the radiation dose deposited in the agent per neutron is approximately independent of the neutron energy. For neutrons with energy in the range from 6 to $20 \mathrm{Mev}$, the dose increases approximately in proportion to the 1.5 power of the neutron energy. This observation has two implications:

1. For warheads, such as our fission warhead, that produce neutrons with energies that are mostly below $6 \mathrm{Mev}$, it is the total number of output neutrons per unit of yield that matters, and not the details of the neutron output spectrum.

2. In order for a fission and a fusion warhead to produce the same radiation dose at the bottom of a typical storage stack, the yield of the fission warhead needs to be an order-of-magnitude larger than that of the fusion warhead.

This greater effectiveness of fusion warheads is due not only to the larger dose deposited by $14 \mathrm{Mev}$ neutrons compared to that deposited by the lower-energy neutrons of fission warheads, but also due to the much larger number of neutrons per unit yield produced by fusion warheads (for our generic warhead types: $2.5 \mathrm{mols}$ of neutrons per kiloton versus $0.4 \mathrm{mols} / \mathrm{kT}$ for the fission warhead).

\section{References}

1. "MCNP4B Monte Carlo N-Particle Transport Code System", Oak Ridge National Laboratory Report CCC-660, April 1997.

2. Hans Kruger and Edgar Mendelsohn, "Neutralization of Chemical/Biological Ballistic Warheads by Low-Yield Nuclear Interceptors", Lawrence Livermore National Laboratory Report UCRL-ID-1 10403, August 1992.

3. Hans Kruger, "Defense Against Biological or Chemical Bomblet Warheads with Nuclear Interceptors", Lawrence Livermore National Laboratory Report UCRL-ID-123815, March 1996.

4. William E. Loewe, "Initial Radiations from Tactical Nuclear Weapons", Nuclear Technology, Vol. 70, 274 (1985).

5. Dean C. Kaul and Stephen D. Egbert, "Radiation Leakage from the Army Pulsed Radiation Facility (APRF) Fast Reactor", Science Applications International Corporation Report SAIC89/1423, May 12, 1989.

6. Yoneho Tabata et al, editors, "CRC Handbook of Radiation Chemistry", CRC Press (1991).

7. Harold Etherington, editor, "Nuclear Engineering Handbook", McGraw-Hill Pub., 1958. 
Generic Fission Warhead Neutron Output Spectrum

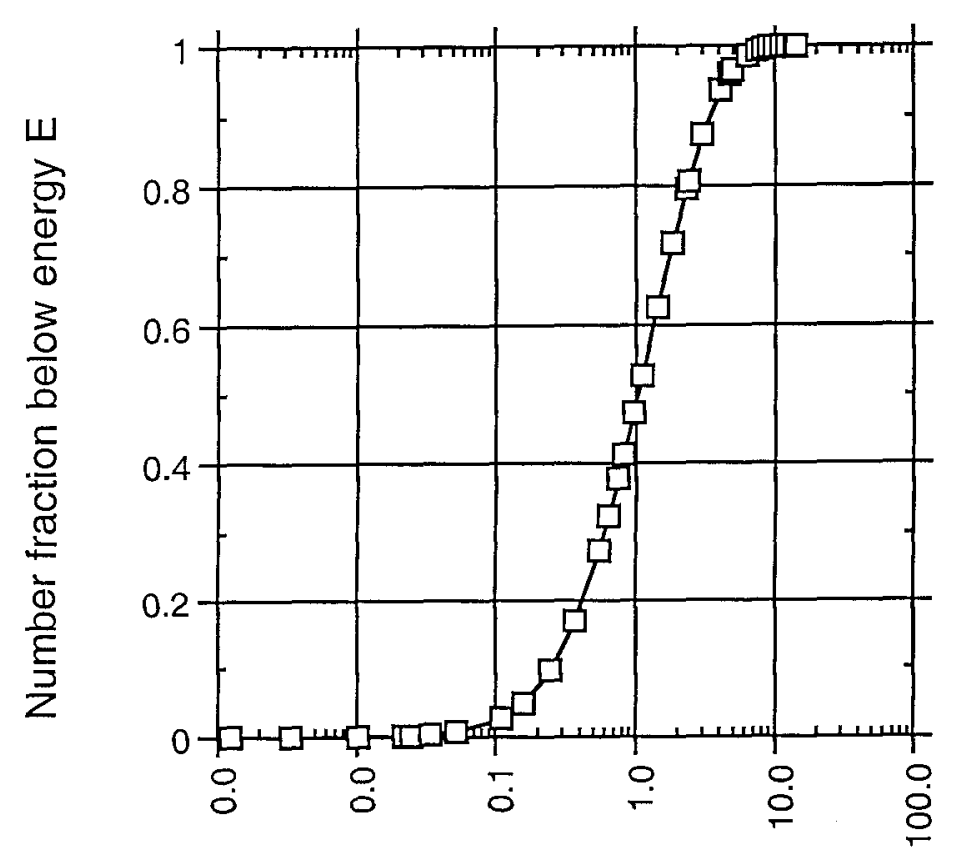

Neutron energy, $E$ (Mev)

Fig. 1 
MCNP Code Geometry for an Agent/Barrel Mixture on the Ground in Open Air

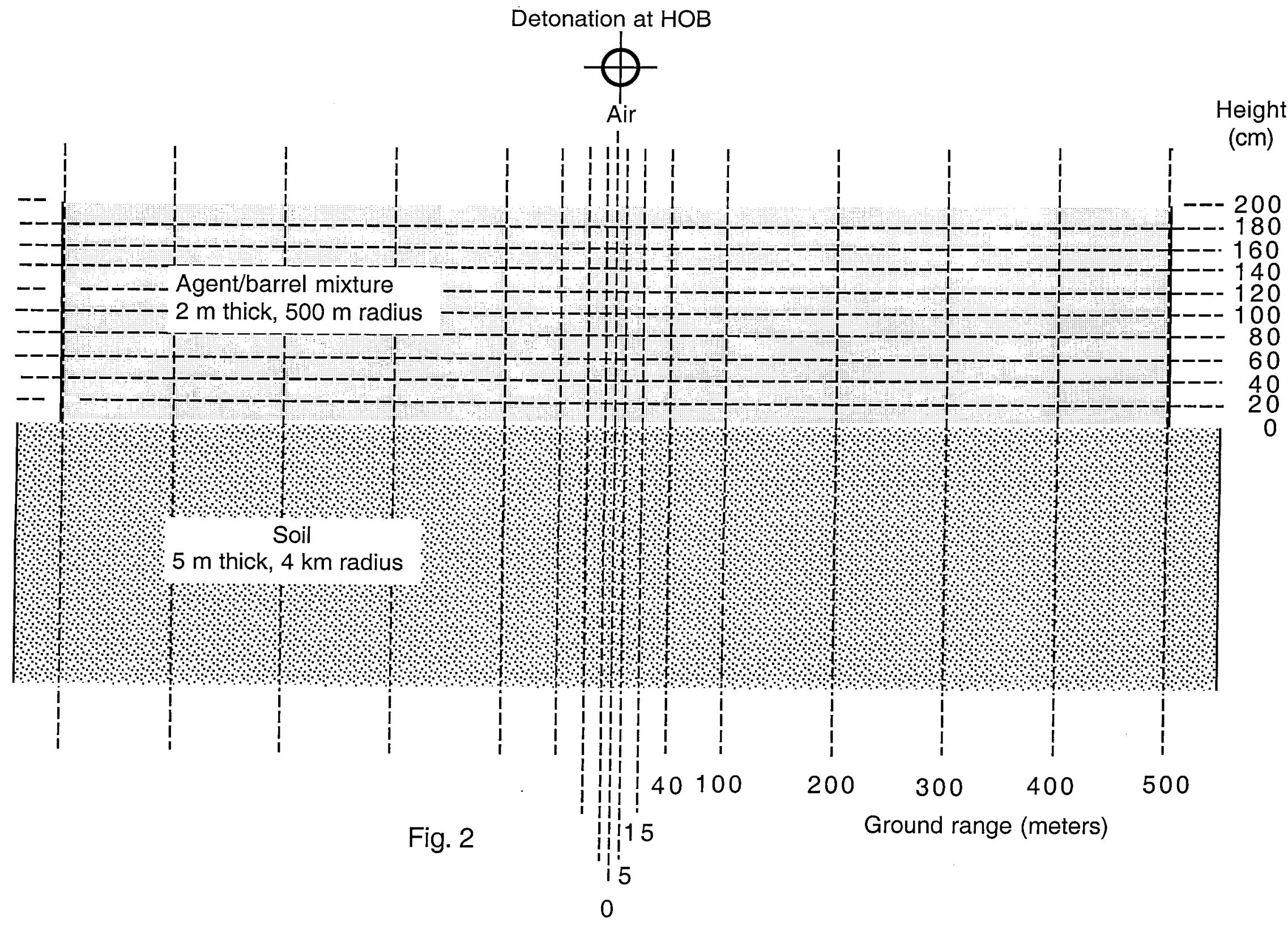


Radiation Dose from $10 \mathrm{kT}$ Fission Yield in an Agent/Barrel Mixture on the Ground in Open Air

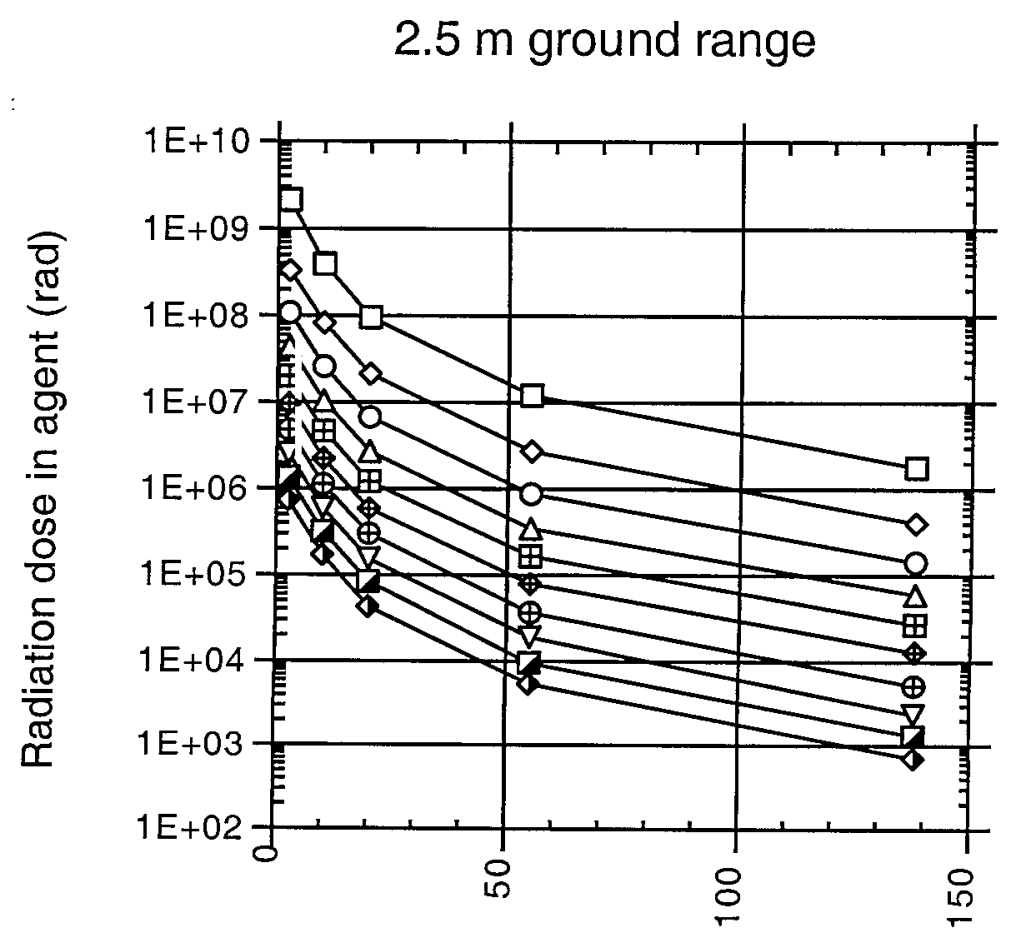

HOB above ground (meters)

Fig. 3
$10 \mathrm{~m}$ ground range

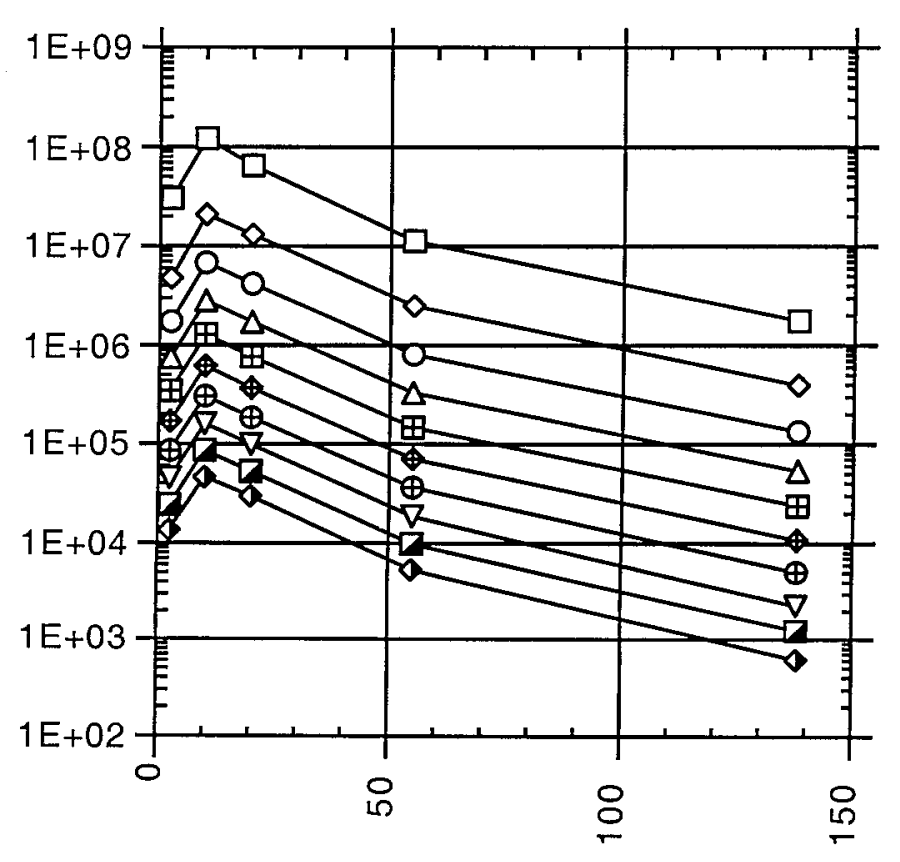

HOB above ground (meters)
Agent depth (cm)

$\square \quad 10$

$\circ \quad 30$

$0 \quad 50$

$\triangle \quad 70$

ㅁ 90

110

(1) 130

$\nabla \quad 150$

ロ 170

- 190

Fig. 4 


\section{Radiation Dose from $10 \mathrm{kT}$ Fission Yield in an Agent/Barrel Mixture on the Ground in Open Air}

$27.5 \mathrm{~m}$ ground range

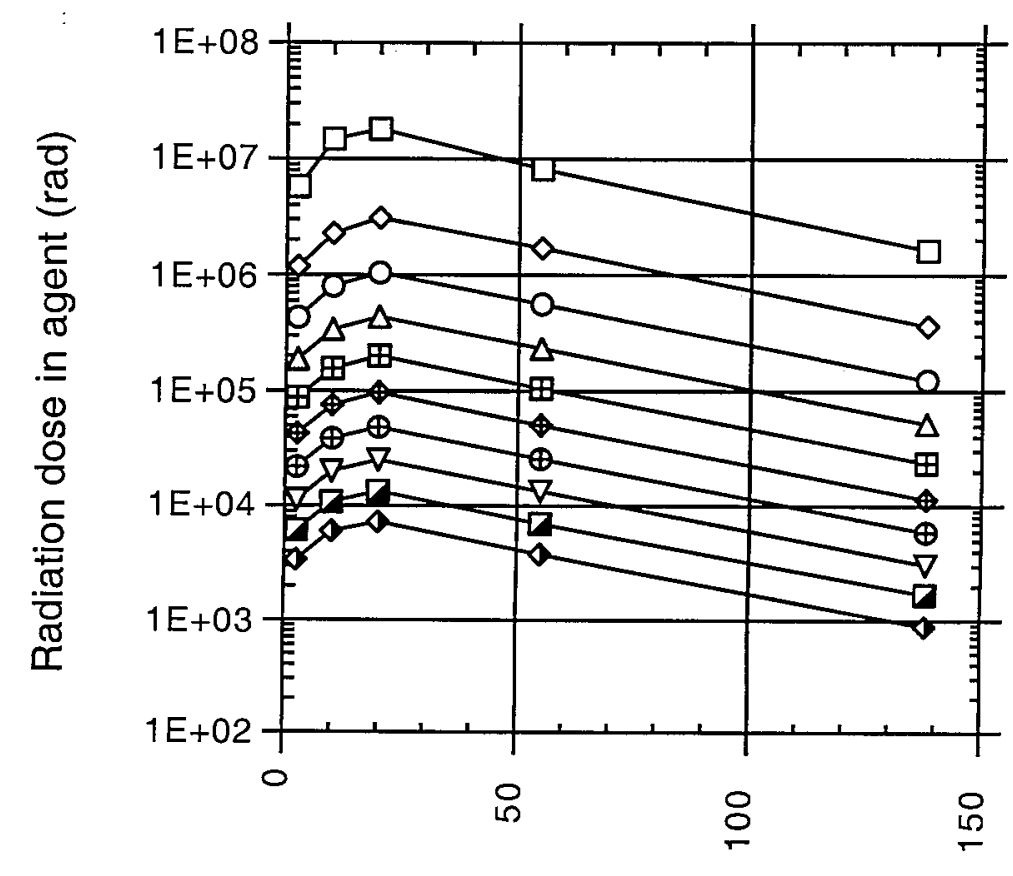

HOB above ground (meters)

Fig. 5
$70 \mathrm{~m}$ ground range

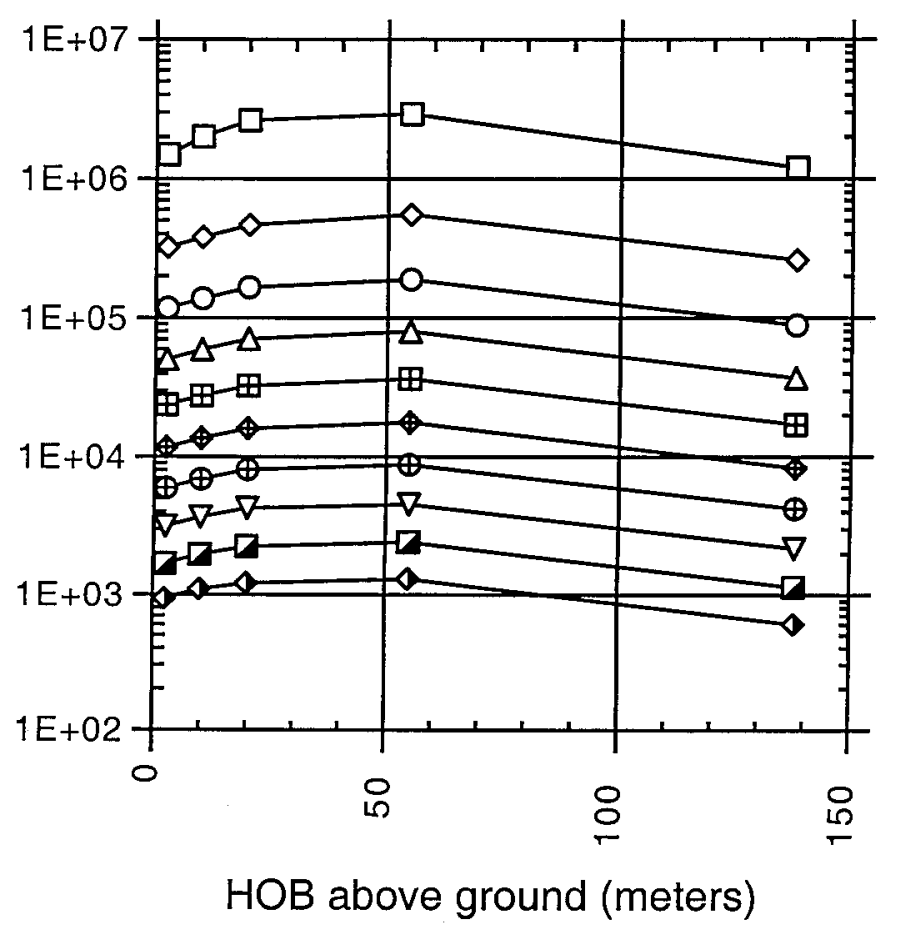

Fig. 6

HOB above ground (meters)
Agent depth (cm)

$\square \quad 10$

- 30

- 50

$\triangle \quad 70$

m 90

- 110

(1) 130

$\nabla \quad 150$

曰 170

- 190 


\section{Radiation Dose from $10 \mathrm{kT}$ Fission Yield in an Agent/Barrel Mixture on the Ground in Open Air}

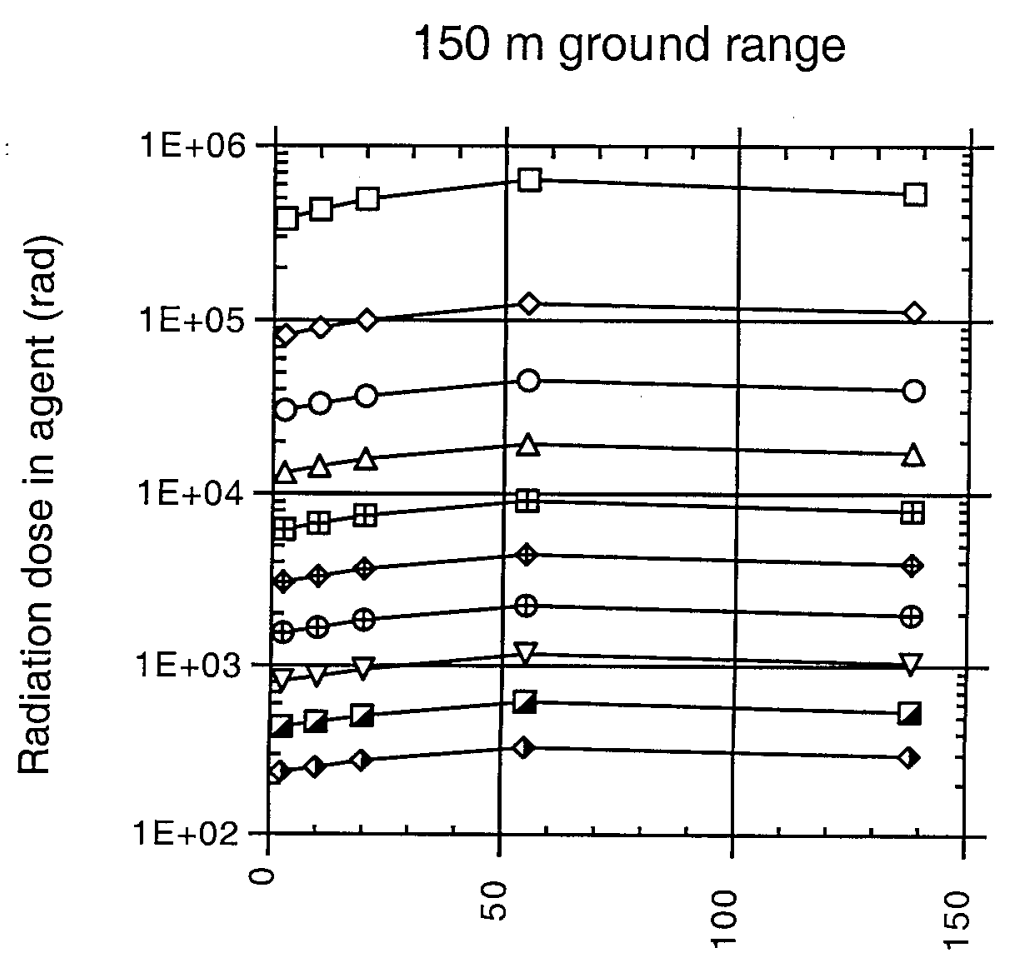

HOB above ground (meters)
$250 \mathrm{~m}$ ground range

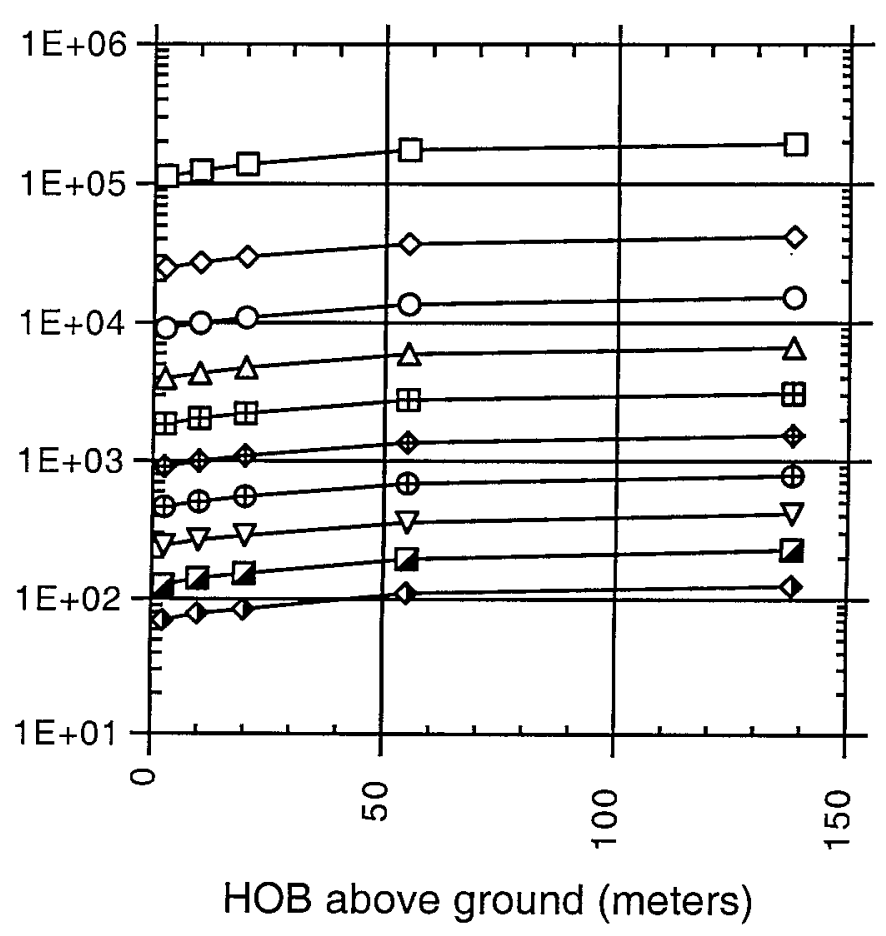

Agent depth $(\mathrm{cm})$

$\square \quad 10$

$\circ \quad 30$

0

$\Delta \quad 70$

m 90

$\$ \quad 110$

(1) 130

$\nabla \quad 150$

(] $\quad 170$

$\checkmark \quad 190$

Fig. 7

Fig. 8 


\section{on the Ground in Open Air}

$350 \mathrm{~m}$ ground range

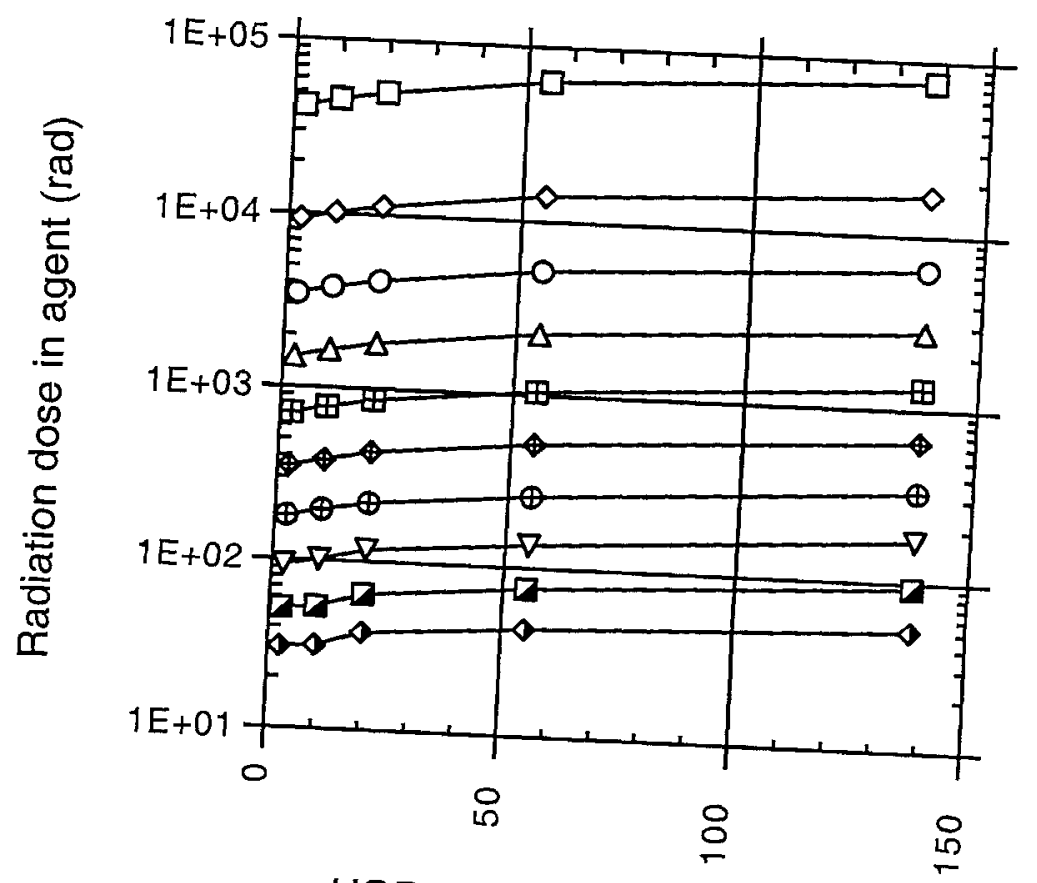

HOB above ground (meters)

Fig. 9
$450 \mathrm{~m}$ ground range

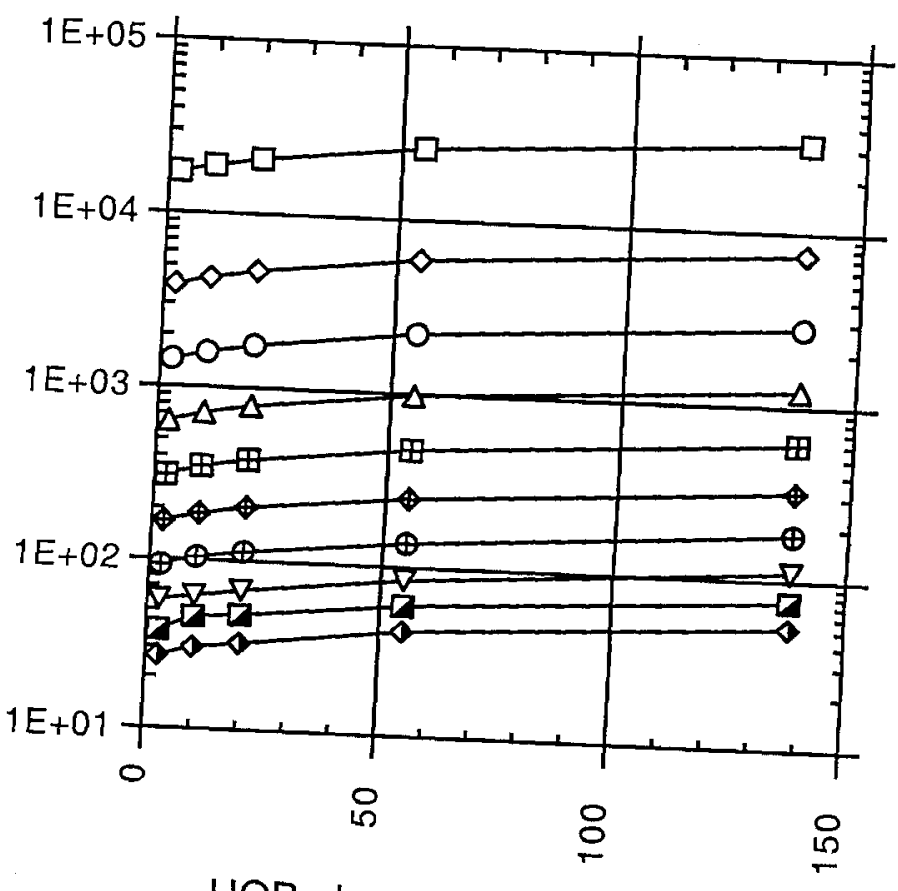

HOB above ground (meters)
Agent depth (cm)

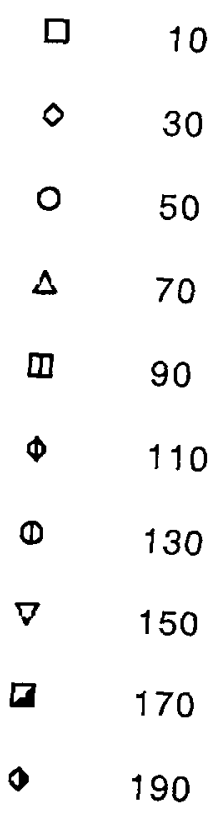

Fig. 10 


\section{Radiation Dose from $10 \mathrm{kT}$ Fusion Yield in an Agent/Barrel Mixture}

on the Ground in Open Air

$2.5 \mathrm{~m}$ ground range

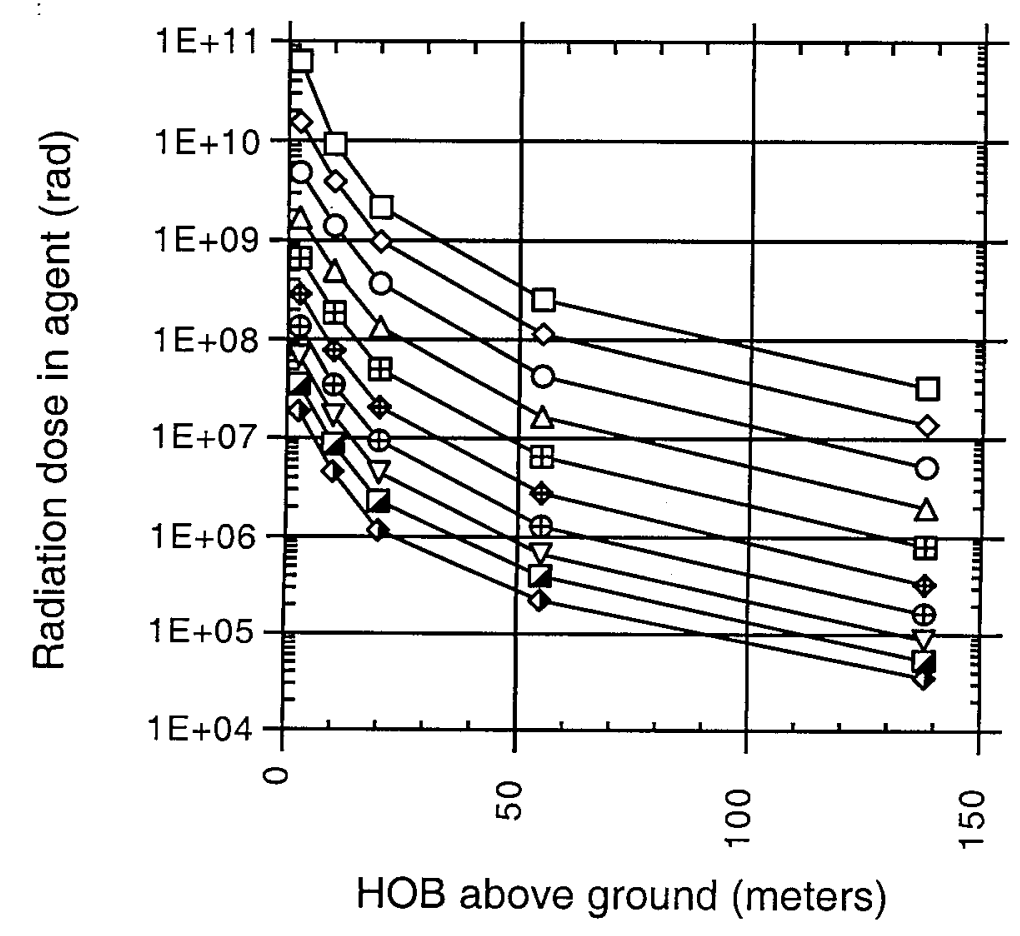

Fig. 11
$10 \mathrm{~m}$ ground range

Agent depth (cm)

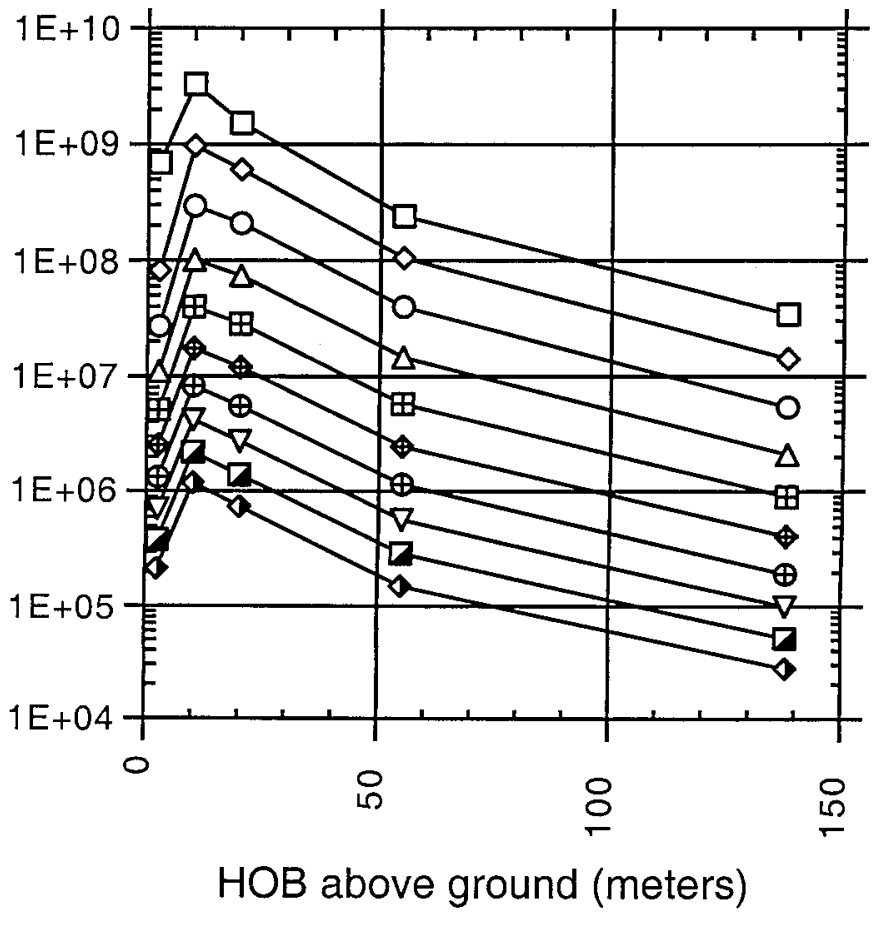

ㅁ 10

$\checkmark \quad 30$

$0 \quad 50$

$\triangle \quad 70$

四 90

$\Phi \quad 110$

(1) 130

$\nabla \quad 150$

曰 170

- 190

Fig. 12 
Radiation Dose from $10 \mathrm{kT}$ Fusion Yield in an Agent/Barrel Mixture on the Ground in Open Air

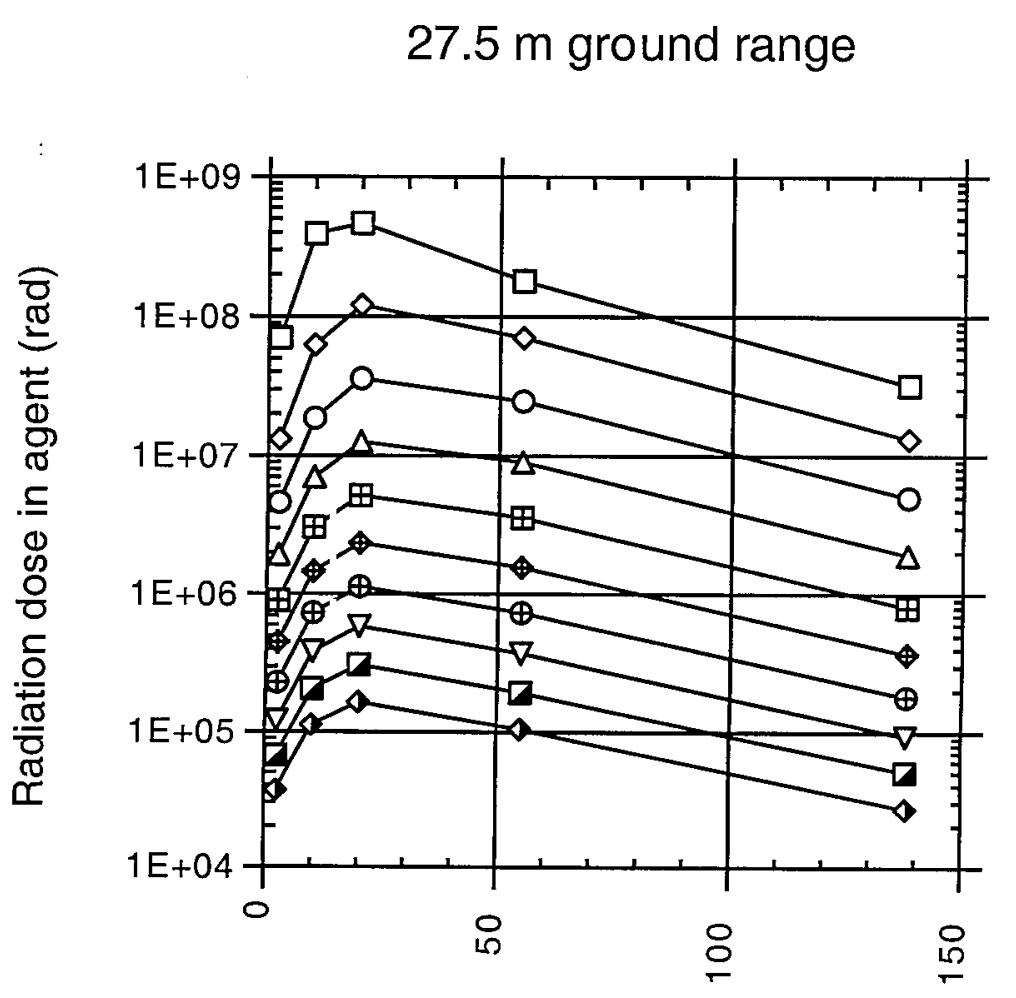

HOB above ground (meters)

Fig. 13
$70 \mathrm{~m}$ ground range

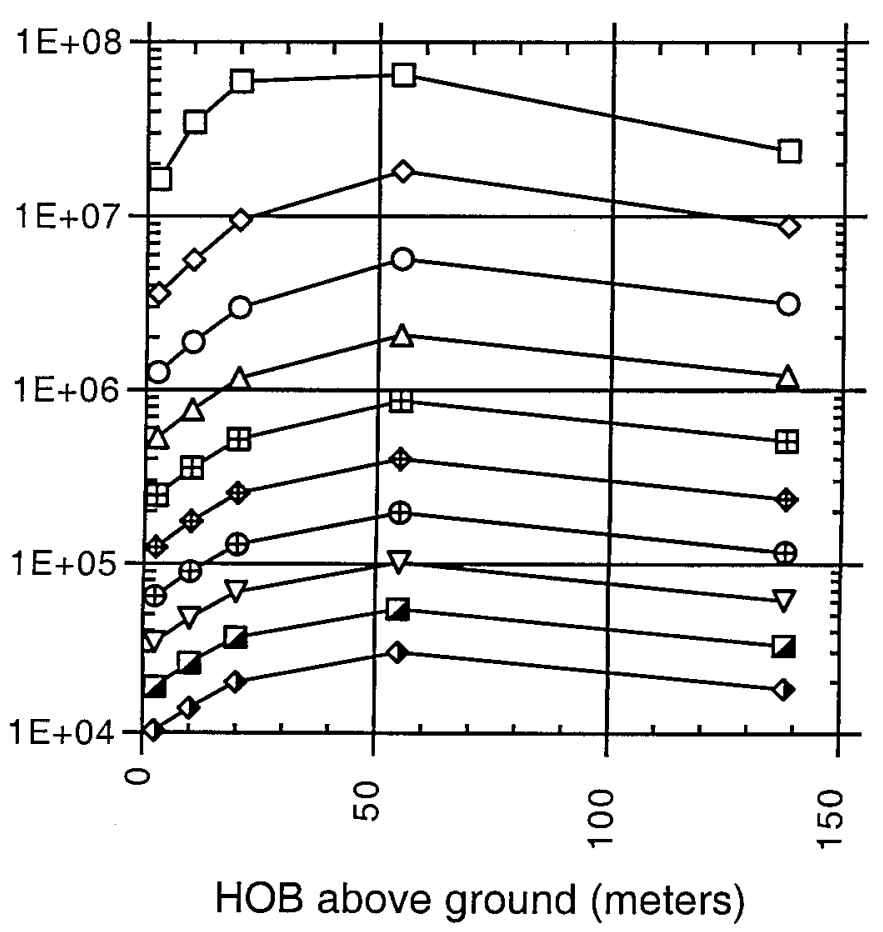

Fig. 14
Agent depth (cm)

\begin{tabular}{ll}
$\square$ & 10 \\
$\diamond$ & 30 \\
\hline & 50 \\
$\Delta$ & 70 \\
$\square$ & 90 \\
$\square$ & 110 \\
$\square$ & 130 \\
$\nabla$ & 150 \\
$\square$ & 170 \\
$\square$ & 190
\end{tabular}


Radiation Dose from $10 \mathrm{kT}$ Fusion Yield in an Agent/Barrel Mixture on the Ground in Open Air

$150 \mathrm{~m}$ ground range

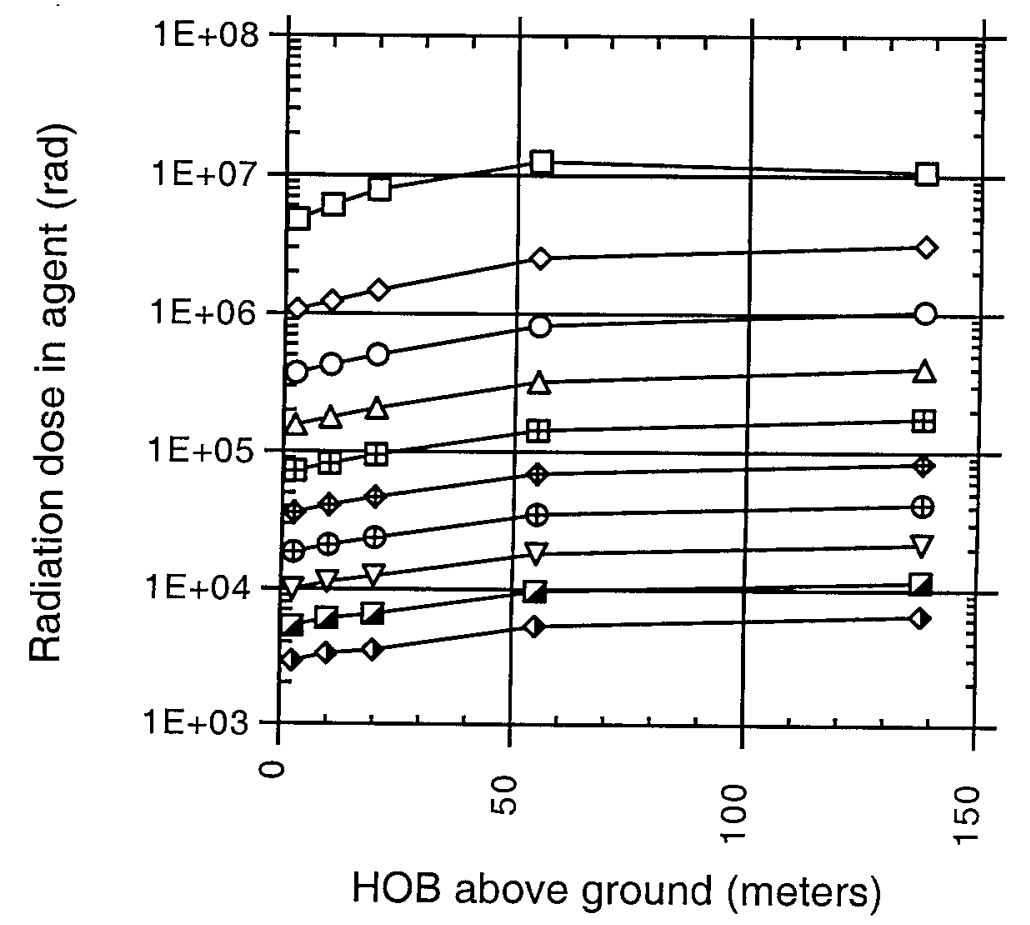

Fig. 15
$250 \mathrm{~m}$ ground range

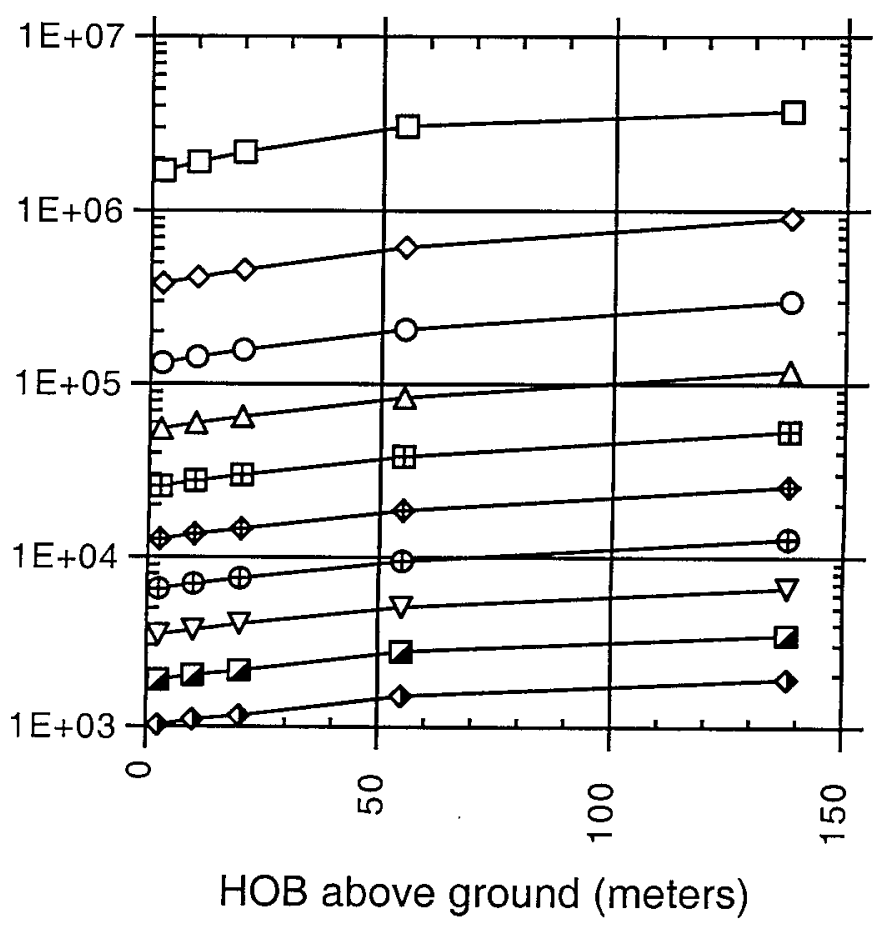

Fig. 16
Agent depth (cm)

\begin{tabular}{ll}
$\square$ & 10 \\
$\nabla$ & 30 \\
\hline & 50 \\
$\Delta$ & 70 \\
$\mathbb{D}$ & 90 \\
$\Phi$ & 110 \\
$\Phi$ & 130 \\
$\nabla$ & 150 \\
$\square$ & 170 \\
$\bullet$ & 190
\end{tabular}




\section{Radiation Dose from $10 \mathrm{kT}$ Fusion Yield in an Agent/Barrel Mixture on the Ground in Open Air}

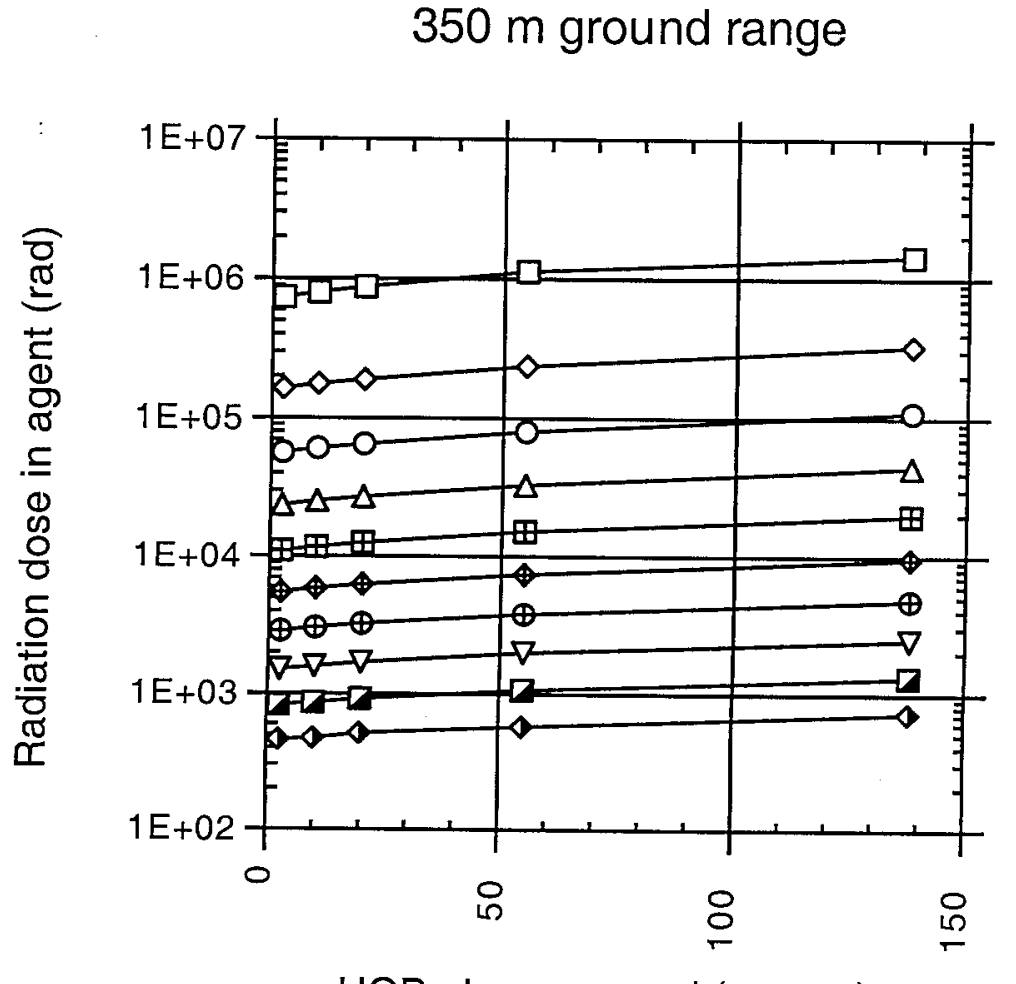

HOB above ground (meters)
$450 \mathrm{~m}$ ground range

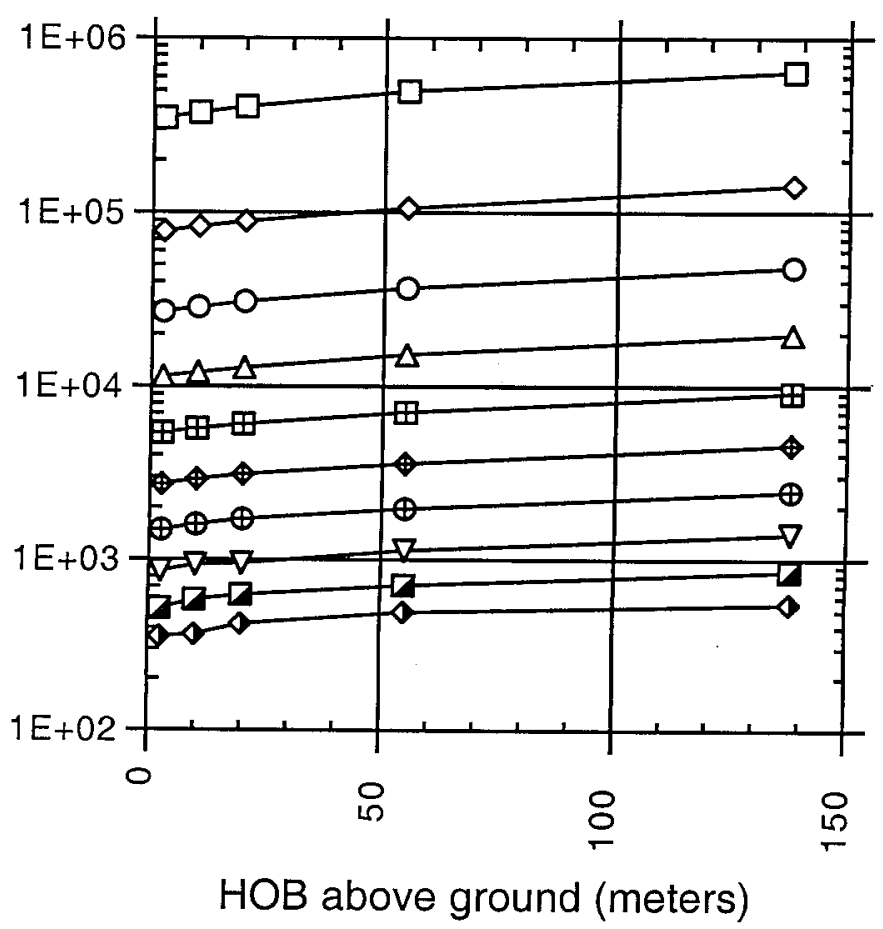

Agent depth $(\mathrm{cm})$

\begin{tabular}{ll}
$\square$ & 10 \\
0 & 30 \\
\hline & 50 \\
$\Delta$ & 70 \\
\hline$\square$ & 90 \\
\hline & 110 \\
\hline & 130 \\
$\nabla$ & 150 \\
$\square$ & 170 \\
\hline & 190
\end{tabular}

$\square \quad 10$ 0

Fig. 17 
Fractional Neutron Dose in an Agent/Barrel Mixture on the Ground in Open Air

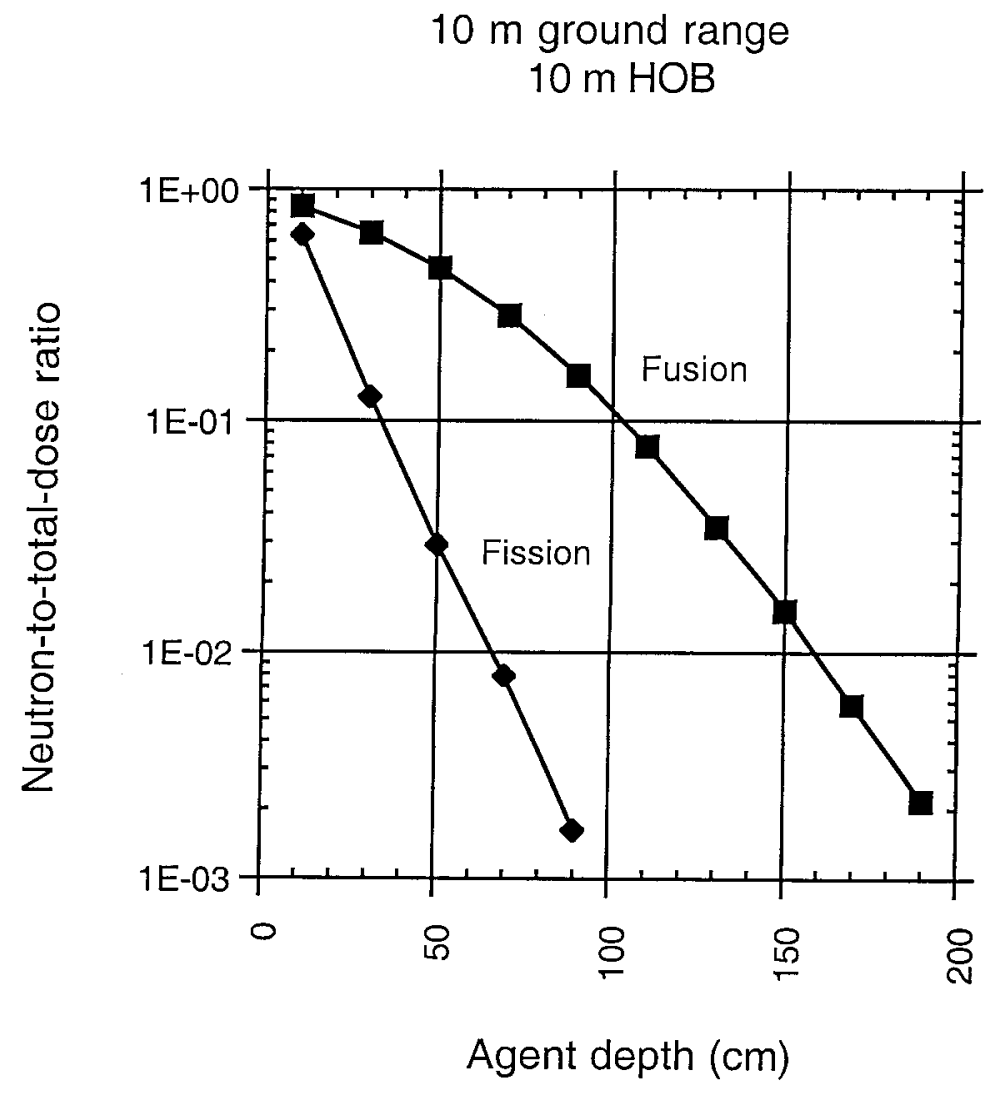

Fig. 19 
MCNP Code Geometry for Pyramid Stack of Agent-Filled 200 liter Barrels in a Storage Building

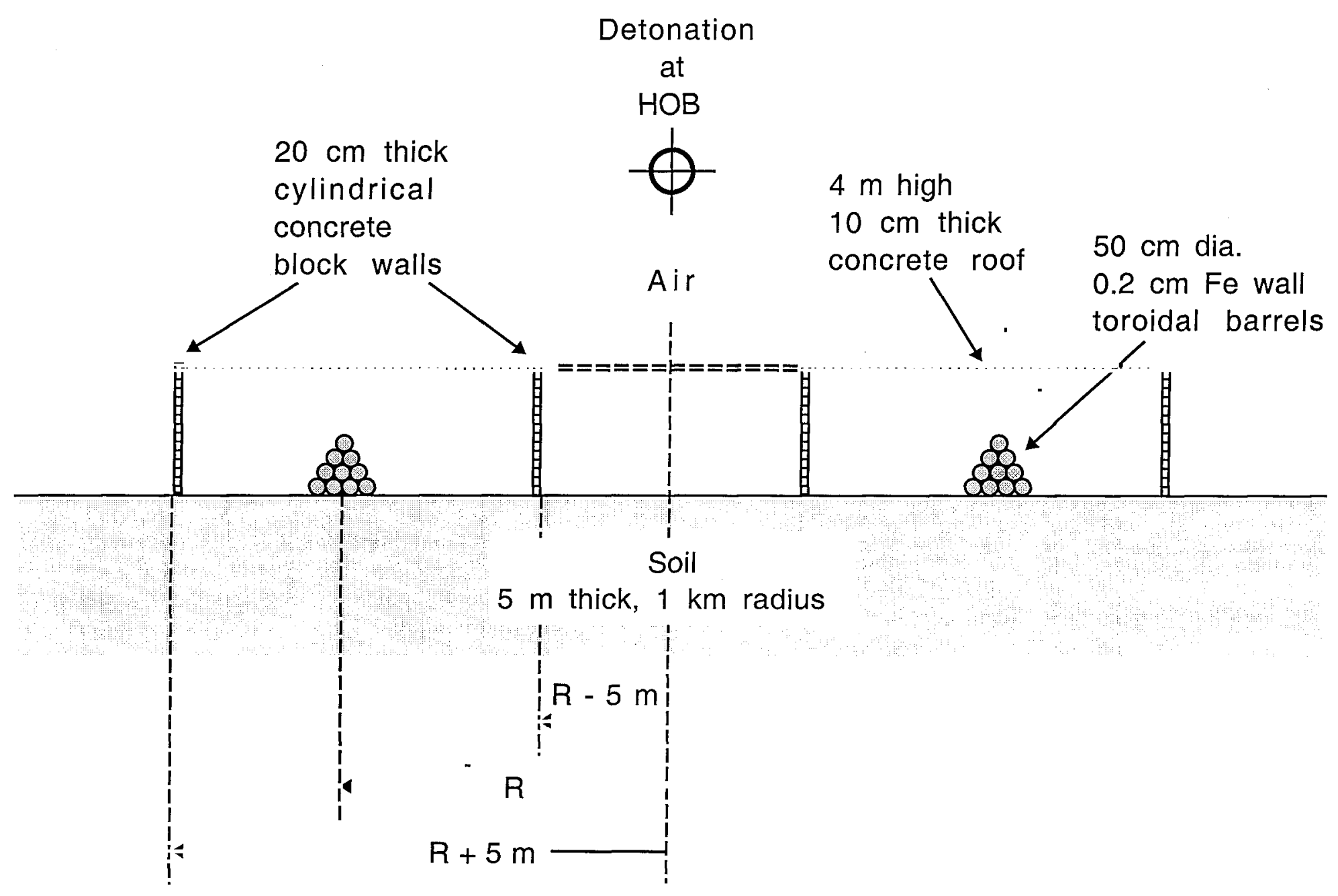

Fig. 20 
Lowest Radiation Dose in Barrel Stack from $10 \mathrm{kT}$ Burst at $10 \mathrm{~m} \mathrm{HOB}$

Adjacent pyramids of ten 200 liter barrels on the ground

in open air or in a concrete block building

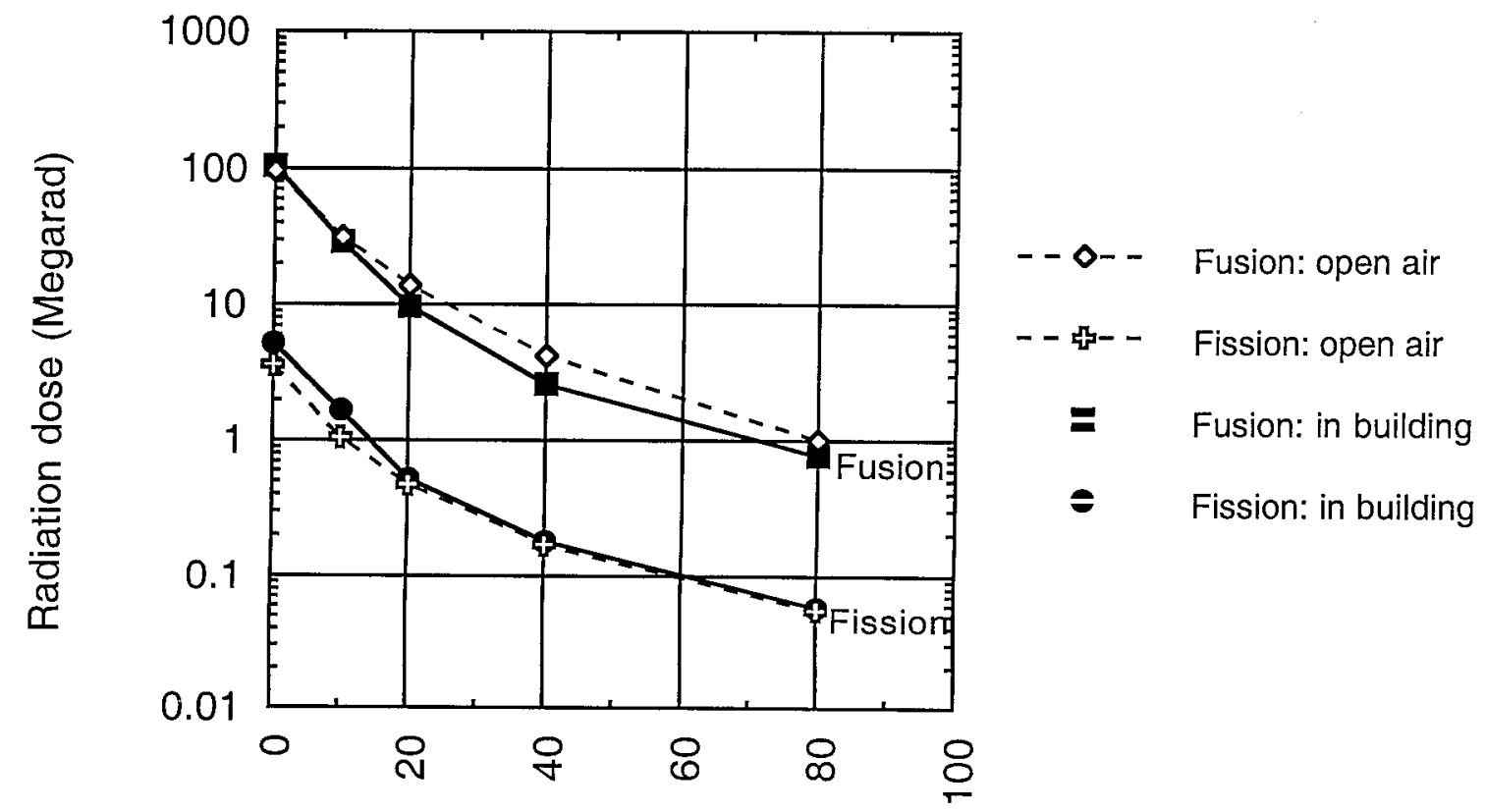

Ground range (meters)

Fig. 21 


\section{Fractional Neutron Dose in a Pyramid Stack of 200-Liter Barrels on the Ground in Open Air}

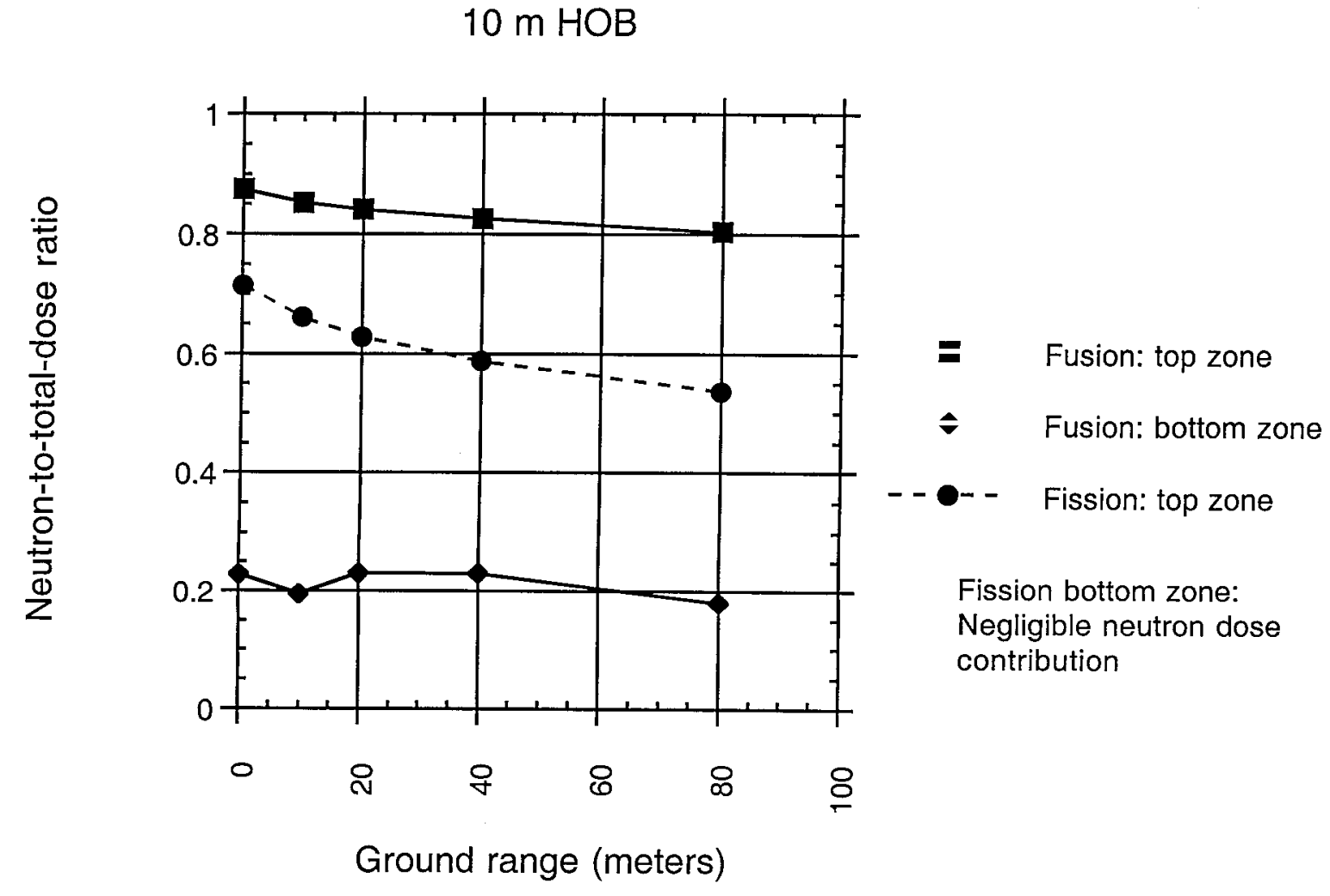

Fig. 22 


\section{HOB Dependence of Lowest Radiation Dose in Barrel Stack}

from a $10 \mathrm{kT}$ Fission or Fusion Burst

Adjacent pyramids of ten 200 liter barrels on the ground

in open air or in a concrete block building

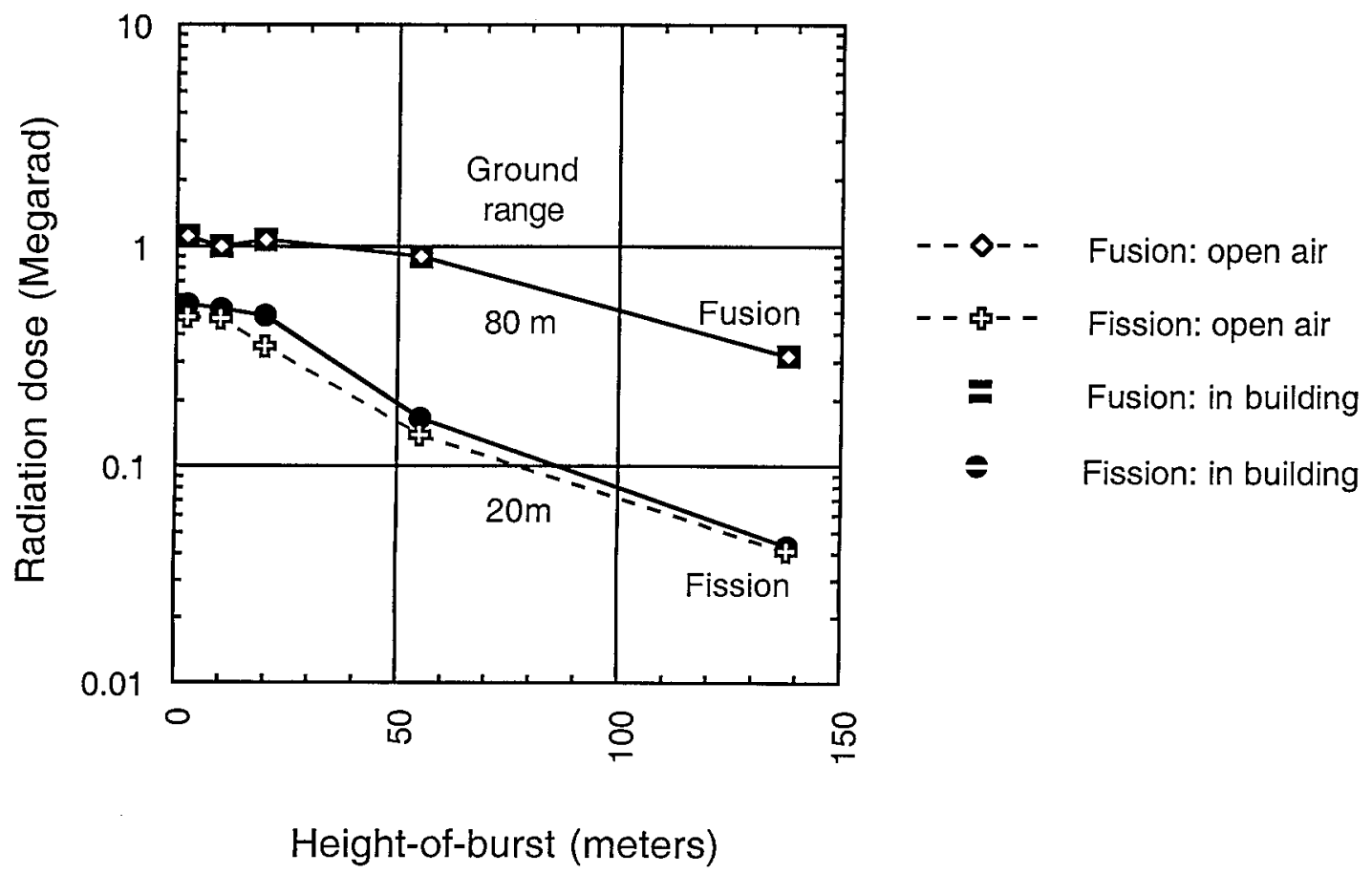

Fig. 23 
Radiation Dose in 200-liter Drums inside a Concrete Block Building at a $80 \mathrm{~m}$ Ground Range

(Megarad)

Yield: $10 \mathrm{kT}$

Neutron spectrum: $14 \mathrm{Mev}$

Fig. A41

$55 \mathrm{~m} \mathrm{HOB}$

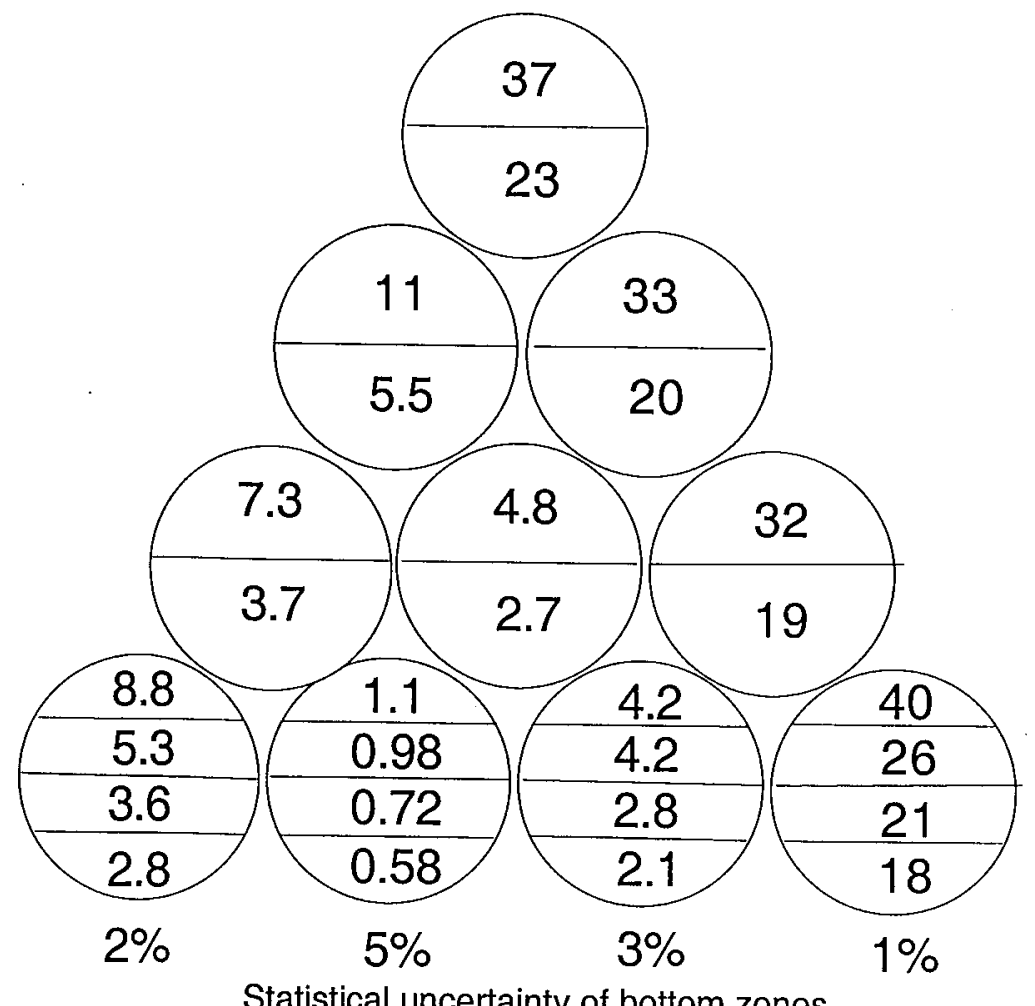

Fig. A42

$138 \mathrm{~m} \mathrm{HOB}$

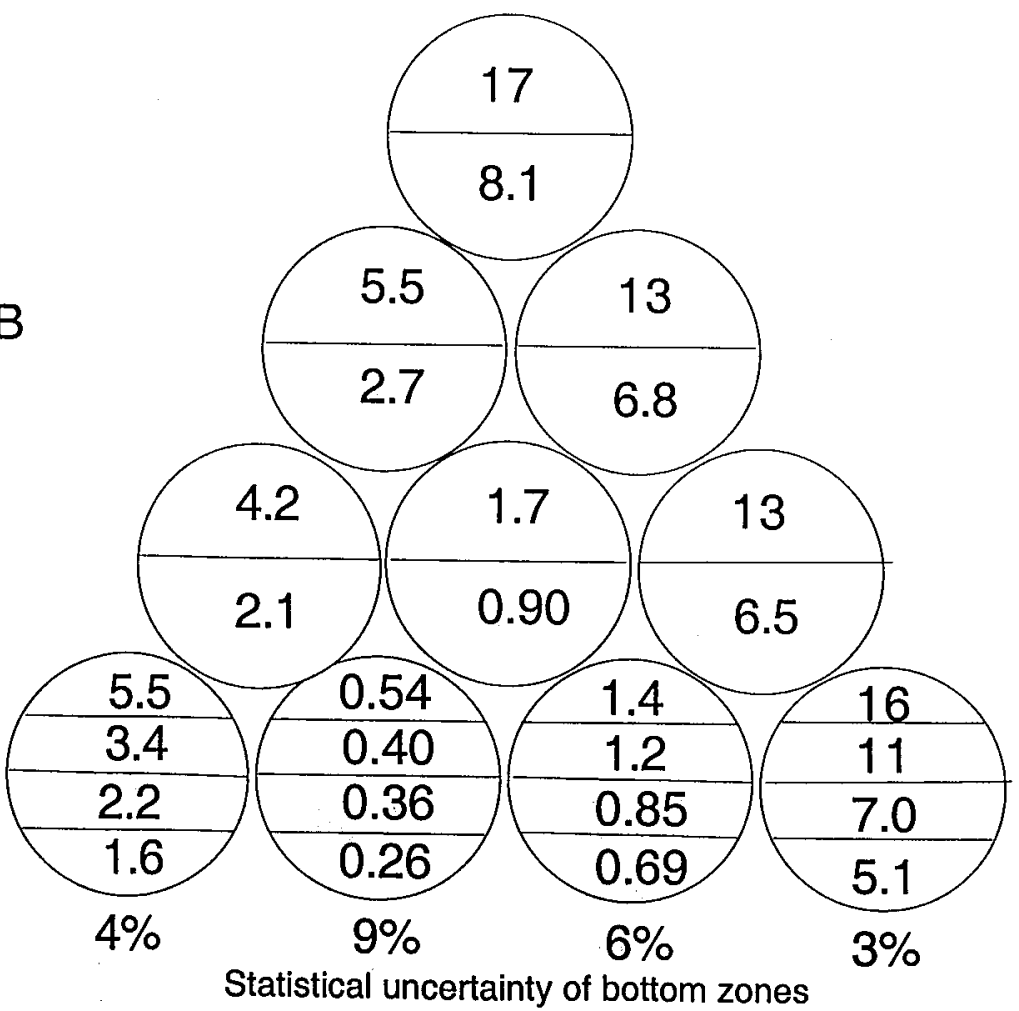


Radiation Dose in 200-liter Drums inside a Concrete Block Building at a $80 \mathrm{~m}$ Ground Range

(Megarad)

Yield: $10 \mathrm{kT}$

Neutron spectrum: $14 \mathrm{Mev}$

Fig. A39

$2.5 \mathrm{~m} \mathrm{HOB}$

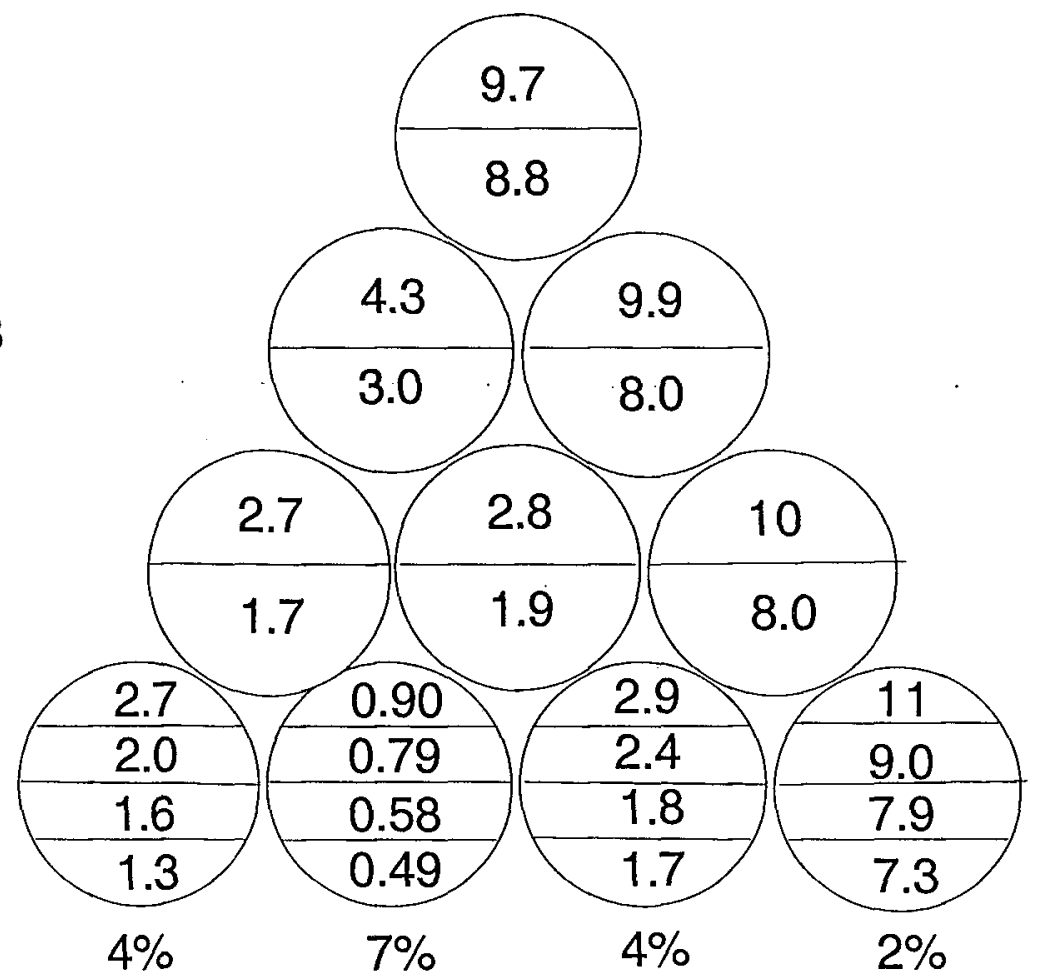

Statistical uncertainty of bottom zones

Fig. A40 $20 \mathrm{~m} \mathrm{HOB}$

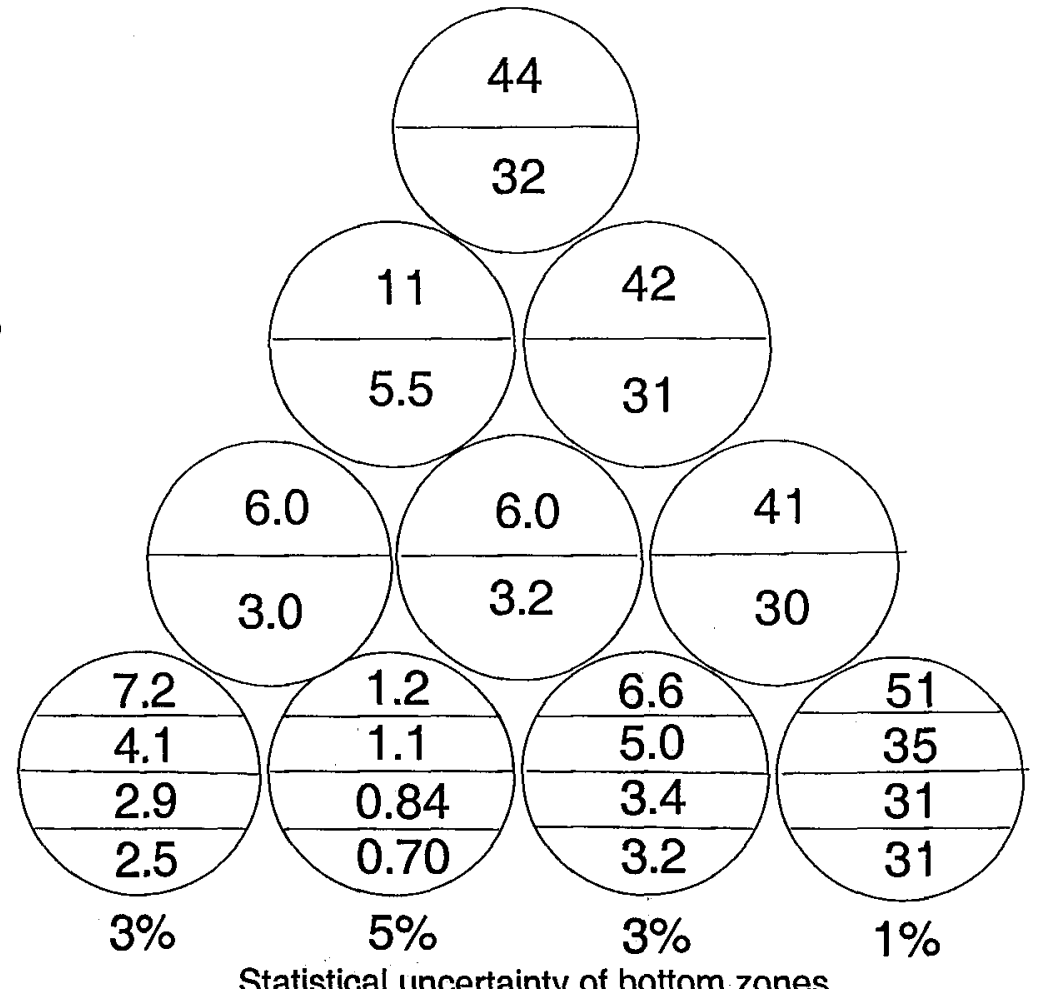

Statistical uncertainty of bottom zones 
Radiation Dose in 200-liter Drums inside a Concrete Block Building at $80 \mathrm{~m}$ Ground Range

(Megarad)

Yield: $10 \mathrm{kT}$

HOB: $10 \mathrm{~m}$

Fig. A37

14 Mev neutrons

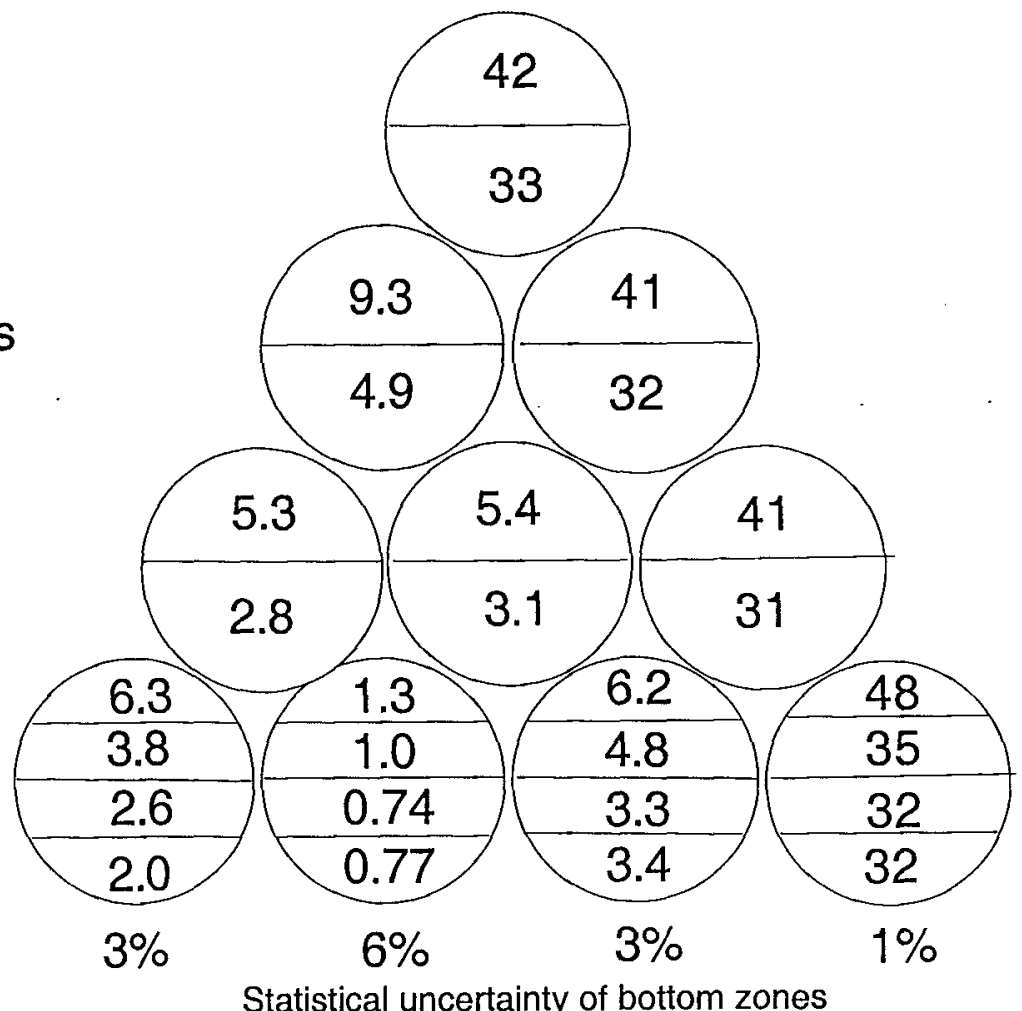

Fig. A38

Fission neutrons

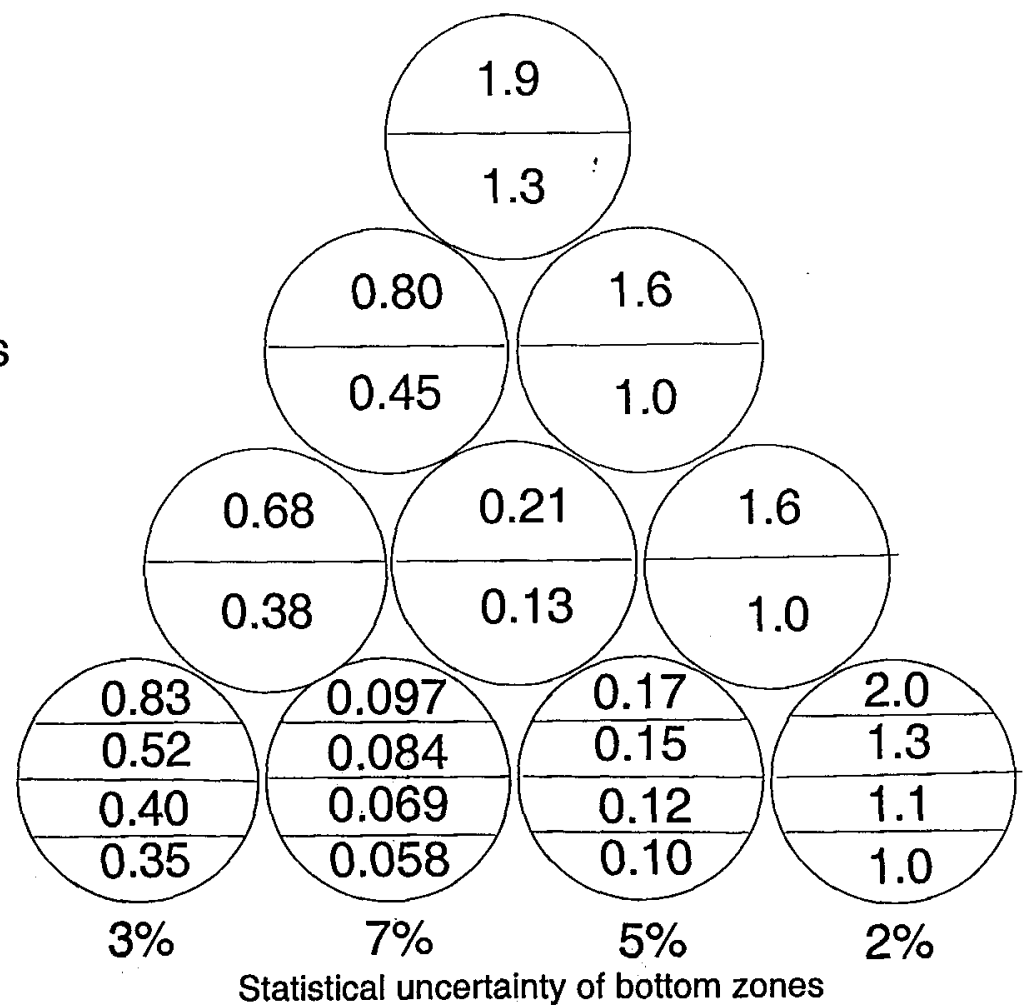


Radiation Dose in 200-liter Drums inside a Concrete Block Building at $40 \mathrm{~m}$ Ground Range (Megarad)

Yield: $10 \mathrm{kT}$

HOB: $10 \mathrm{~m}$

Fig. A35

$14 \mathrm{Mev}$ neutrons

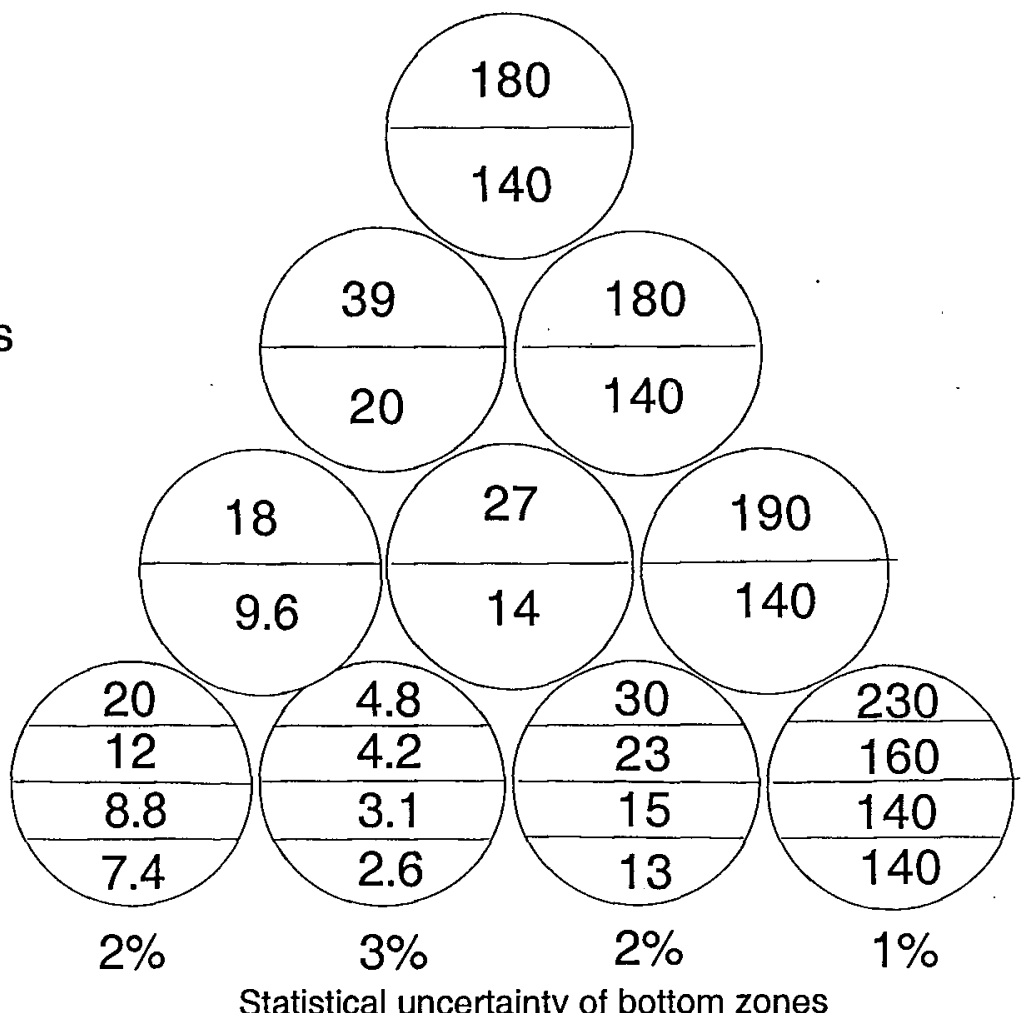

Fig. A36

Fission neutrons

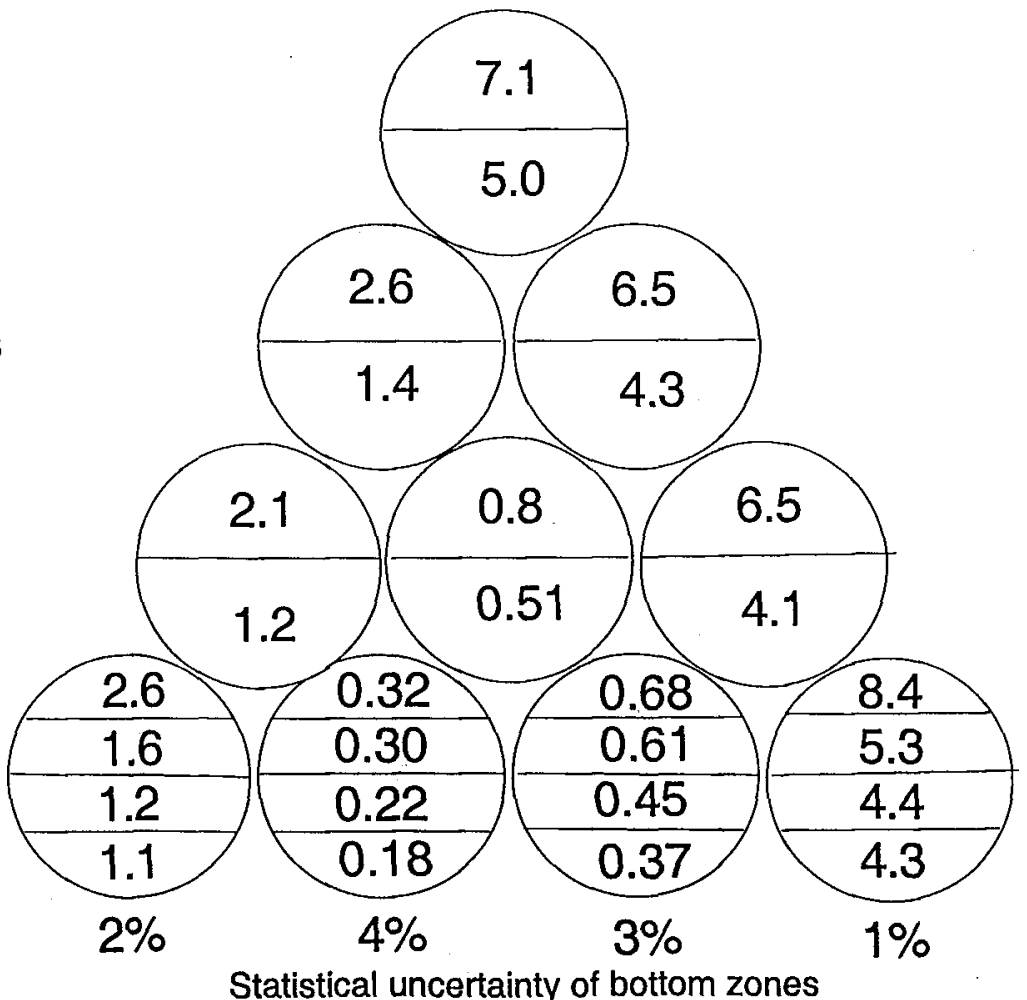


Radiation Dose in 200-liter Drums inside a Concrete Block

Building at $20 \mathrm{~m}$ Ground Range

(Megarad)

Yield: $10 \mathrm{kT}$

HOB: $10 \mathrm{~m}$

Fig. A33

$14 \mathrm{Mev}$ neutrons

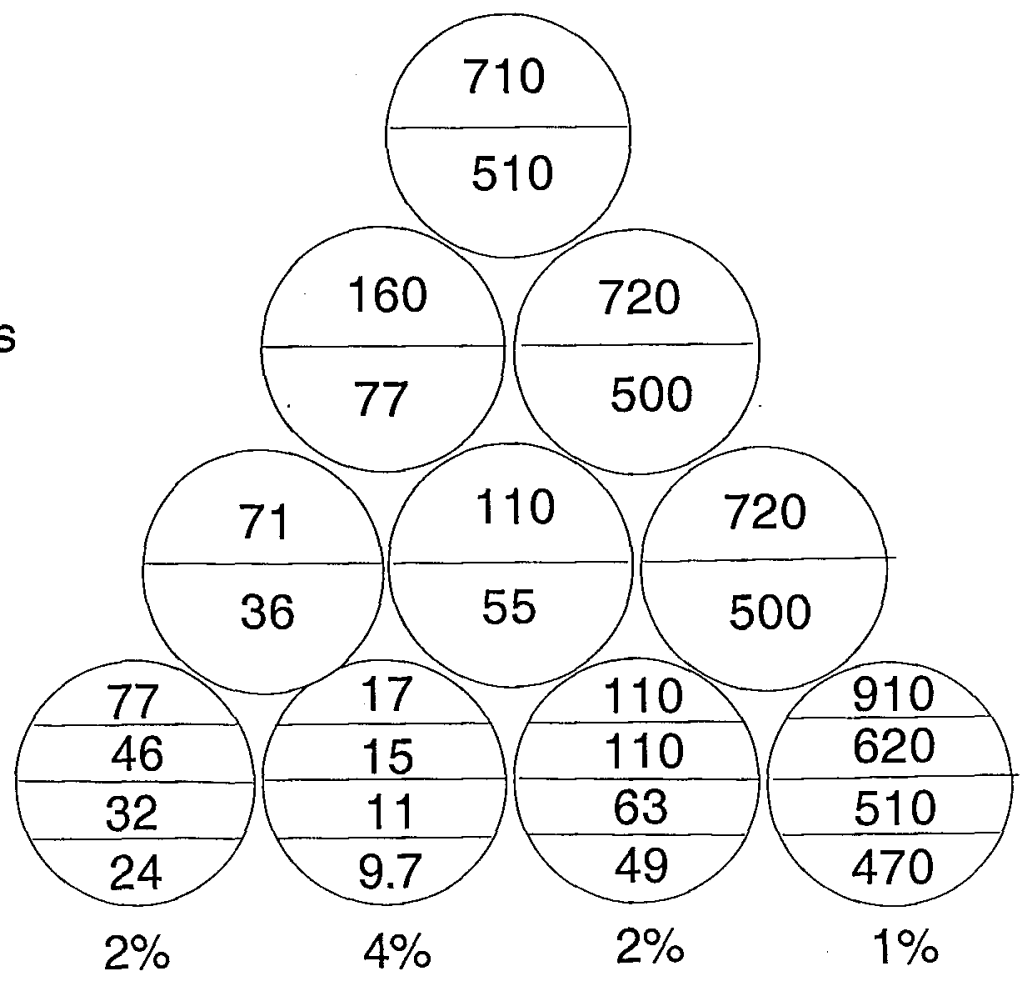

Statistical uncertainty of bottom zones

Fig. A34

Fission neutrons

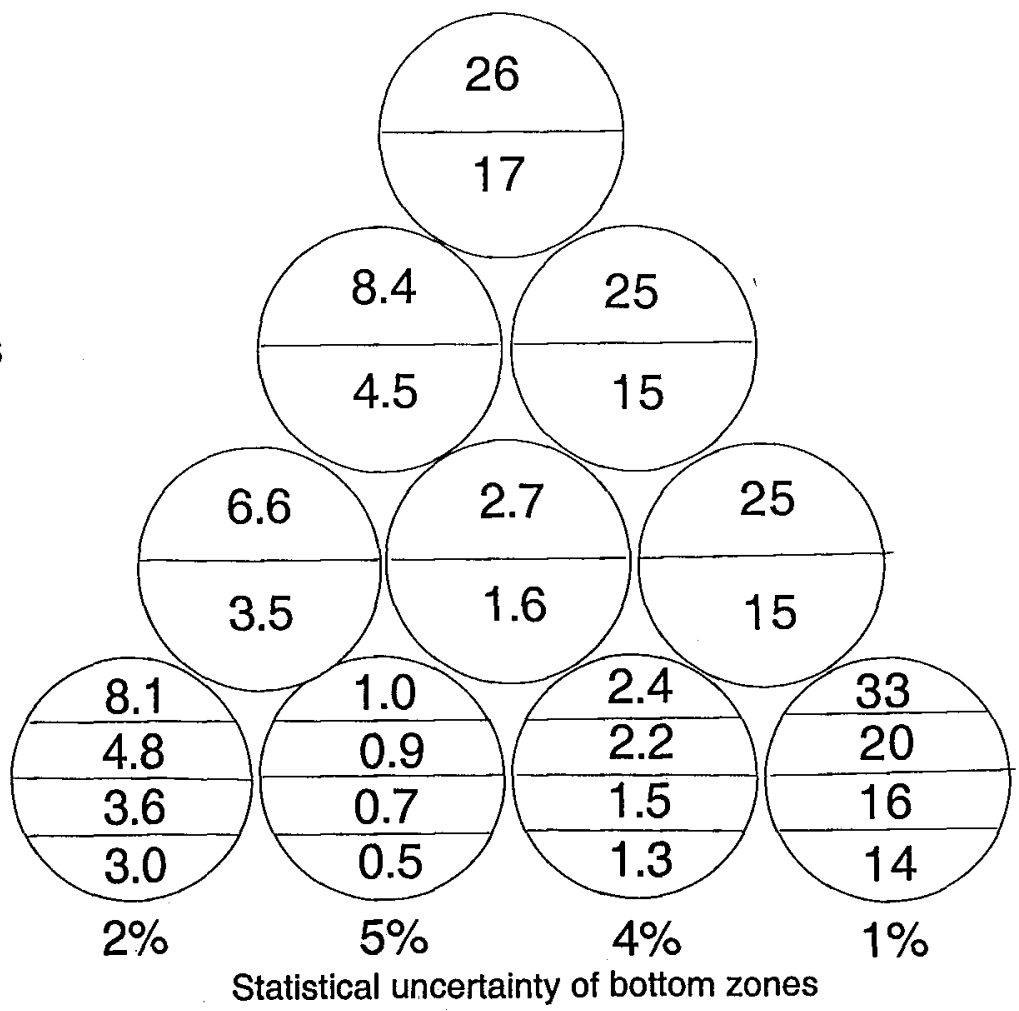


Radiation Dose in 200-liter Drums inside a Concrete Block Building at $10 \mathrm{~m}$ Ground Range (Megarad)

Yield: $10 \mathrm{kT}$

HOB: $10 \mathrm{~m}$

Fig. A31

$14 \mathrm{Mev}$ neutrons

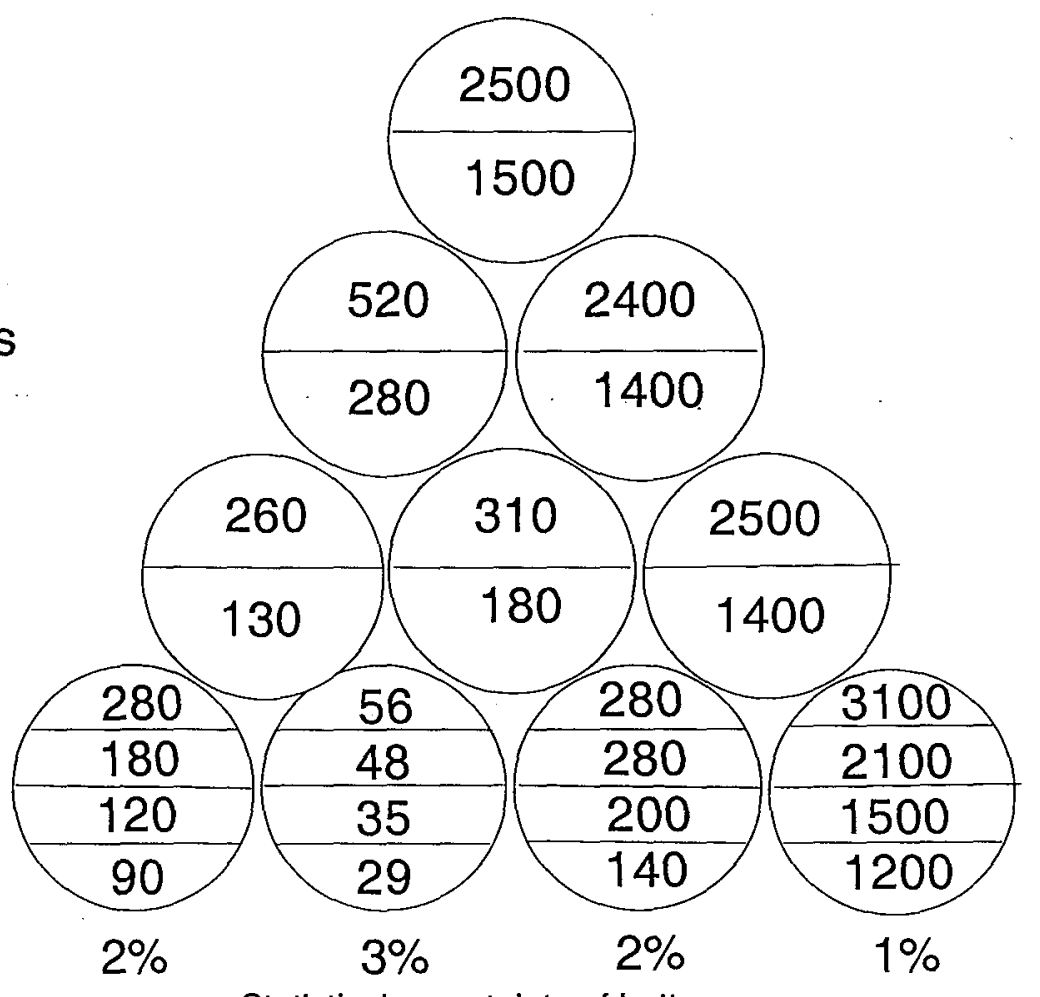

Fig. A32

Fission neutrons

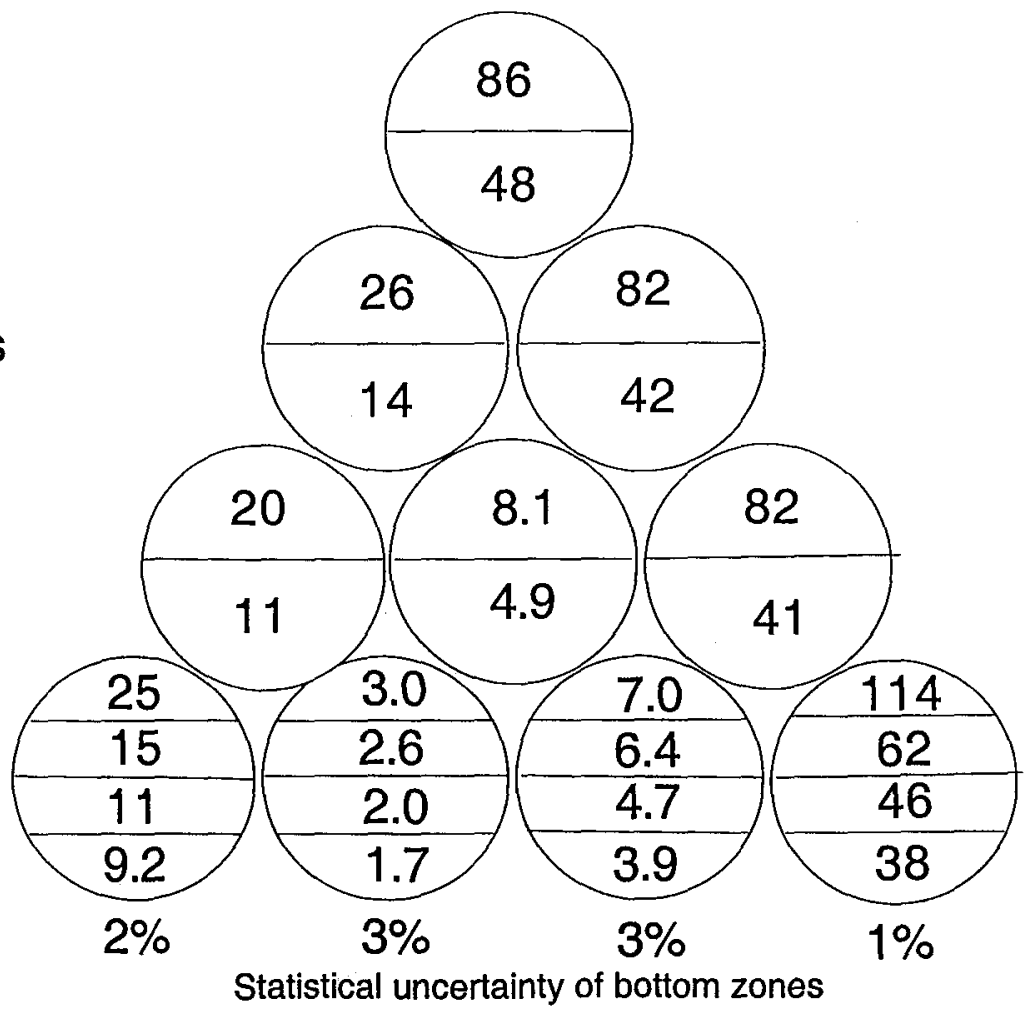


Radiation Dose in 200-liter Drums inside a Concrete Block Building underneath the Burst Point

(Megarad)

Yield: $10 \mathrm{kT}$

HOB: $10 \mathrm{~m}$

Fig. A29

14 Mev neutrons

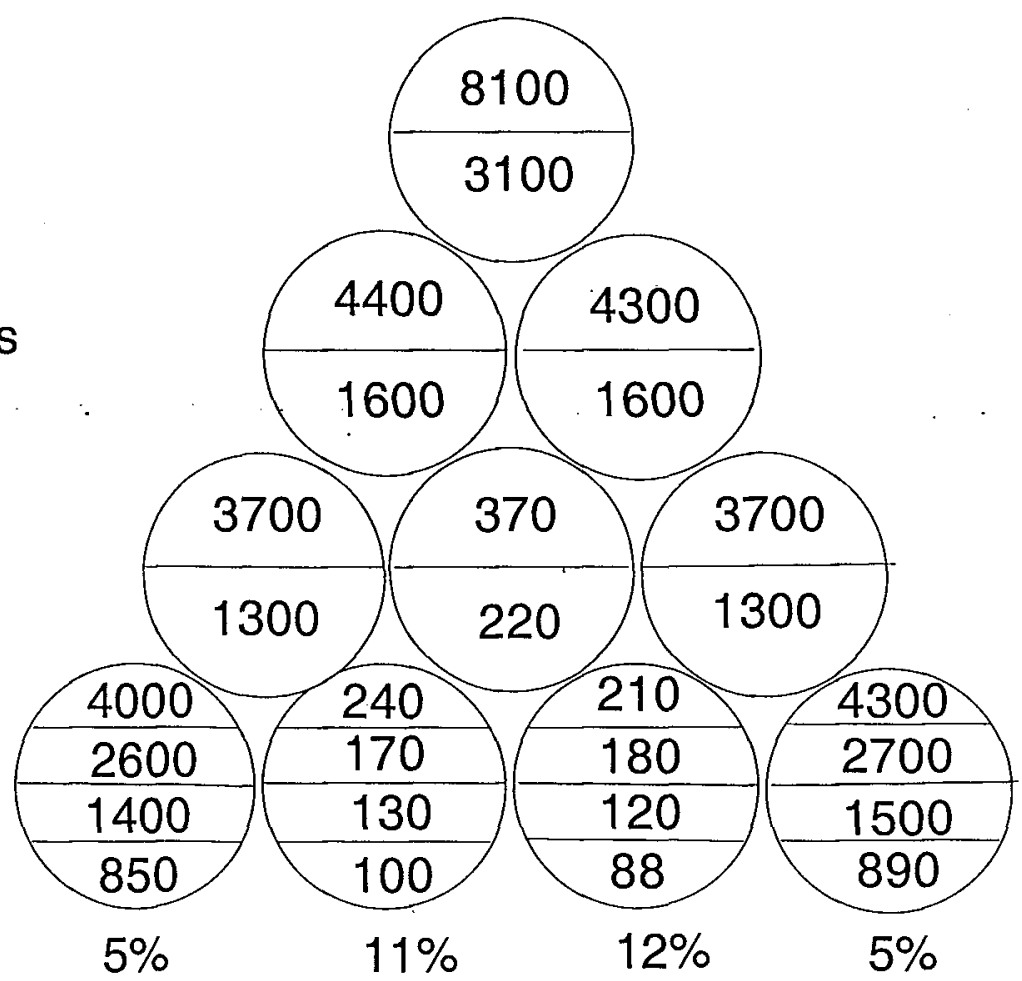

Statistical uncertainty of bottom zones

Fig. A30

Fission neutrons

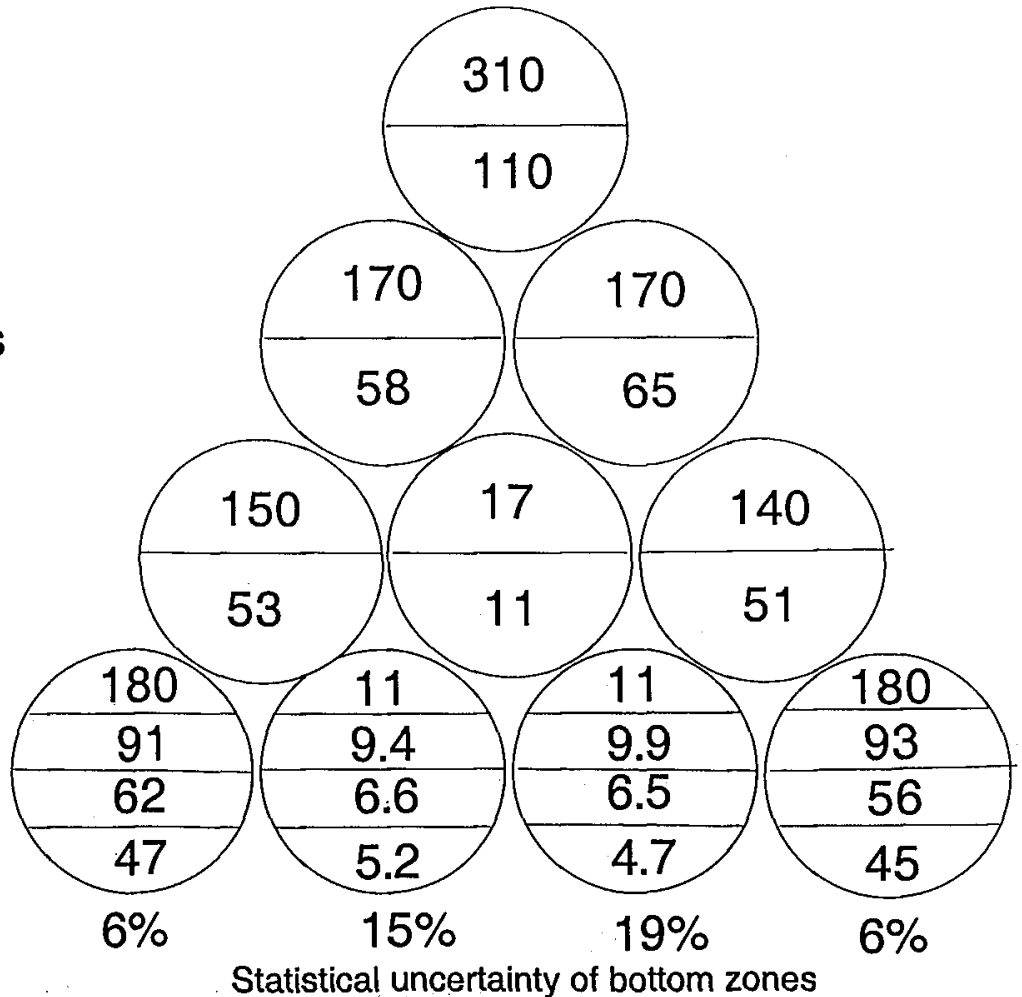


Radiation Dose in 200-liter Drums on the Ground in Open Air at a $10 \mathrm{~m}$ Ground Range

(Megarad)

Neutron yield: 25 moles

HOB: $10 \mathrm{~m}$

Fig. A27

100 ev neutrons

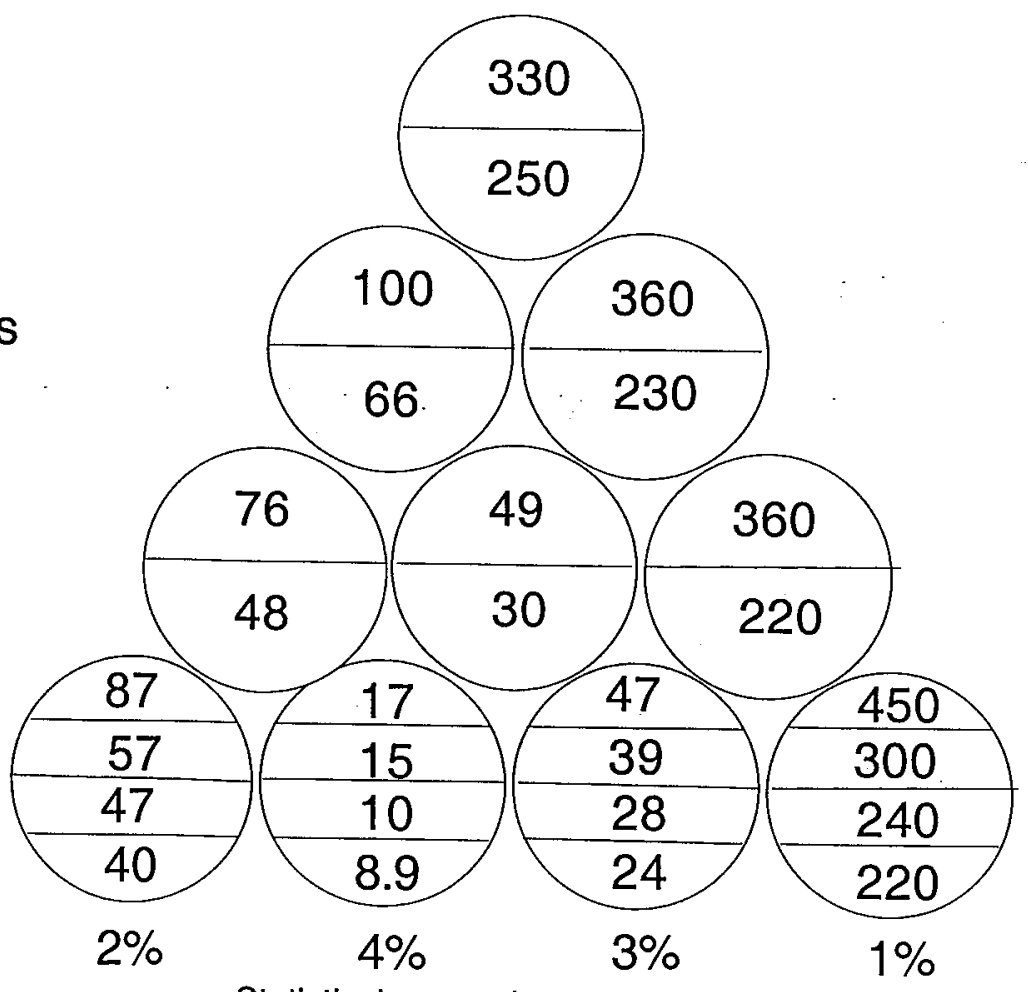

Statistical uncertainty of bottom zones

Fig. A28

10 ev neutrons

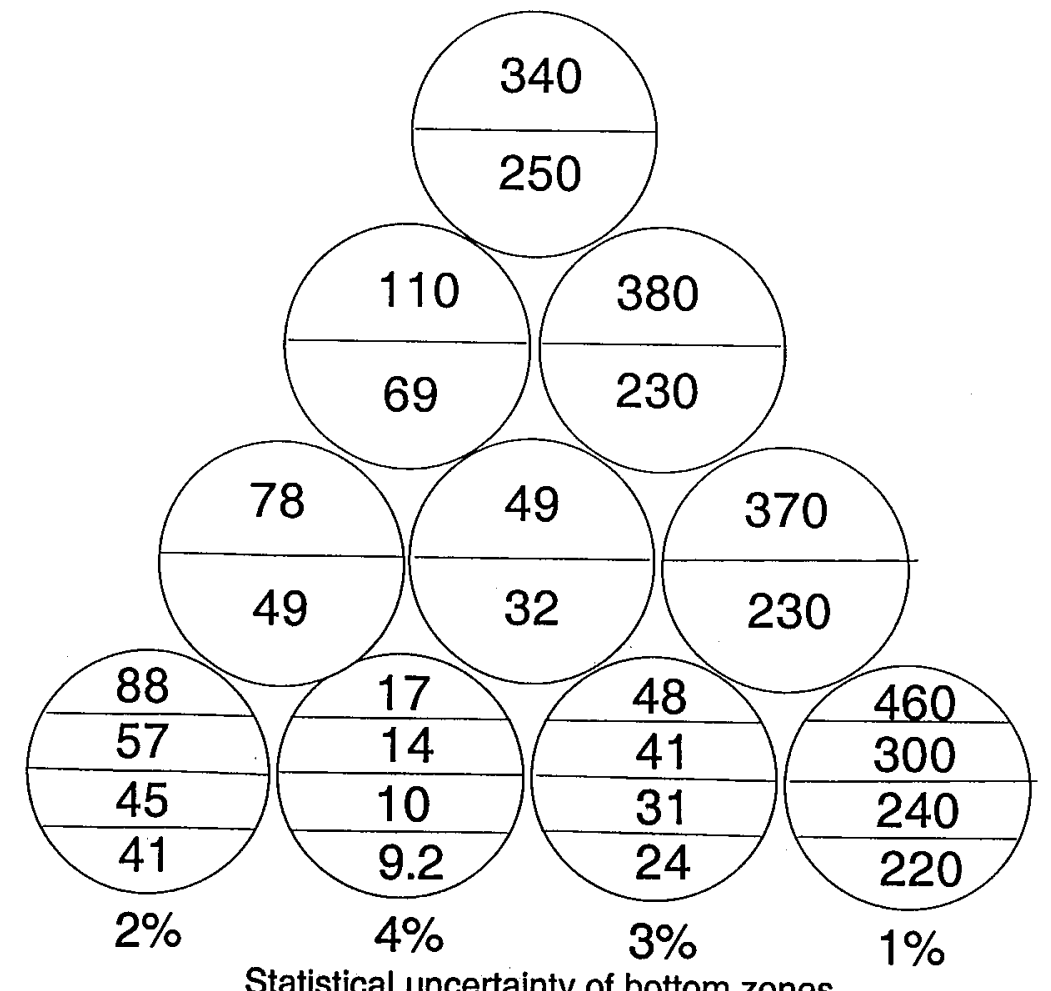


Radiation Dose in 200-liter Drums on the Ground in Open Air at a $10 \mathrm{~m}$ Ground Range

(Megarad)

Neutron yield: 25 moles

HOB: $10 \mathrm{~m}$

Fig. A25

$10 \mathrm{Kev}$ neutrons

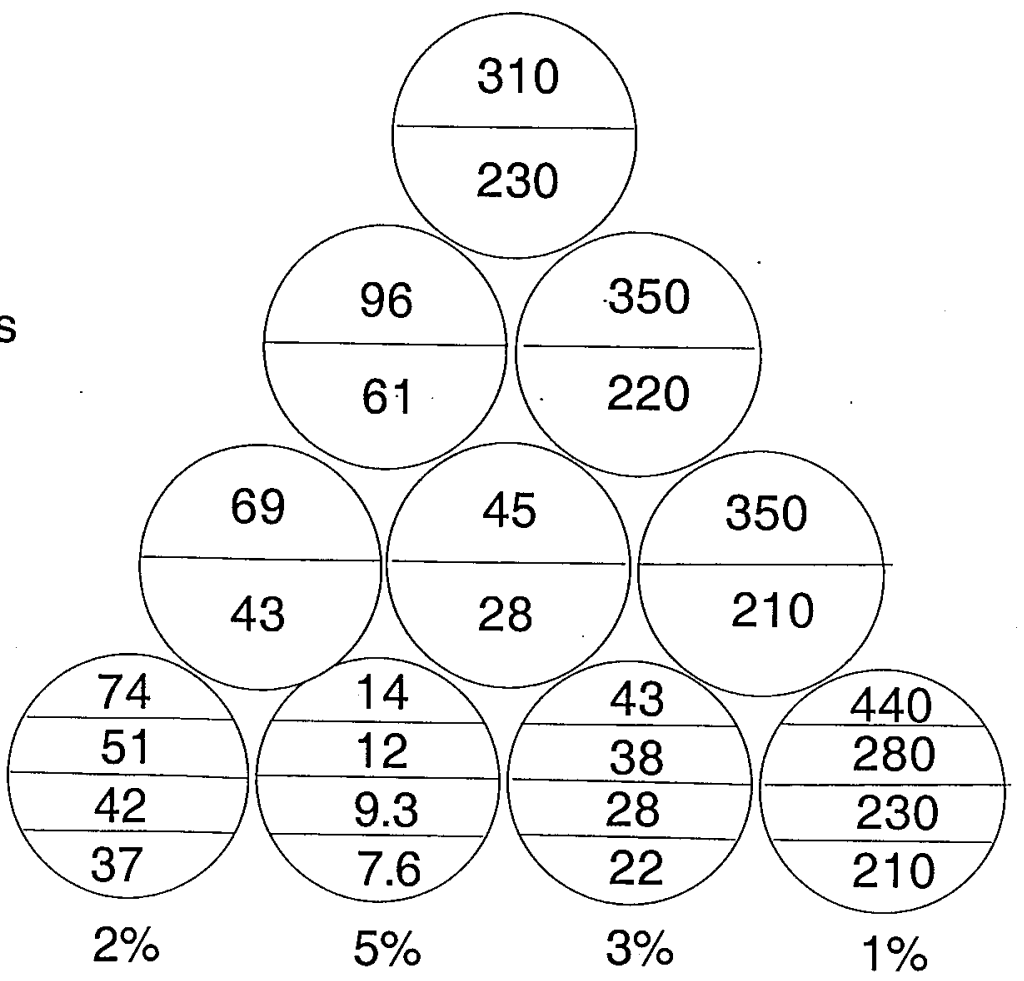

Statistical uncertainty of bottom zones

Fig. A26

1 Kev neutrons

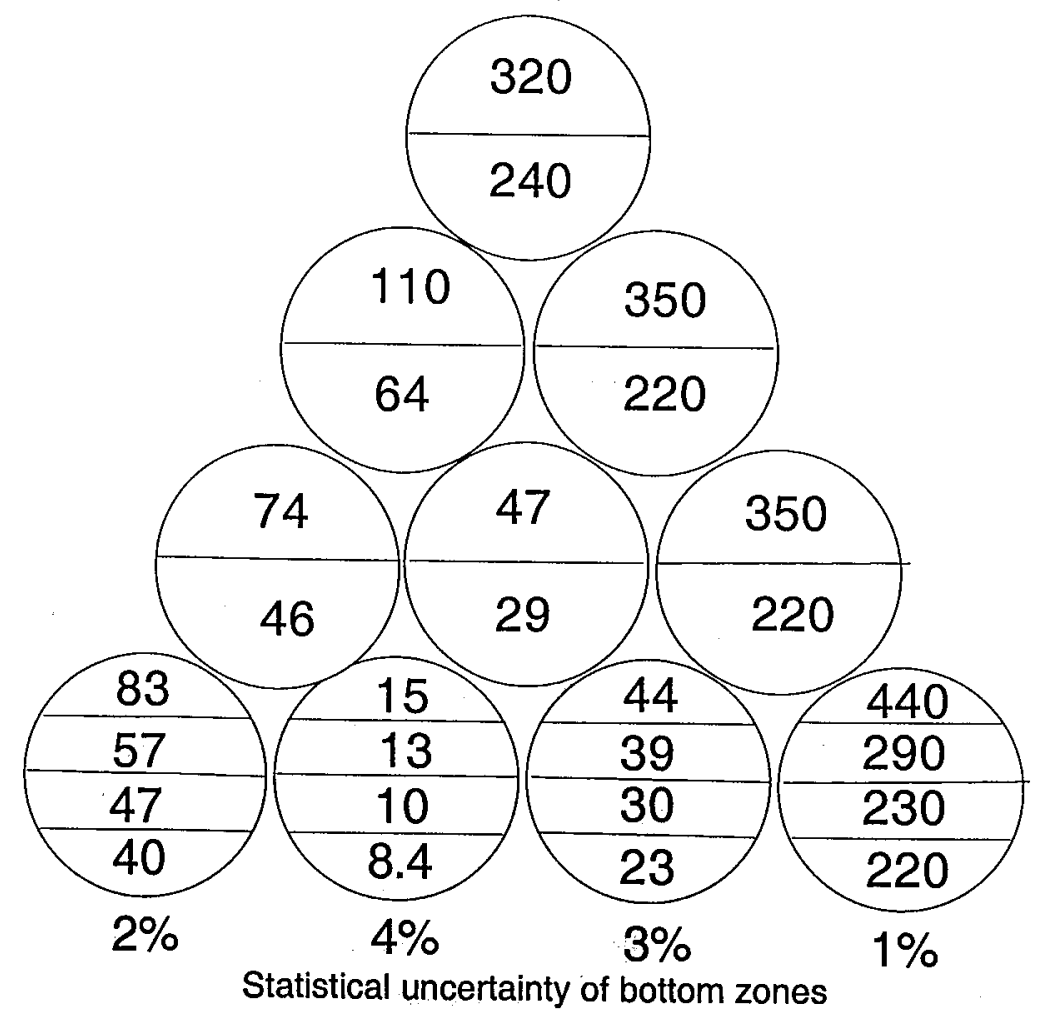


Radiation Dose in 200-liter Drums on the Ground in Open Air at a $10 \mathrm{~m}$ Ground Range

(Megarad)

Neutron yield: 25 moles

HOB: $10 \mathrm{~m}$

Fig. A23

1 Mev neutrons

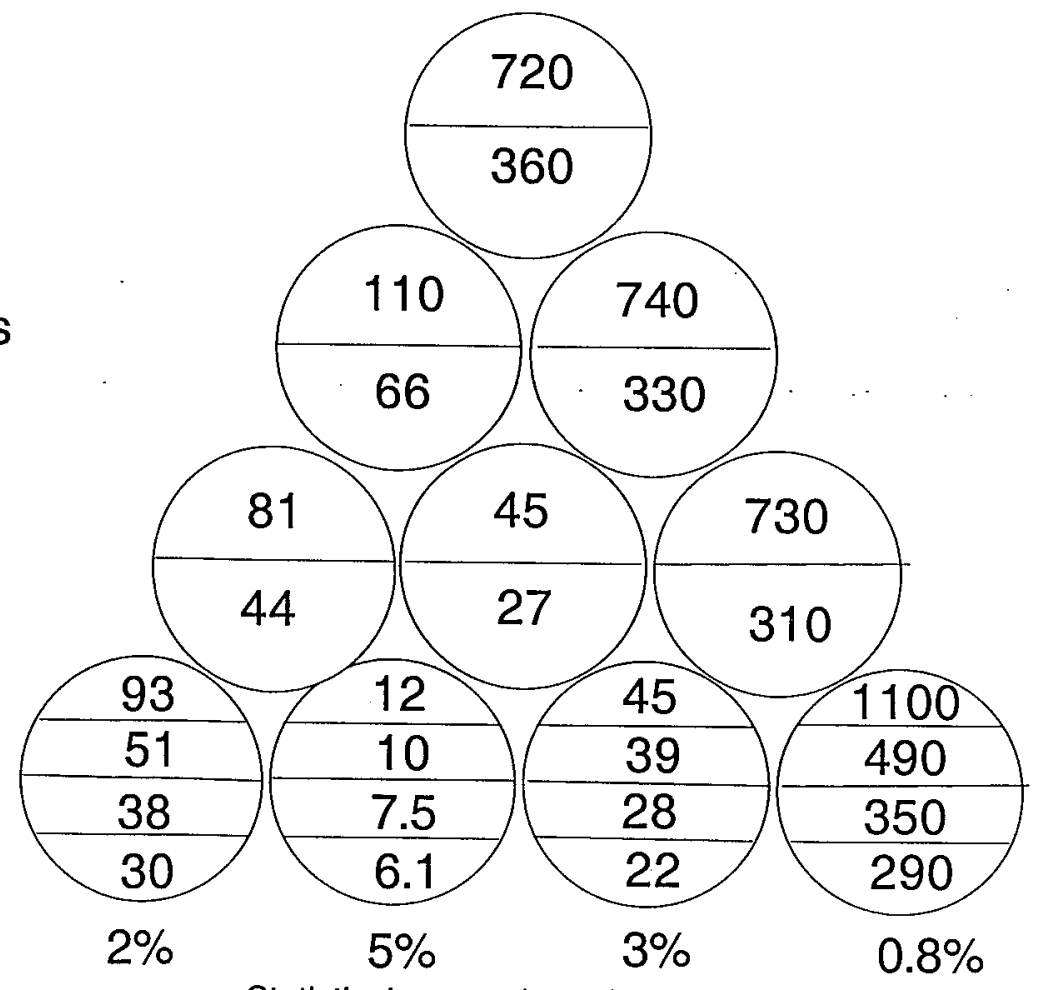

Statistical uncertainty of bottom zones

Fig. A24

0.1 Mev neutrons

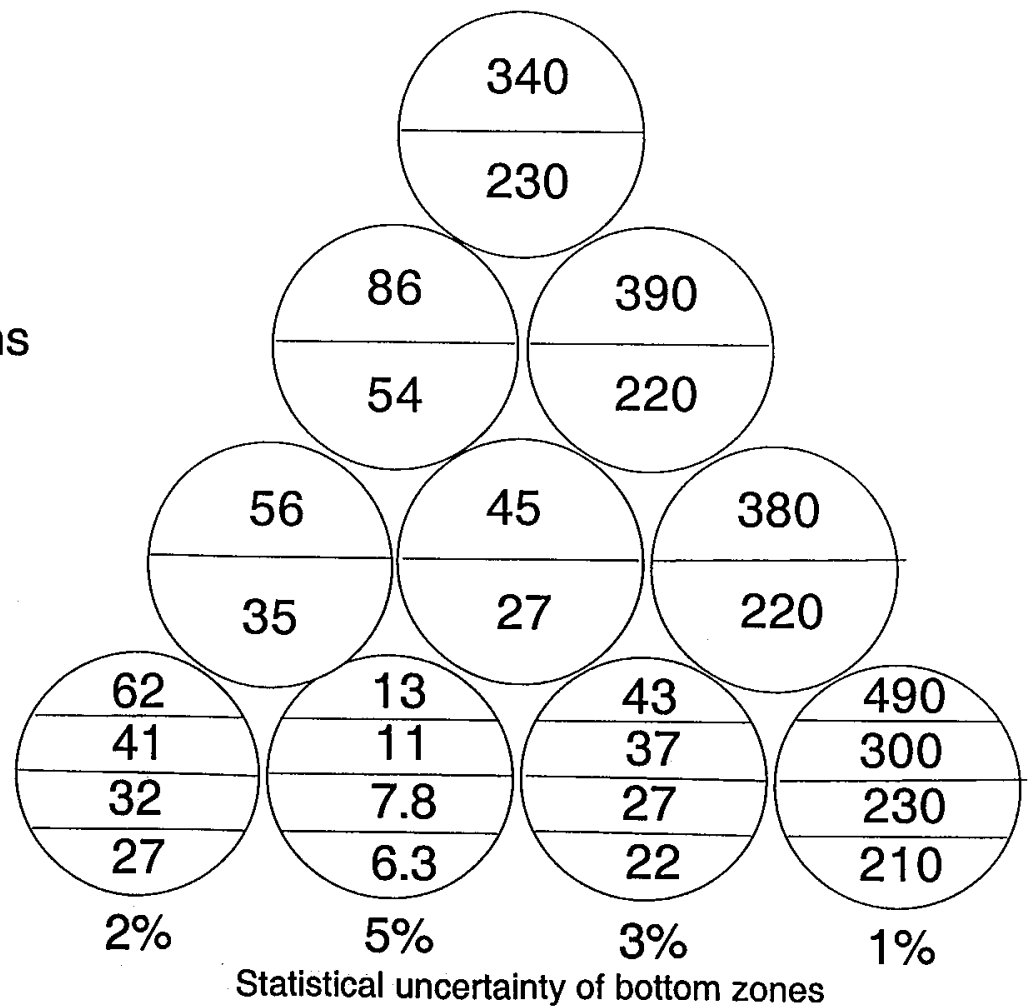


Radiation Dose in 200-liter Drums on the Ground in Open Air at a $10 \mathrm{~m}$ Ground Range

(Megarad)

Neutron yield: 25 moles

HOB: $10 \mathrm{~m}$

Fig. A21

6 Mev neutrons

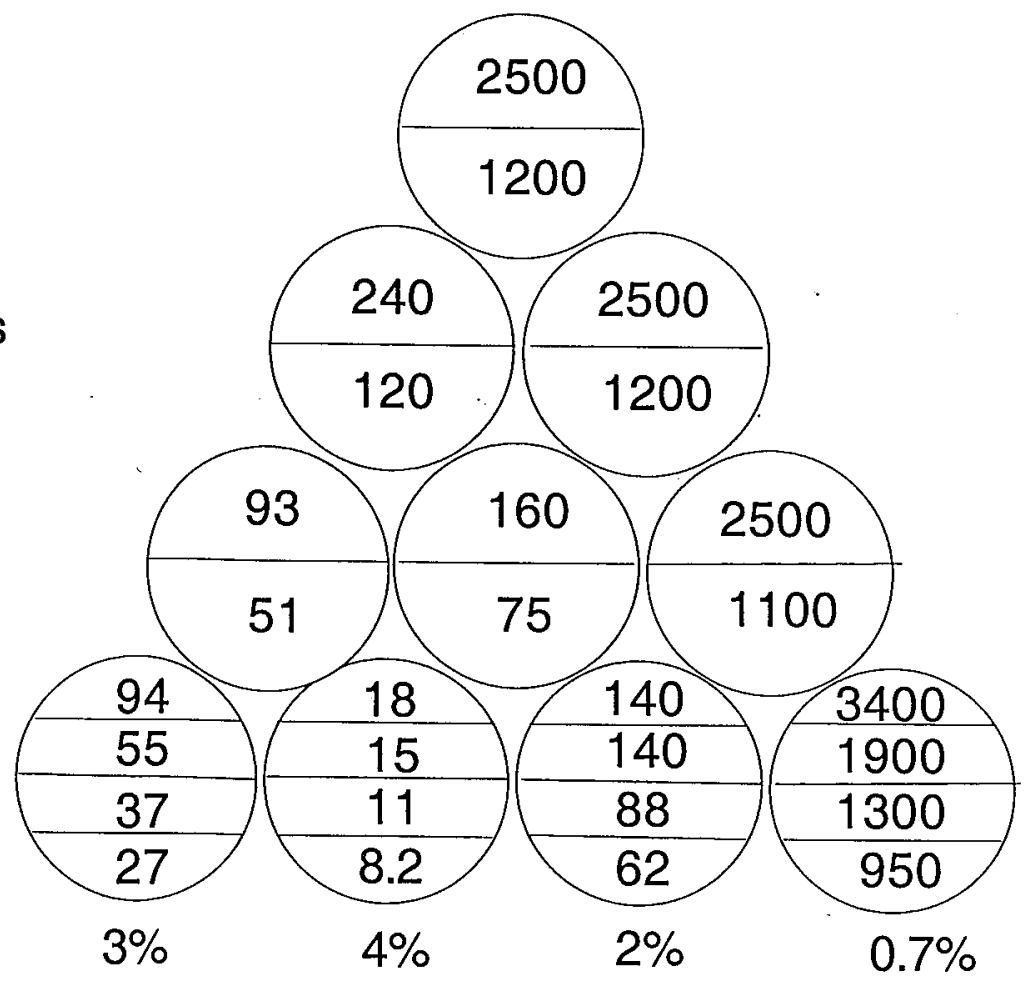

Statistical uncertainty of bottom zones

Fig. A22

3 Mev neutrons

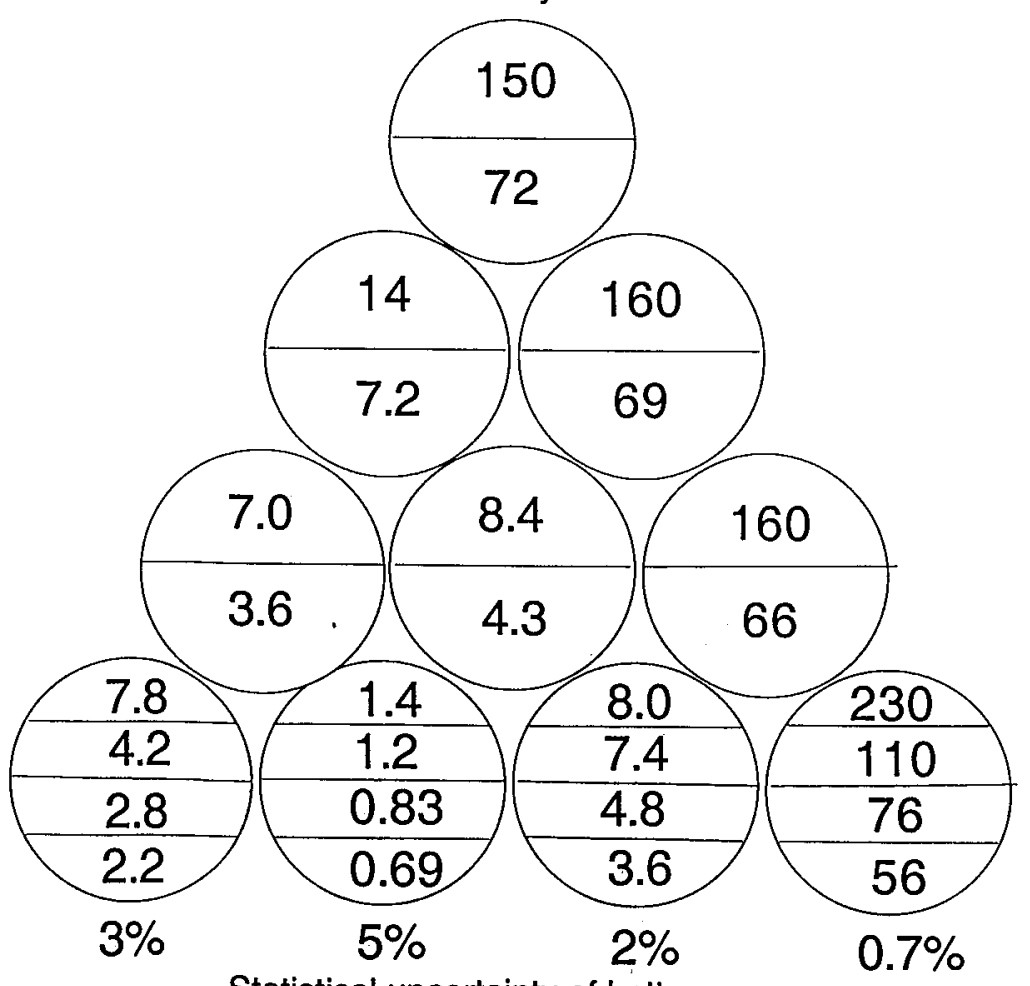

Statistical uncertainty of bottom zones 
Radiation Dose in 200-liter Drums on the Ground in Open Air at a $10 \mathrm{~m}$ Ground Range

(Megarad)

Neutron yield: 25 moles

HOB: $10 m$

Fig. A19

$20 \mathrm{Mev}$ neutrons

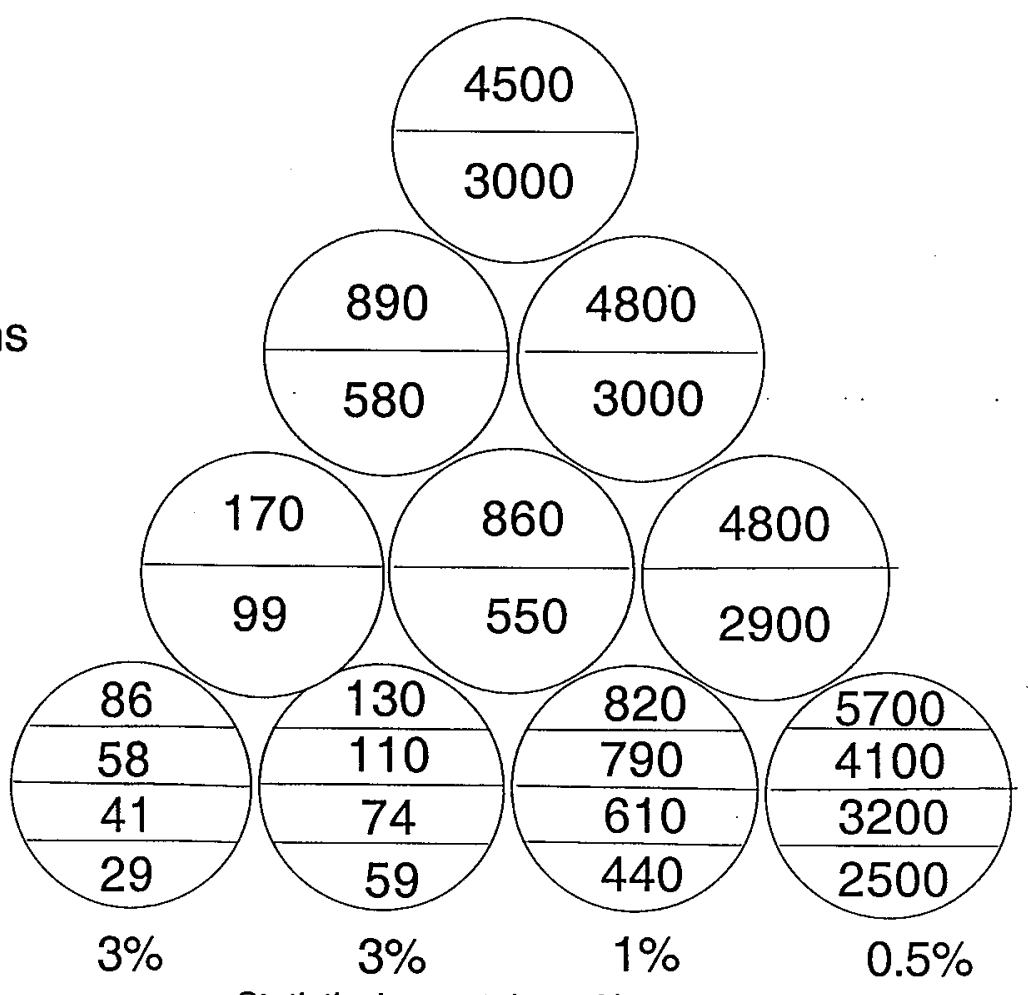

Fig. A20

10 Mev neutrons

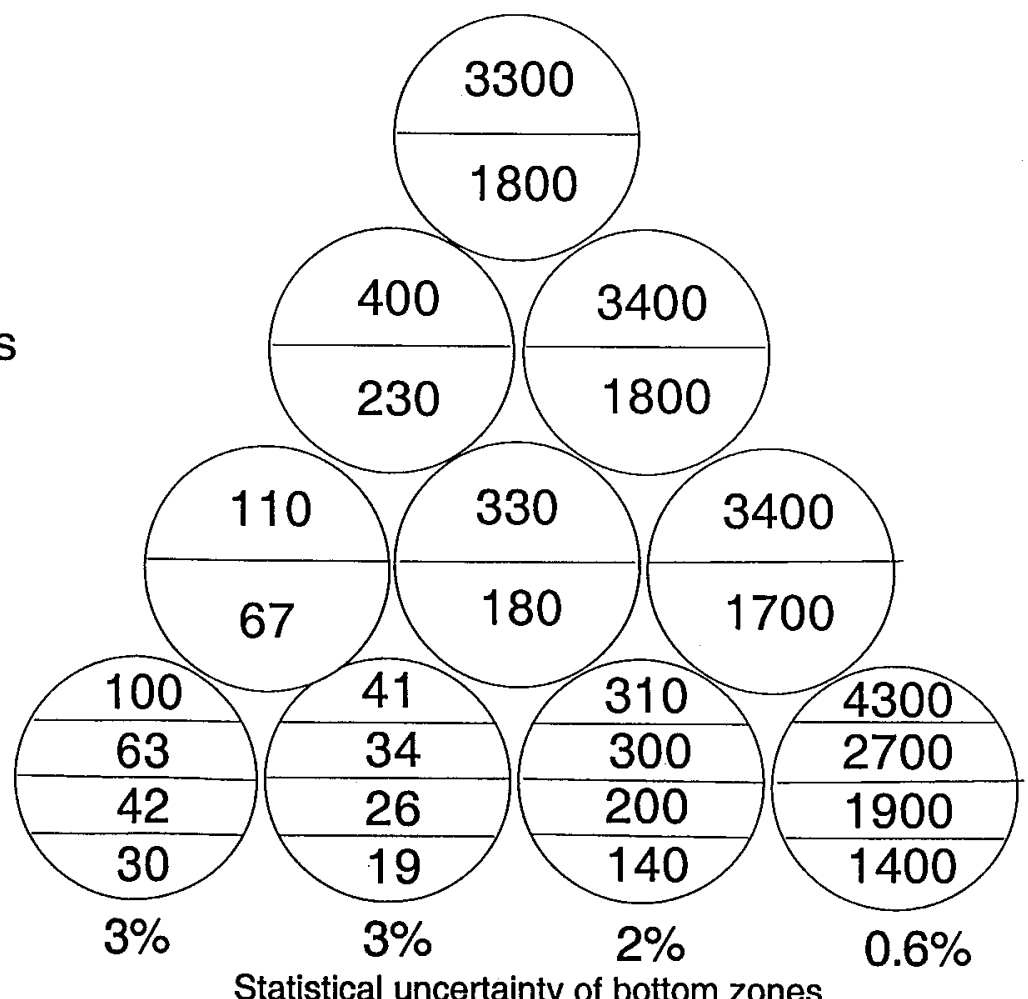


Radiation Dose in 200-liter Drums on the Ground in Open Air at a $20 \mathrm{~m}$ Ground Range

(Megarad)

Yield: $10 \mathrm{kT}$

Neutron spectrum: Fission

Fig. A17

$55 \mathrm{~m} \mathrm{HOB}$

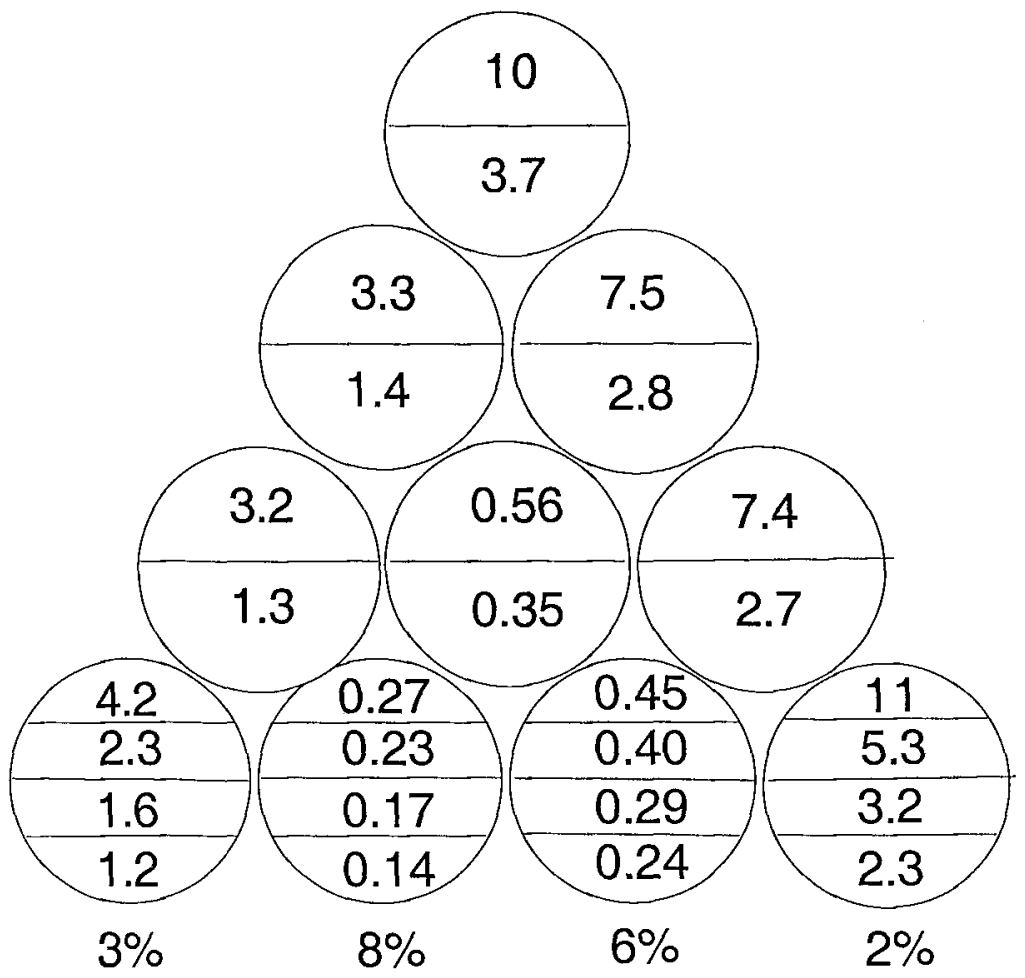

Statistical uncertainty of bottom zones

Fig. A18

$138 \mathrm{~m} \mathrm{HOB}$

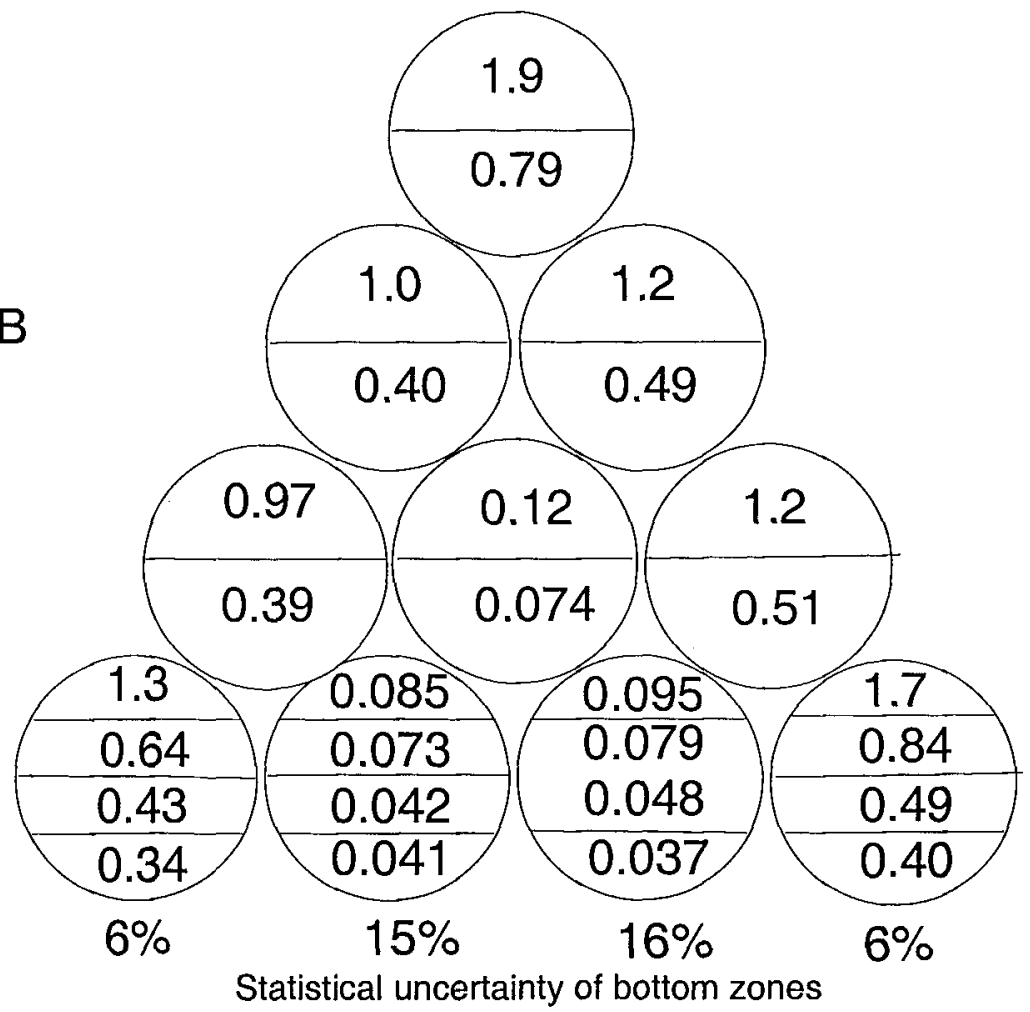


Radiation Dose in 200-liter Drums on the Ground in Open Air at a $20 \mathrm{~m}$ Ground Range

(Megarad)

Yield: $10 \mathrm{kT}$

Neutron spectrum: Fission

Fig. A15

$2.5 \mathrm{~m} \mathrm{HOB}$

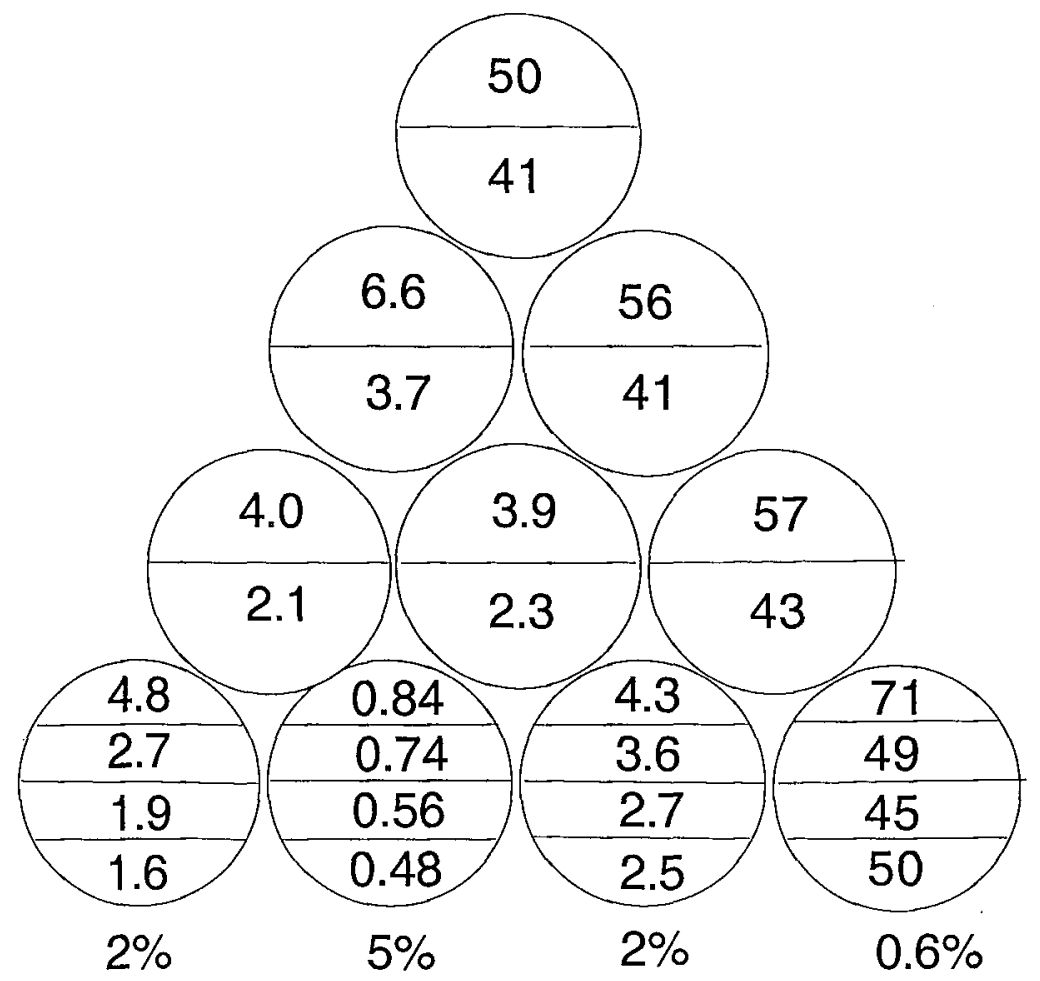

Statistical uncertainty of bottom zones

Fig. A16 $20 \mathrm{~m} \mathrm{HOB}$

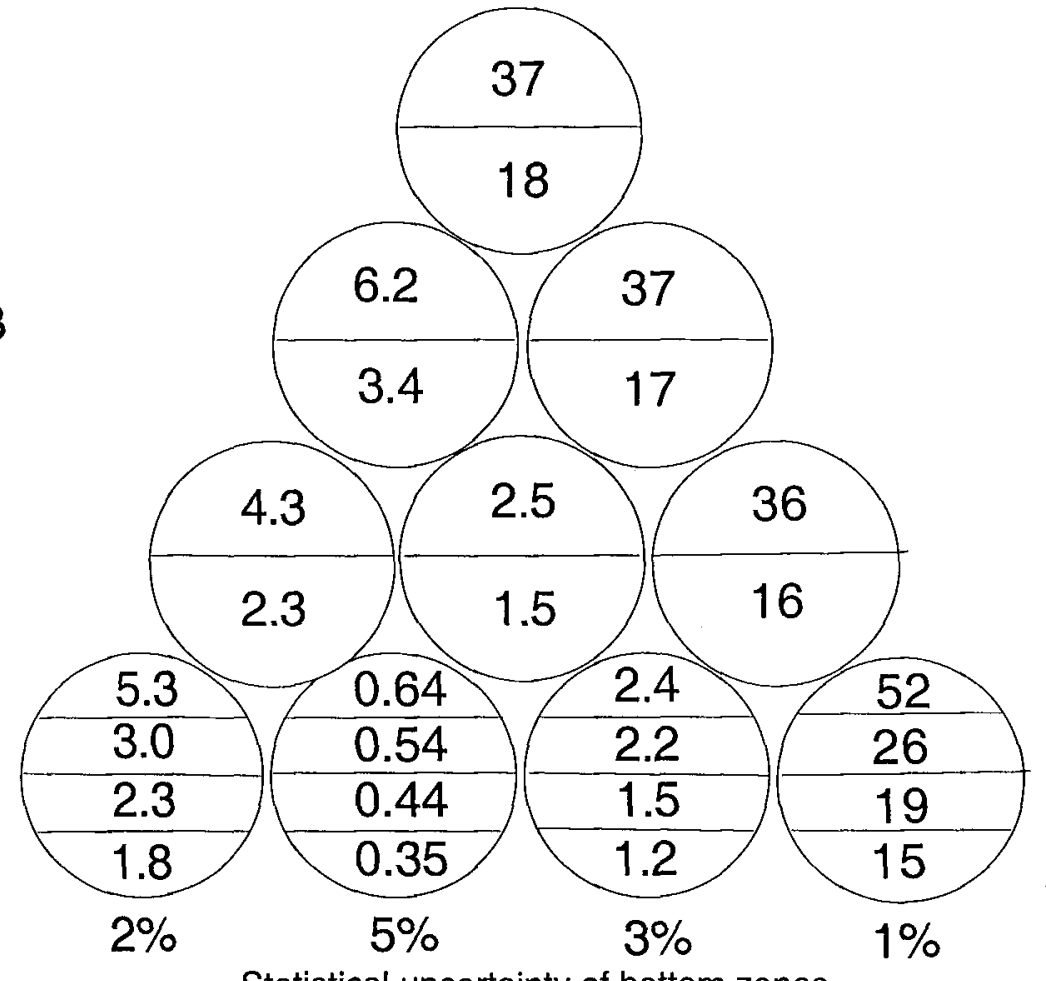

Statistical uncertainty of bottom zones 
Radiation Dose in 200-liter Drums on the Ground in Open Air at a $80 \mathrm{~m}$ Ground Range

(Megarad)

Yield: $10 \mathrm{kT}$

Neutron spectrum: $14 \mathrm{Mev}$

Fig. A13

$55 \mathrm{~m} \mathrm{HOB}$

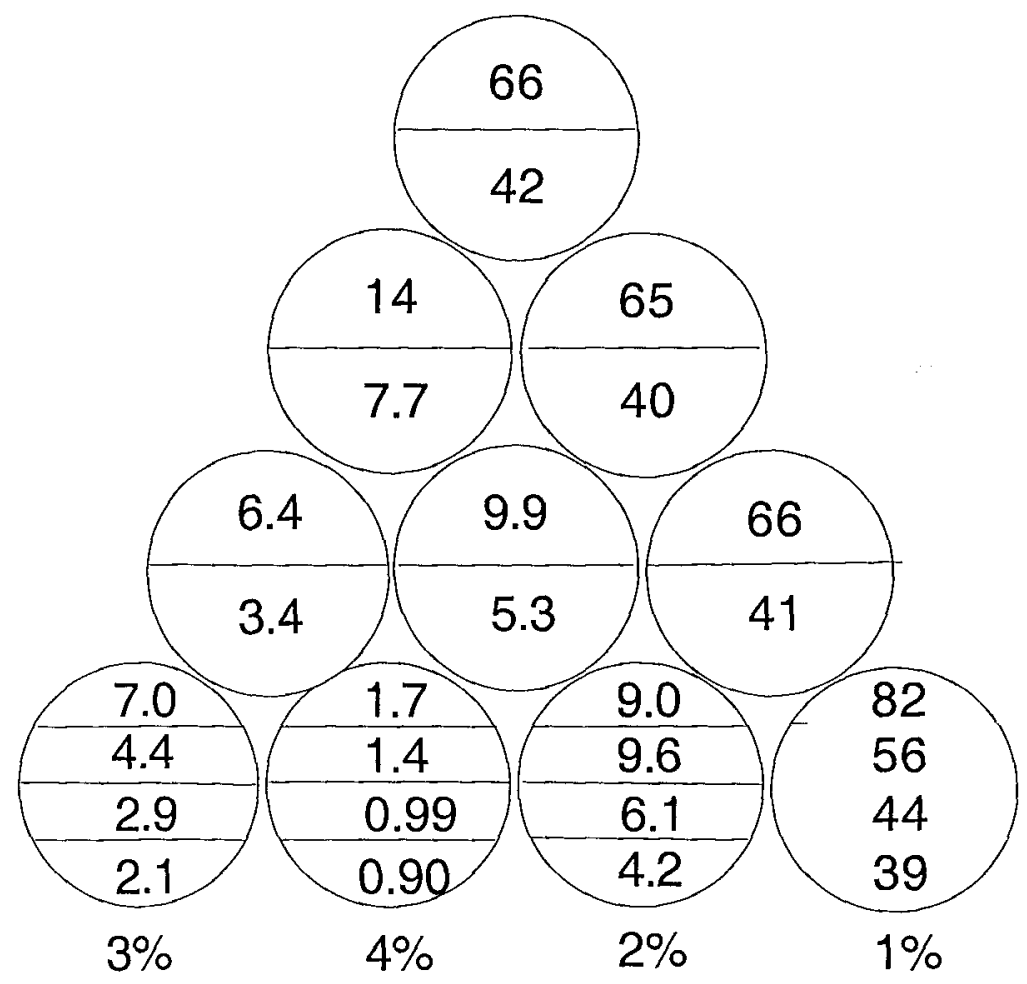

Statistical uncertainty of bottom zones

Fig. A14

$138 \mathrm{~m} \mathrm{HOB}$

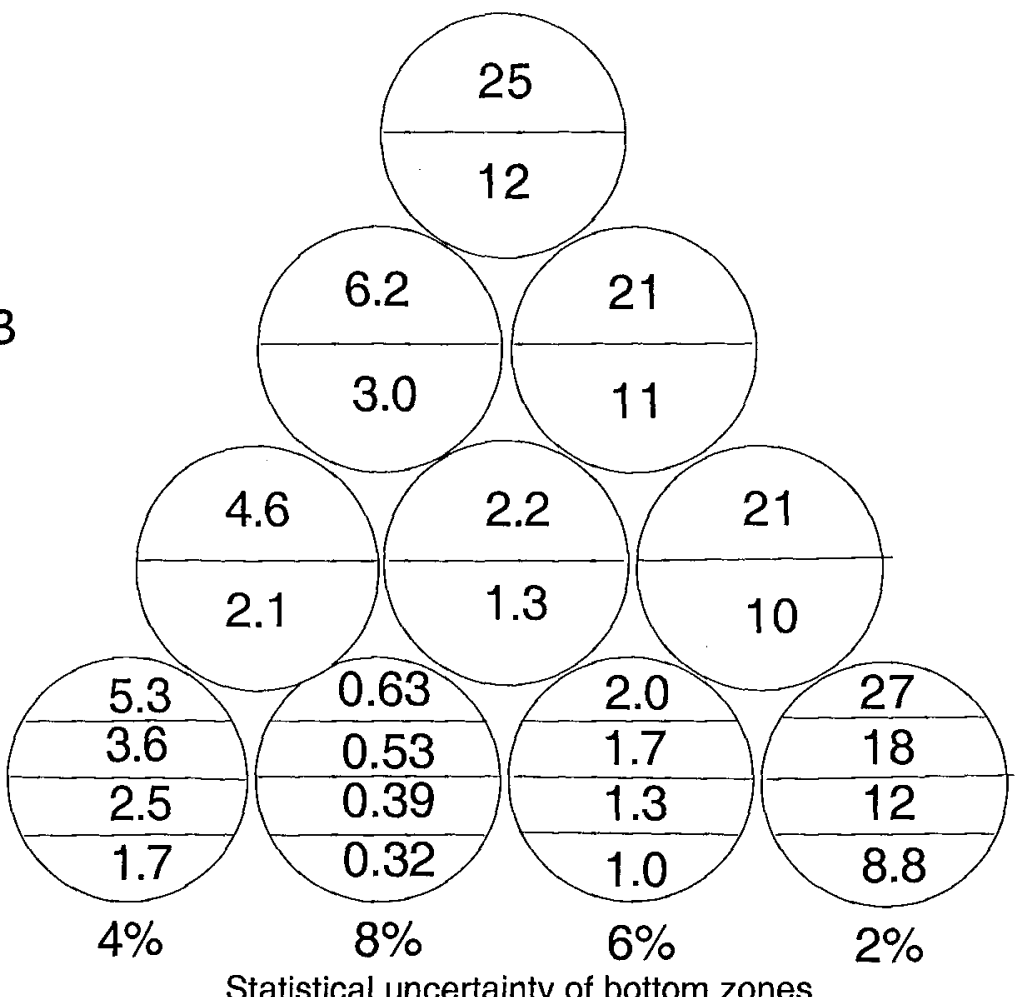

Statistical uncertainty of bottom zones 
Radiation Dose in 200-liter Drums on the Ground in Open Air at a $80 \mathrm{~m}$ Ground Range

(Megarad)

Yield: $10 \mathrm{kT}$

Neutron spectrum: $14 \mathrm{Mev}$

Fig. A11

$2.5 \mathrm{~m} \mathrm{HOB}$

Fig. A12

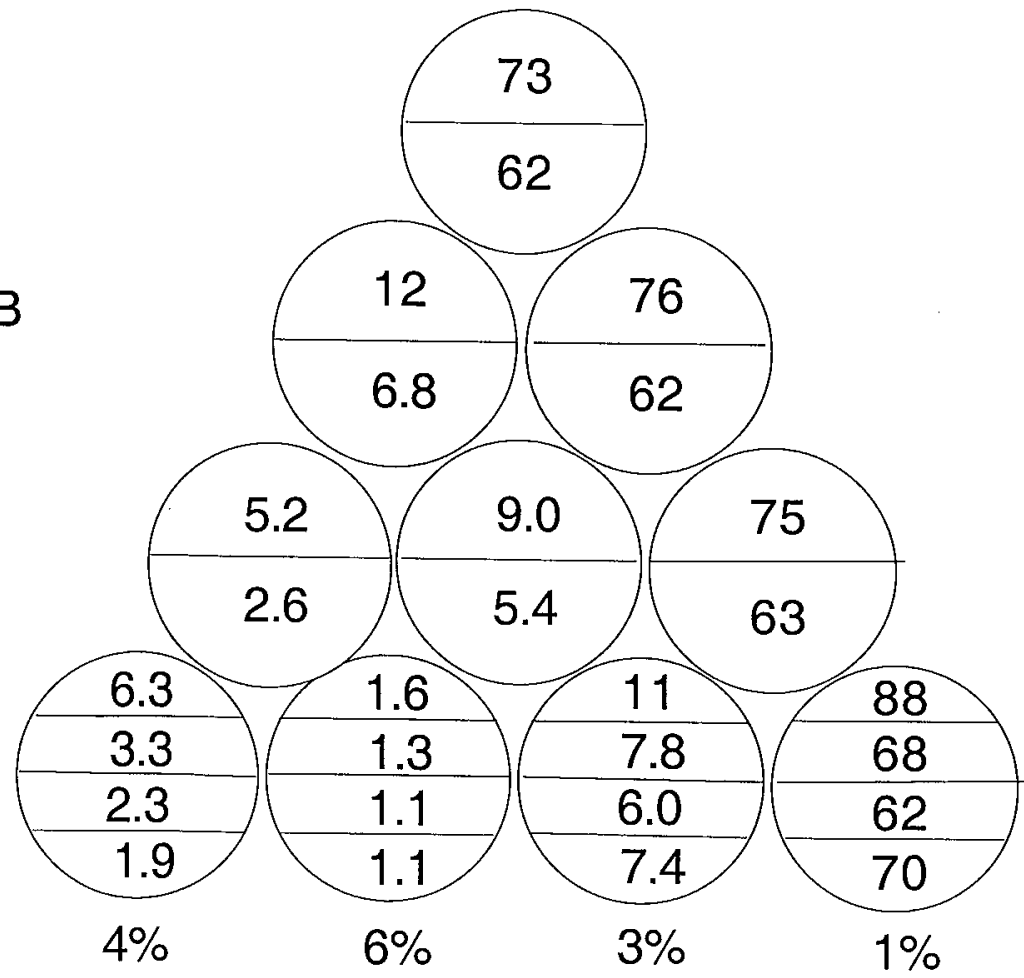

Statistical uncertainty of bottom zones

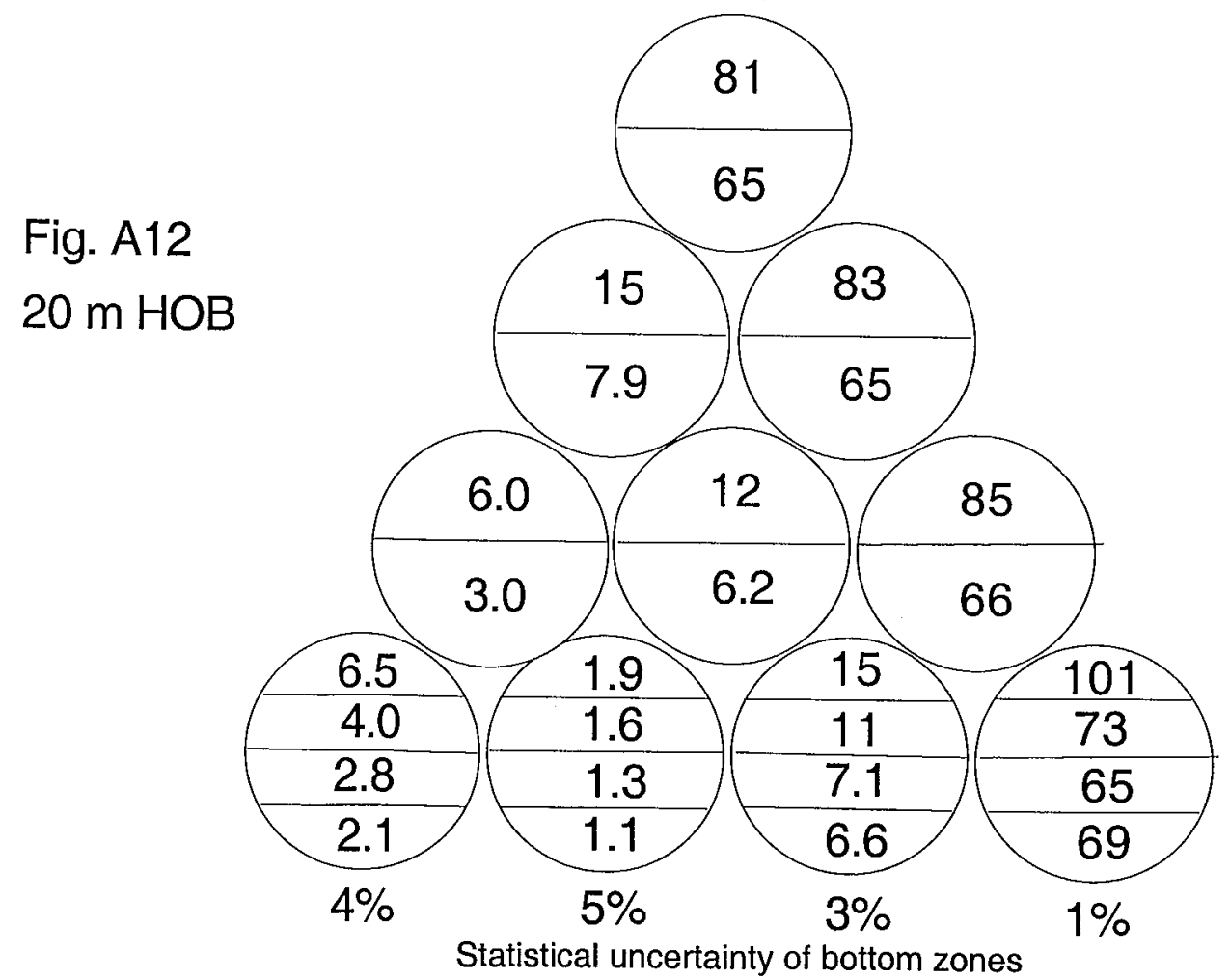


Radiation Dose in 200-liter Drums on the Ground in Open Air at a $80 \mathrm{~m}$ Ground Range

(Megarad)

Yield: $10 \mathrm{kT}$

HOB: $10 \mathrm{~m}$

Fig. A9

$14 \mathrm{Mev}$ neutrons

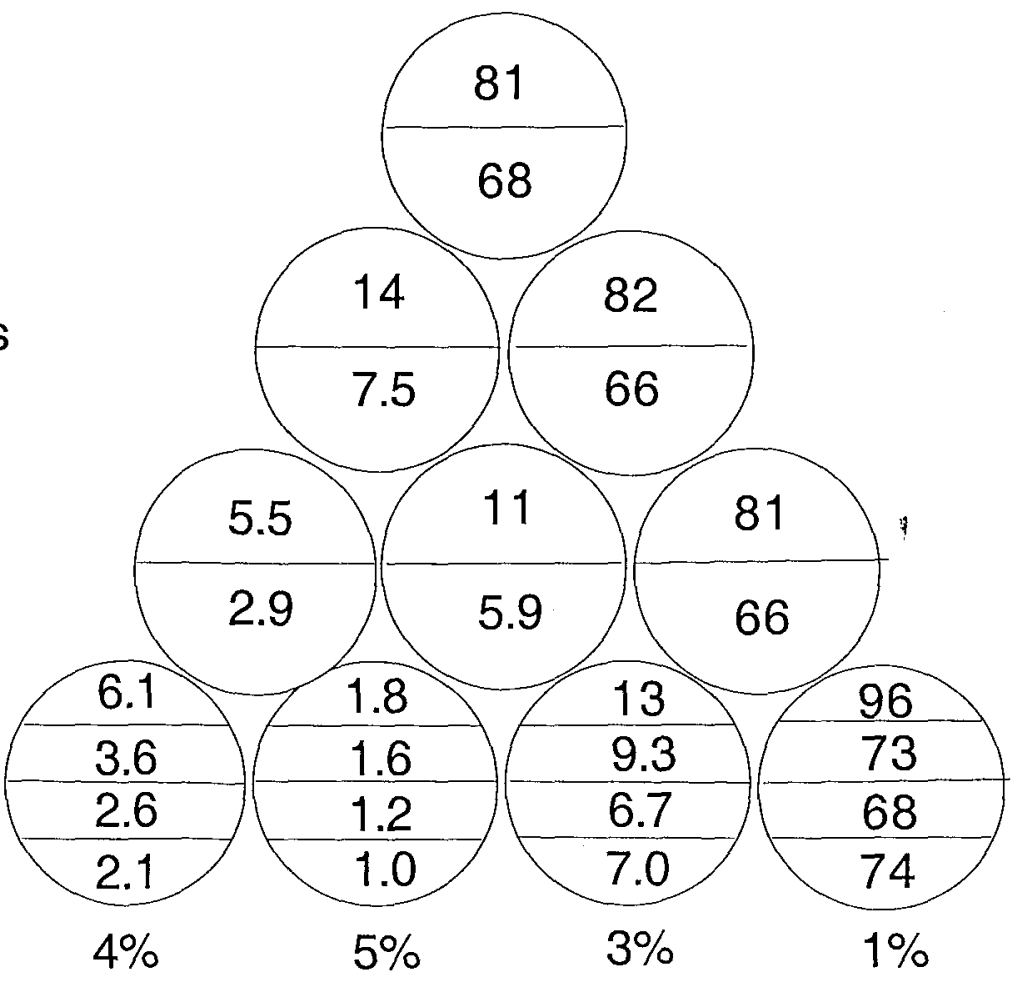

Fig. A10

Fission neutrons

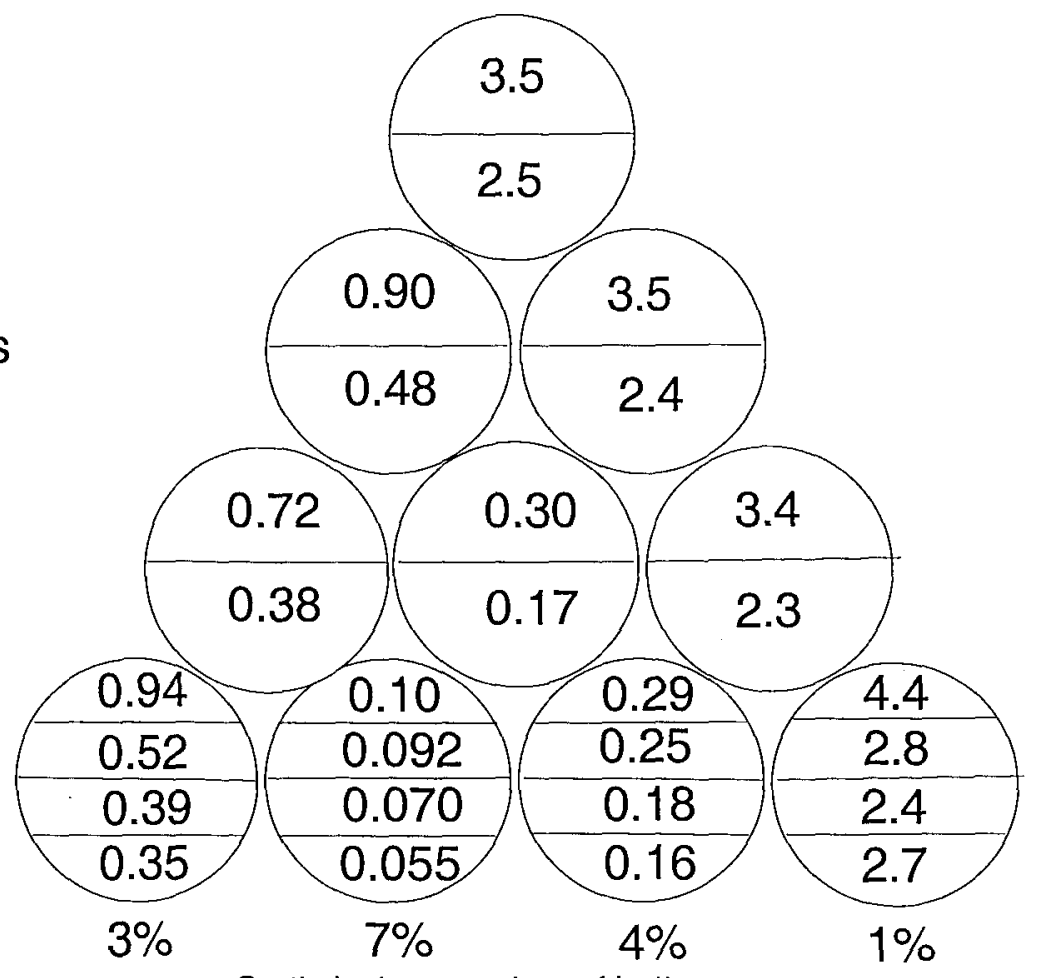

Statistical uncertainty of bottom zones 
Radiation Dose in 200-liter Drums on the Ground in Open Air at a $40 \mathrm{~m}$ Ground Range

(Megarad)

Yield: $10 \mathrm{kT}$

HOB: $10 \mathrm{~m}$

Fig. A7

14 Mev neutrons

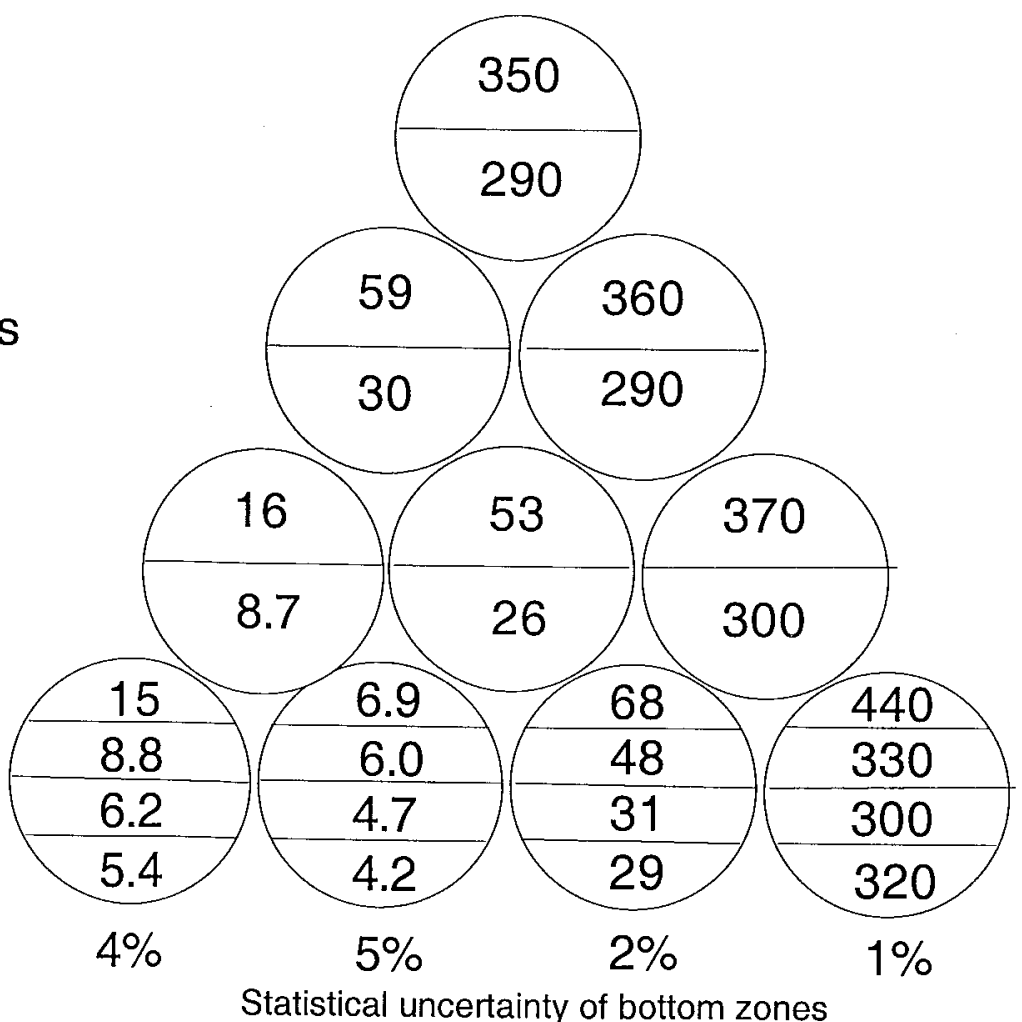

Fig. A8

Fission neutrons

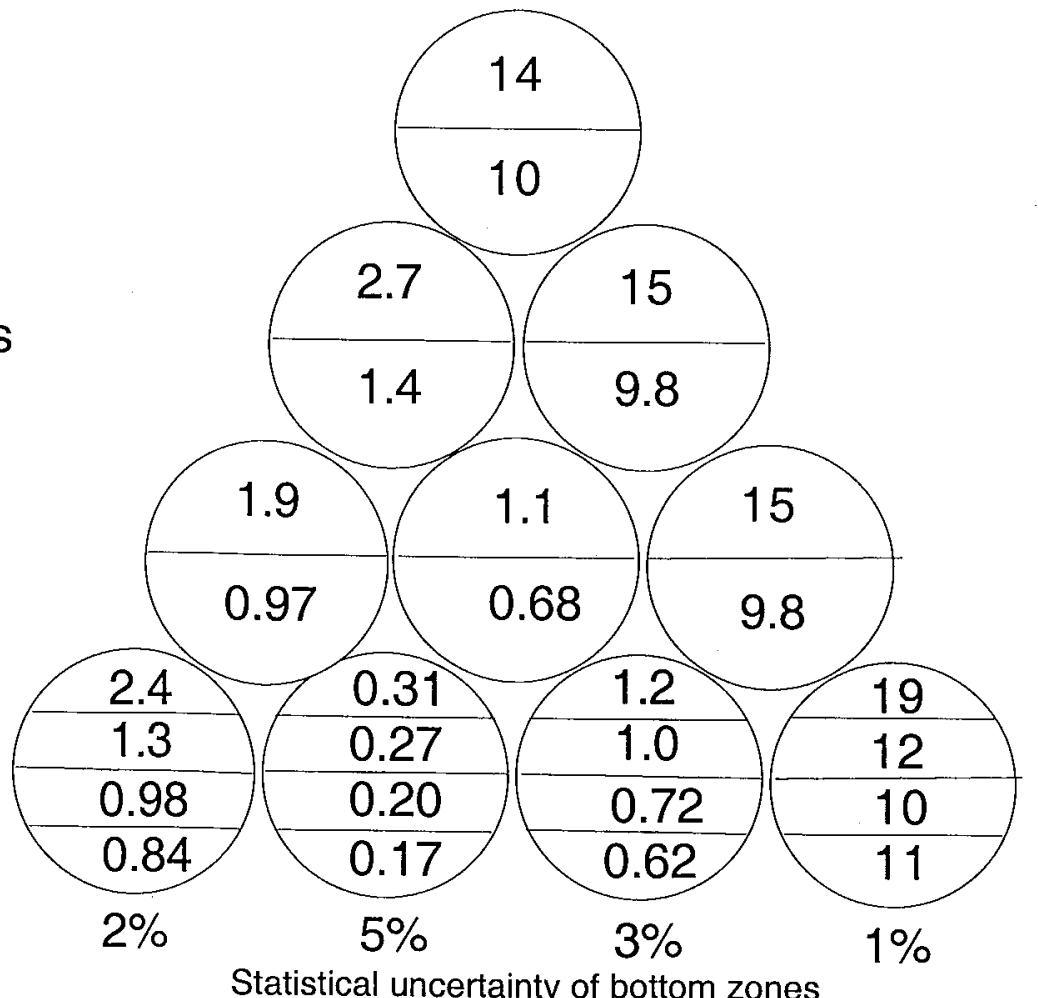


Radiation Dose in 200-liter Drums on the Ground in Open Air at a $20 \mathrm{~m}$ Ground Range (Megarad)

Yield: $10 \mathrm{kT}$

HOB: $10 \mathrm{~m}$

Fig. A5

14 Mev neutrons

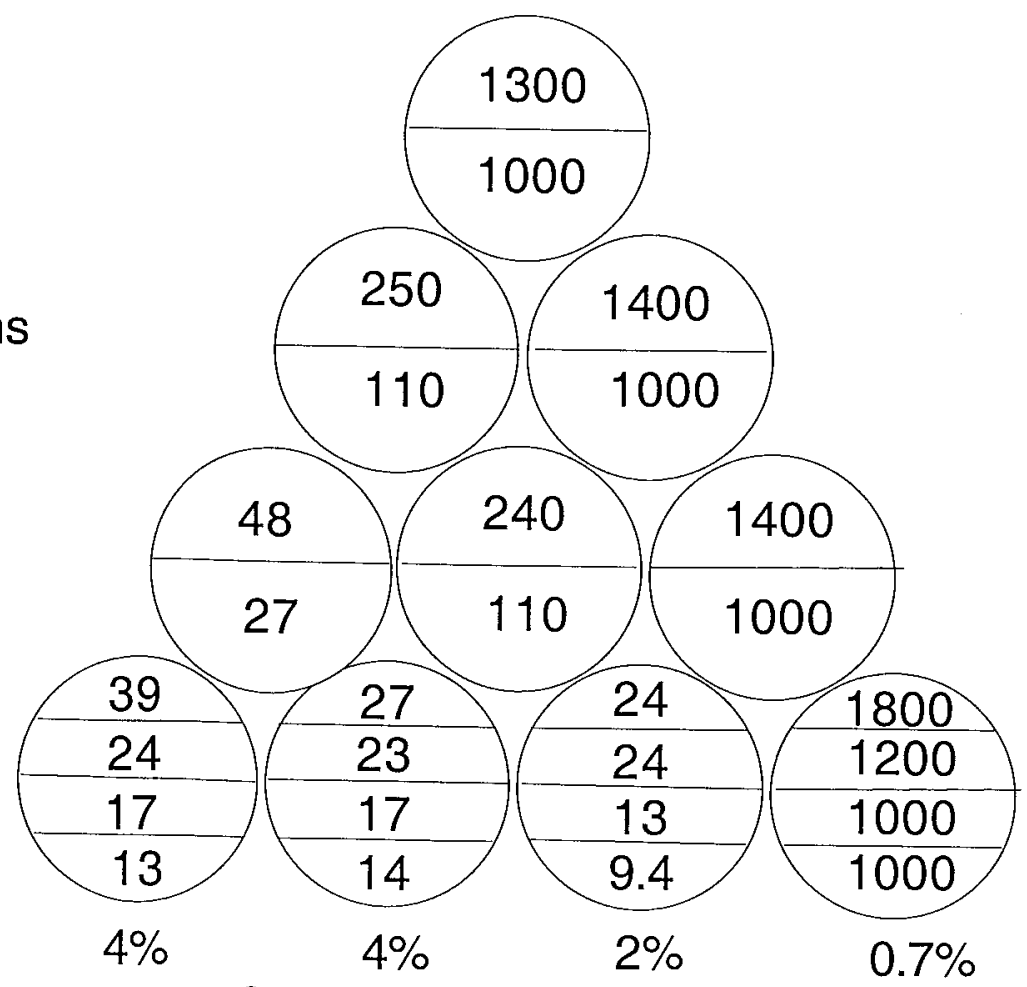

Fig. A6

Fission neutrons

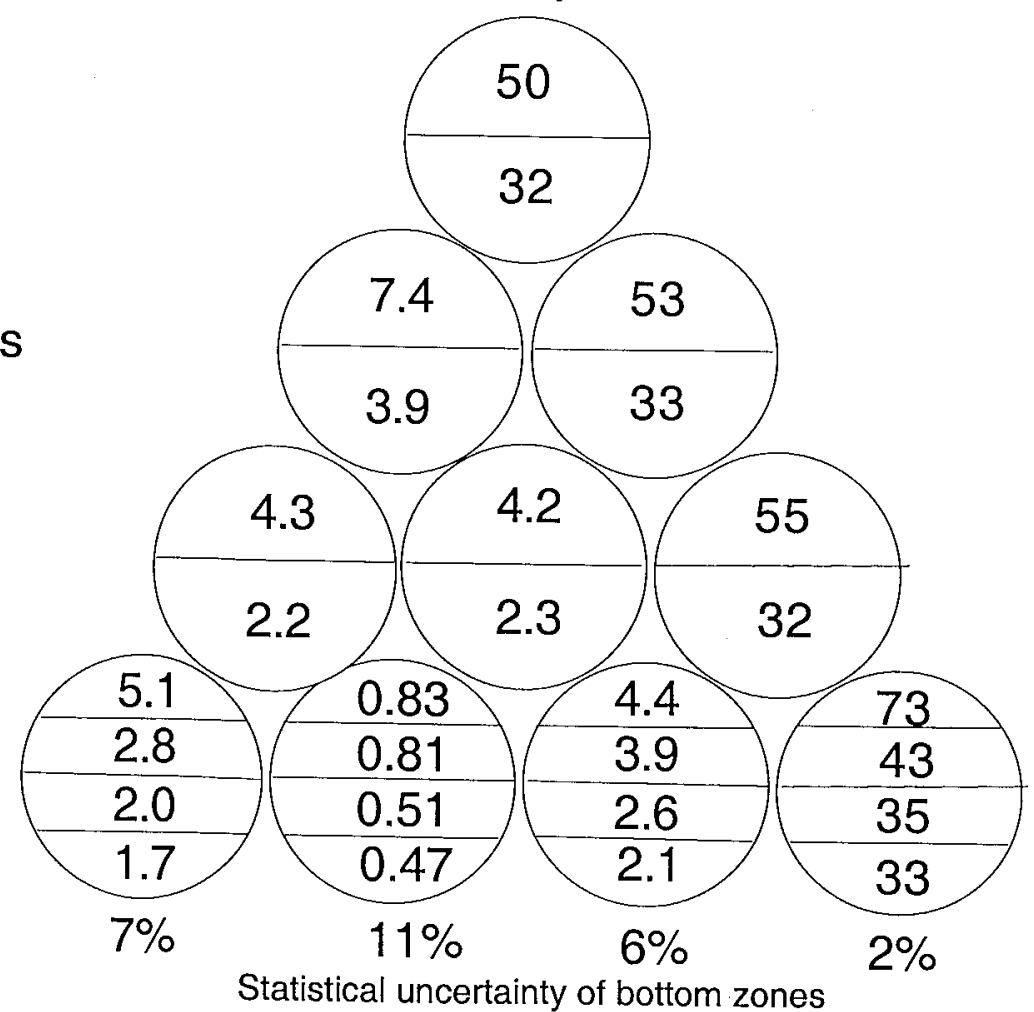


Radiation Dose in 200-liter Drums on the Ground in Open Air at a $10 \mathrm{~m}$ Ground Range

(Megarad)

Yield: $10 \mathrm{kT}$

HOB: $10 \mathrm{~m}$

Fig. A3

14 Mev neutrons

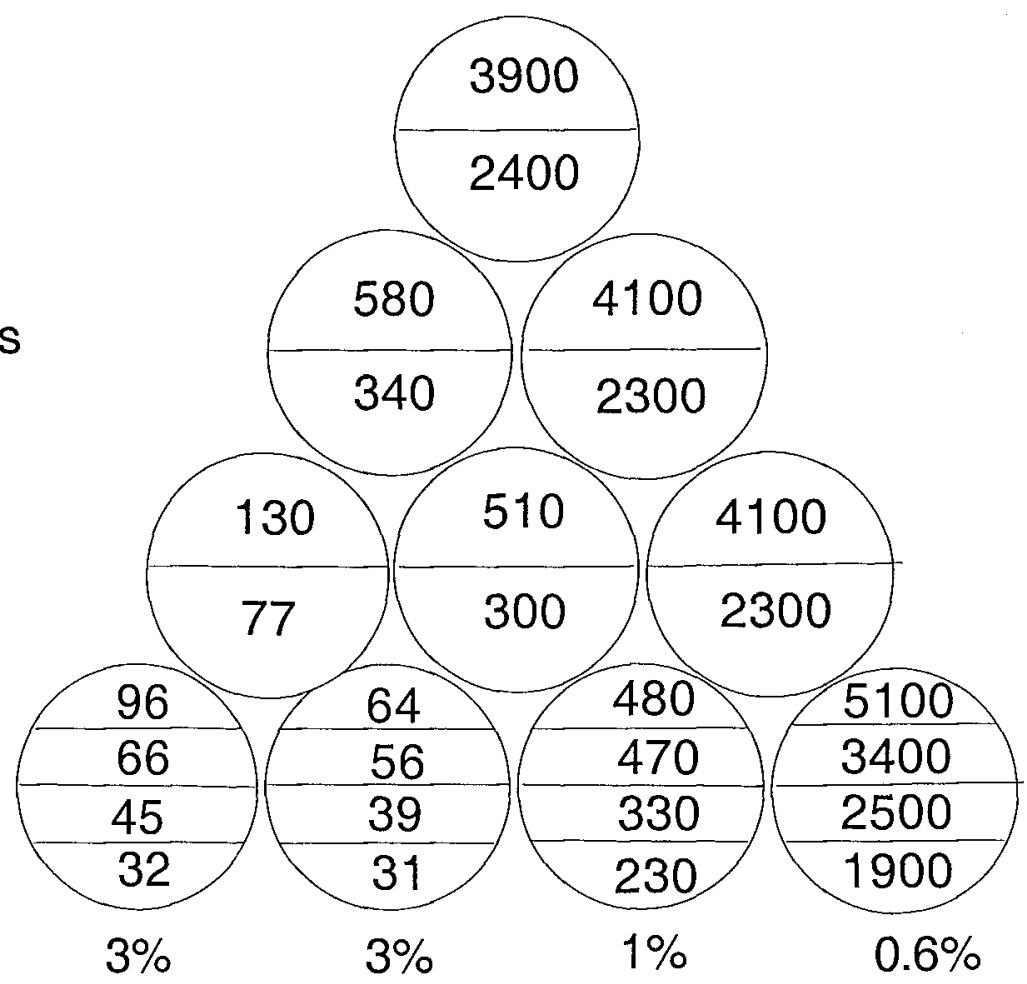

Fig. A4

Fission neutrons

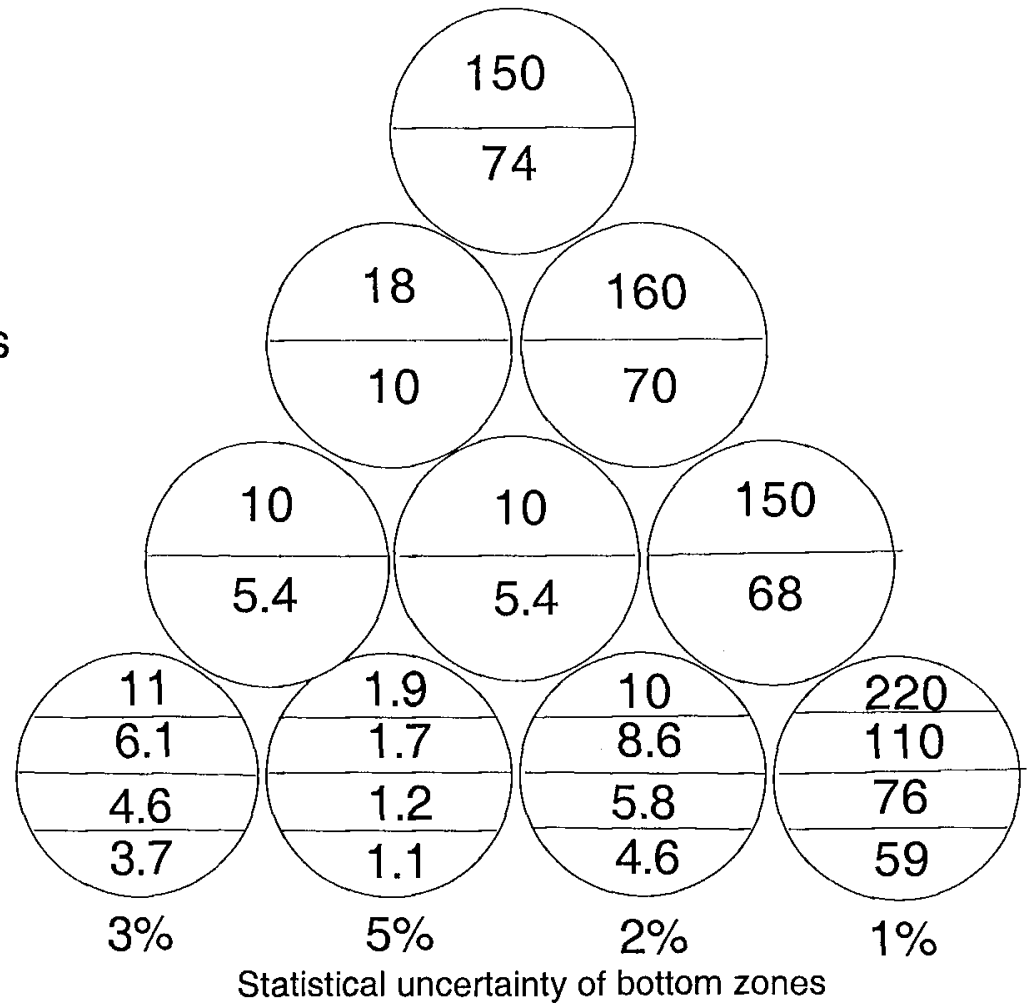


Radiation Dose in 200-liter Drums on the Ground in Open Air underneath the Burst Point

(Megarad)

Yield: $10 \mathrm{kT}$

HOB: $10 \mathrm{~m}$

Fig. A1

$14 \mathrm{Mev}$ neutrons

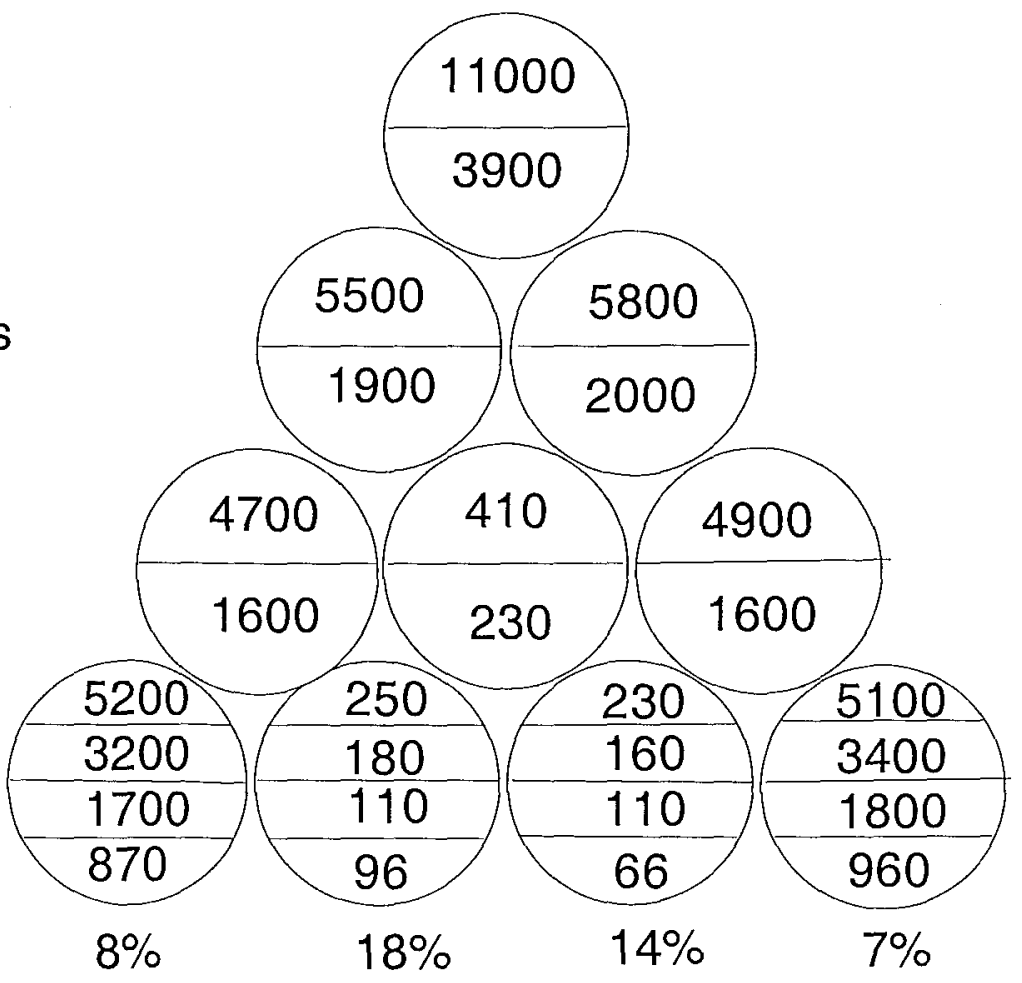

Statistical uncertainty of bottom zones

Fig. A2

Fission neutrons

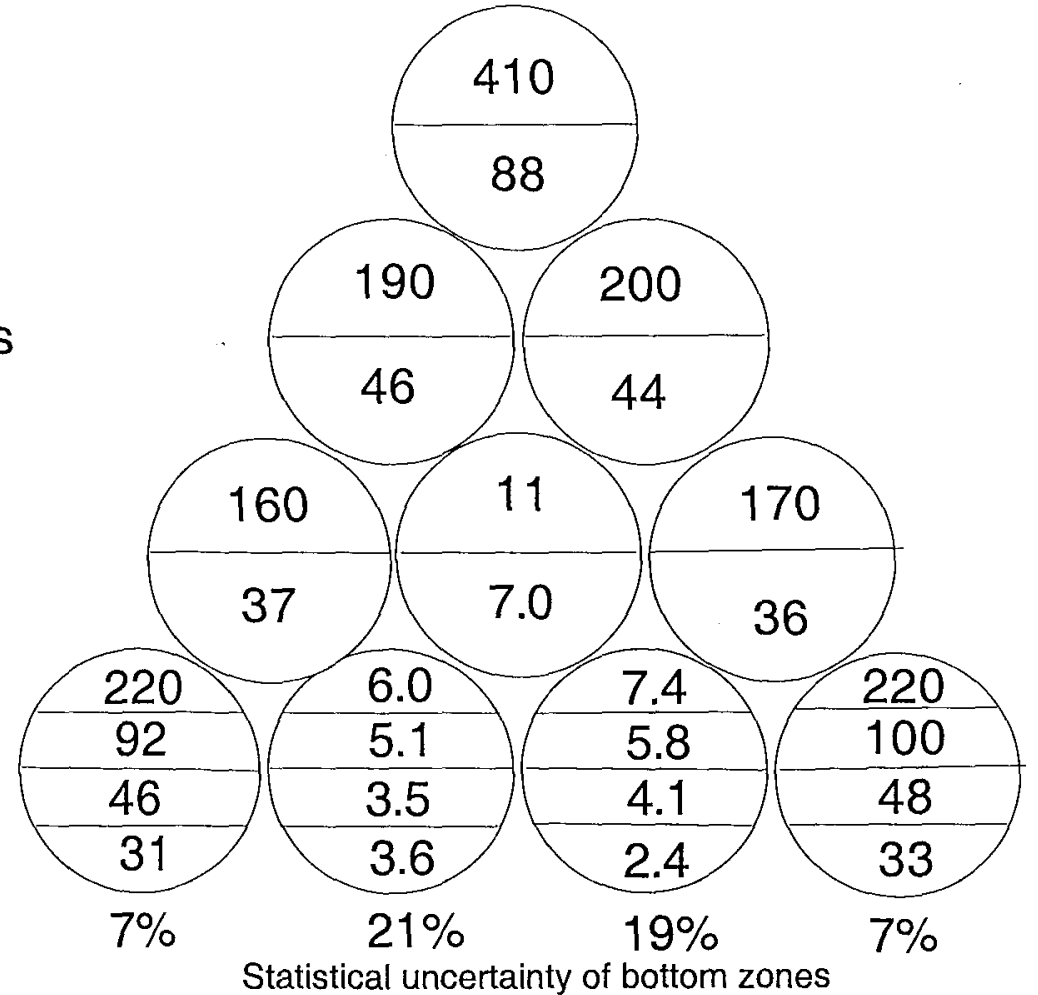




\section{Appendix}

Detailed Agent Dose Distributions

Within Barrel and Container Stacks 
HOB Dependence of Lowest Radiation Dose in Double-Layer Running Stack of 200-Liter Barrels in a Metal Roof Building at $20 \mathrm{~m}$ Ground Range from a $10 \mathrm{kT}$ Burst

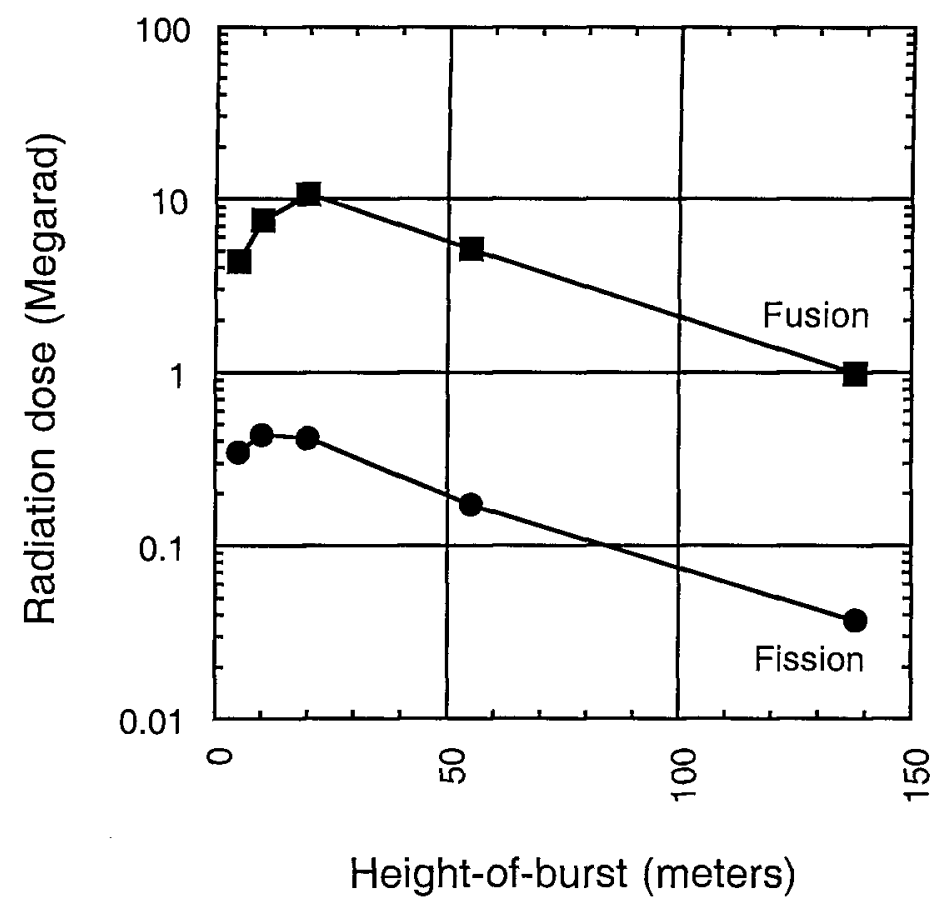

Fig. 33 
Fractional Neutron Dose in 200-liter Drums inside a Metal Roof Building $10 \mathrm{~m} \mathrm{HOB}$

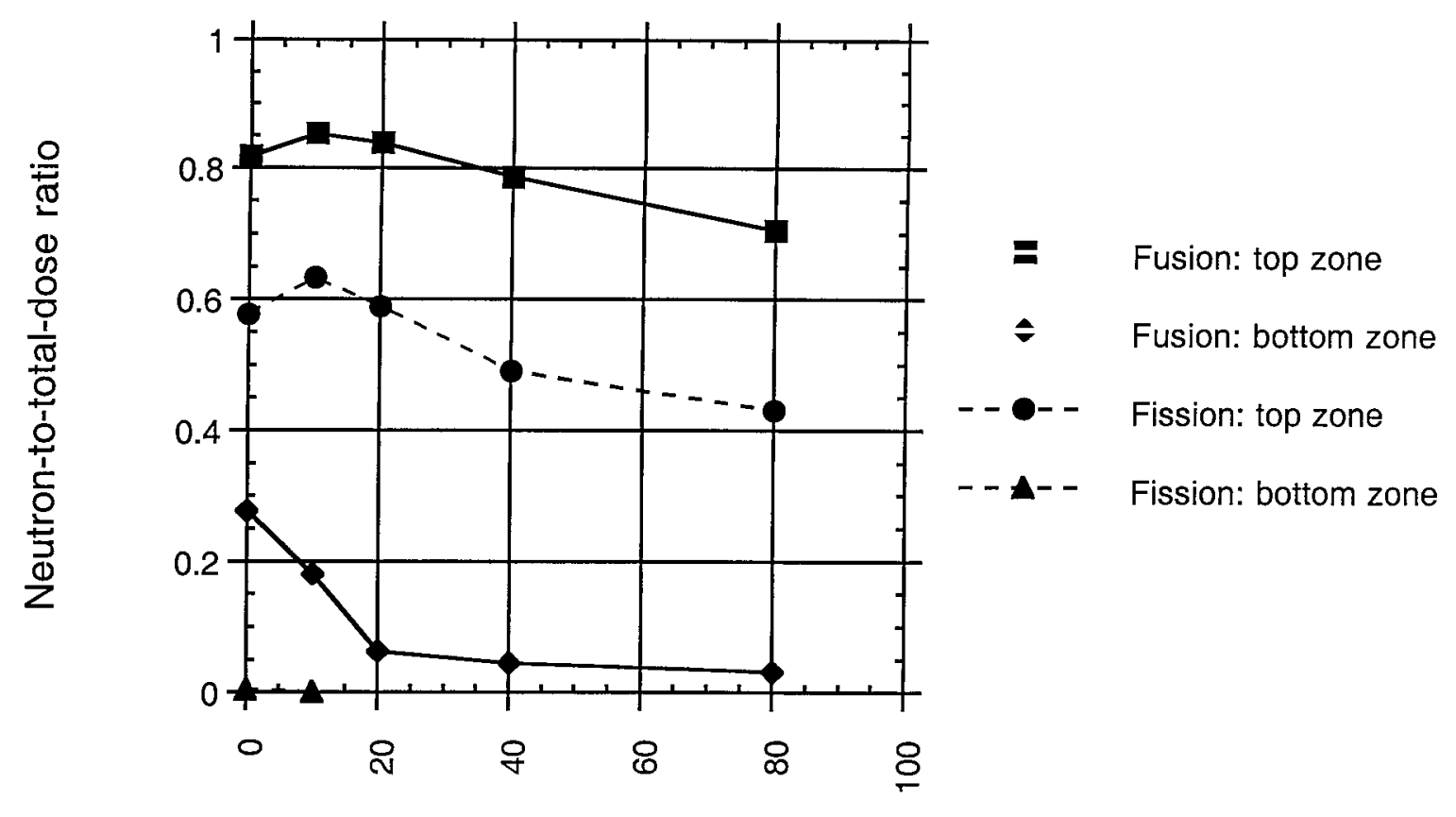

Ground range (meters)

Fig. 32 


\section{$1 \varepsilon \cdot 6 !$}

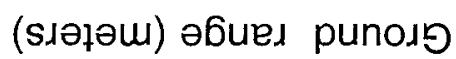

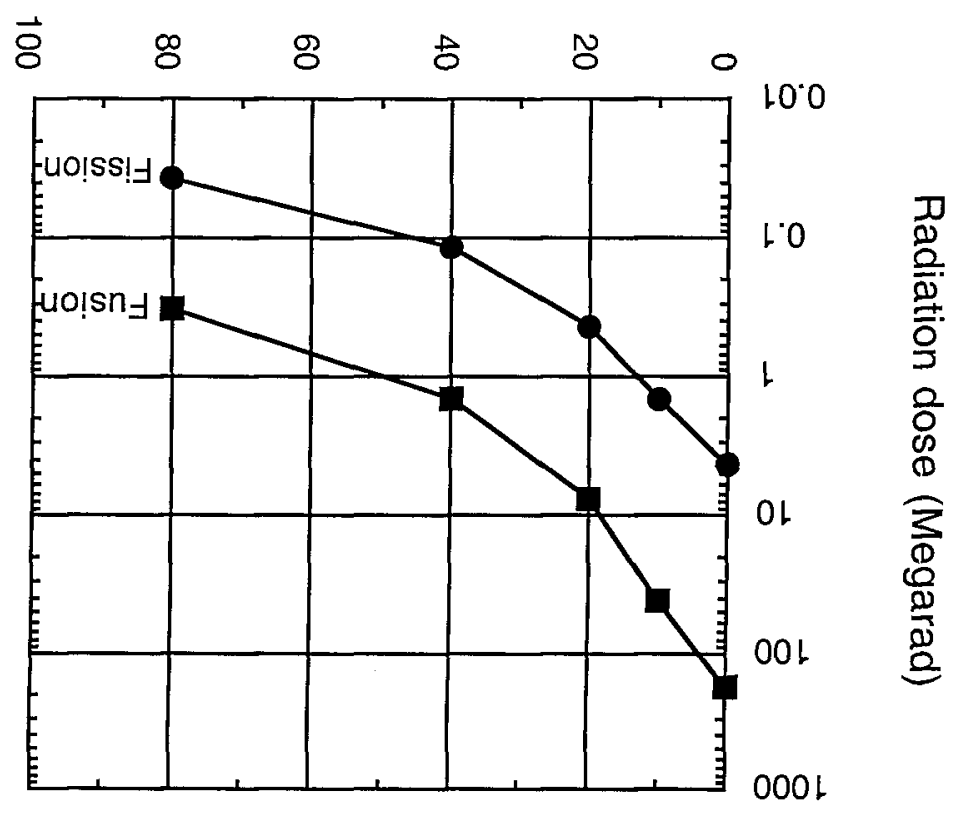

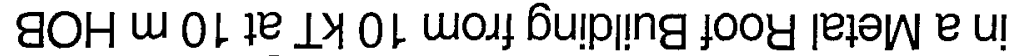

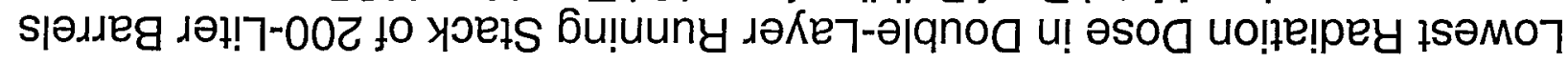


MCNP Code Geometry for Double-Layered Running Stack of Agent-filled 200 liter Barrels in a Storage Building

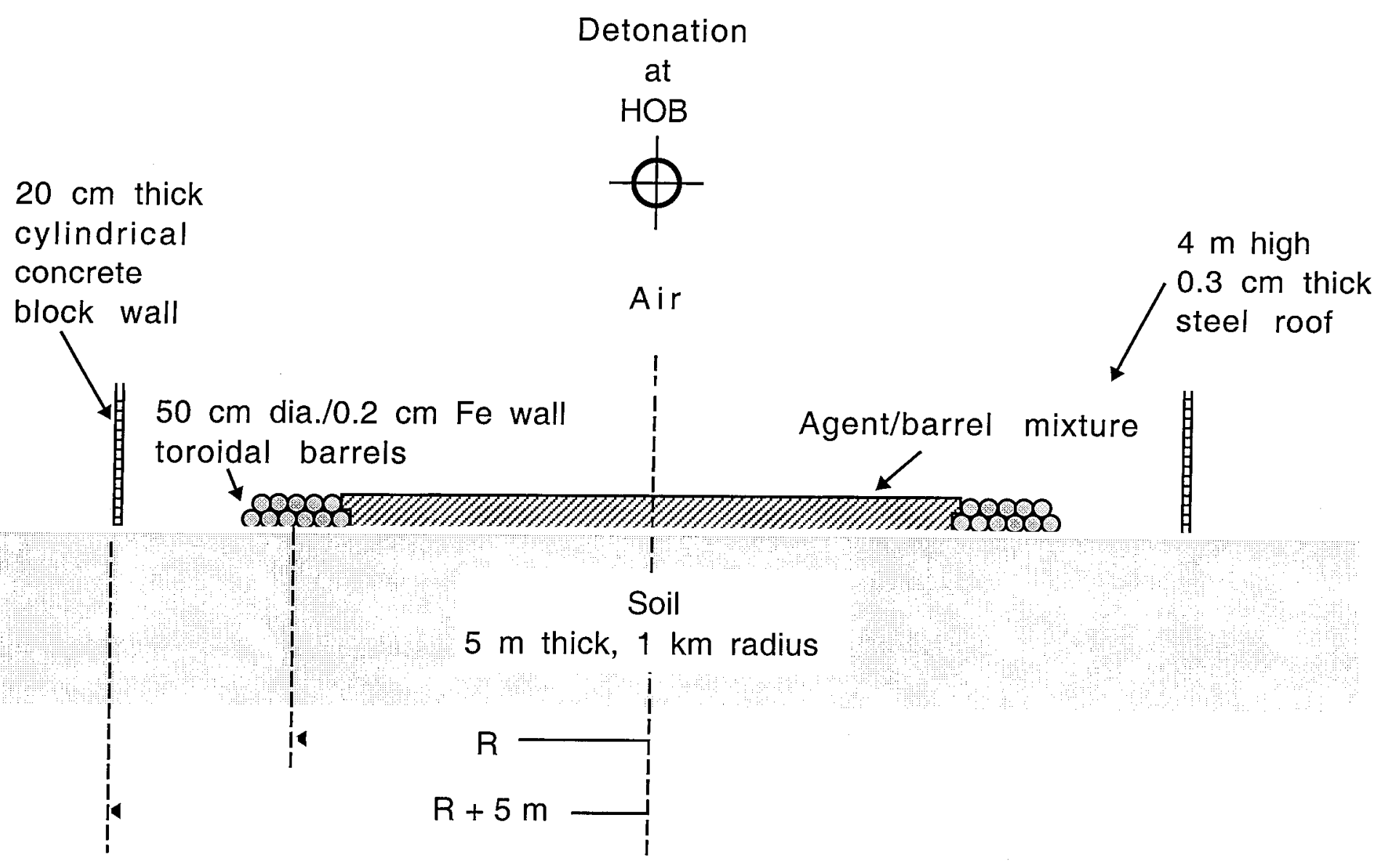

Fig. 30 


\section{Fractional Neutron Dose in a Double-Layer Running Stack of One-Ton Containers}

on the Ground in Open Air

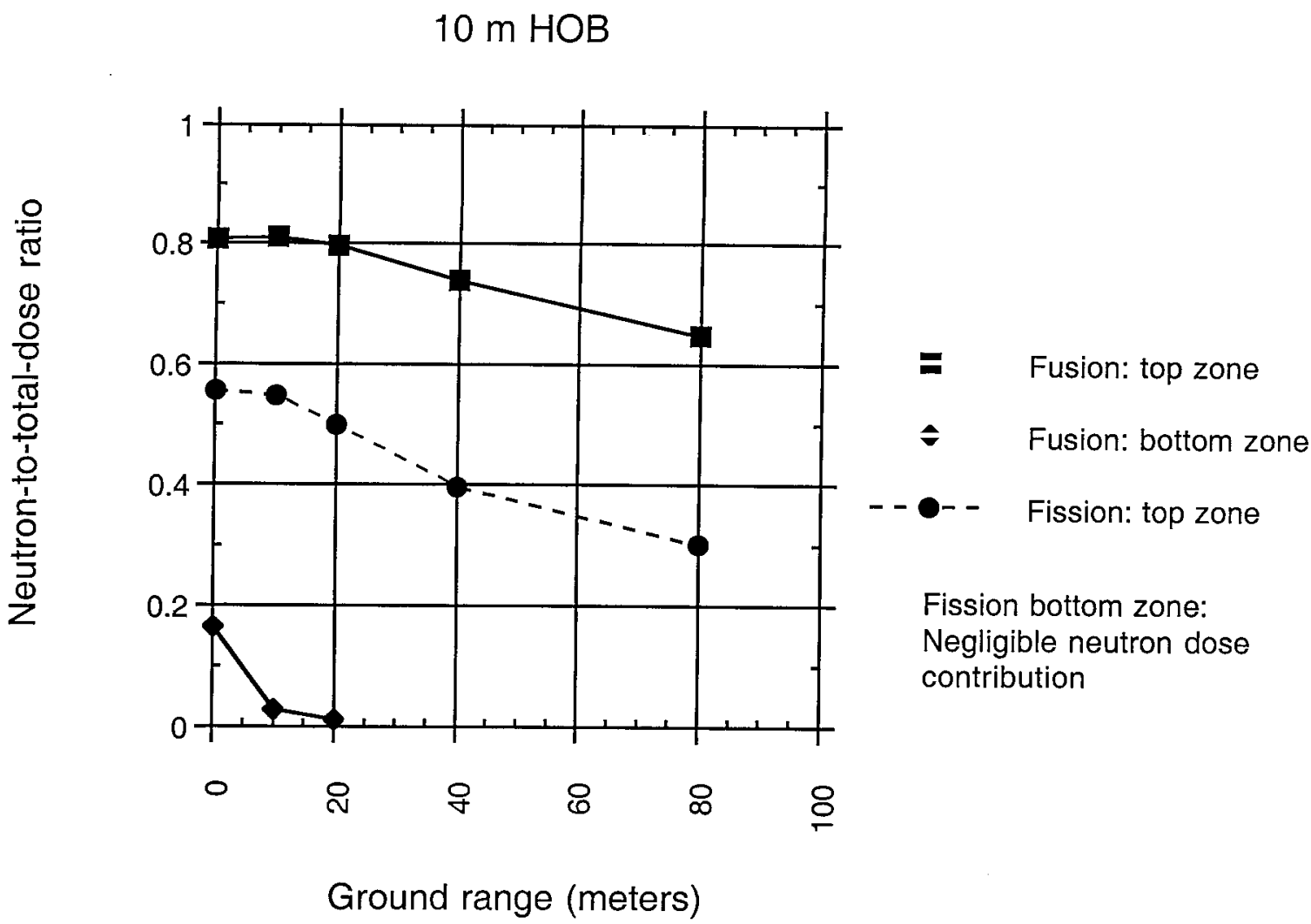

Fig. 29 


\section{Lowest Radiation Dose in Double-Layer Running Stack of One-Ton Agent Containers}

from $10 \mathrm{kT}$ Burst at $10 \mathrm{~m} \mathrm{HOB}$

Containers on the ground in open air or in a concrete block building

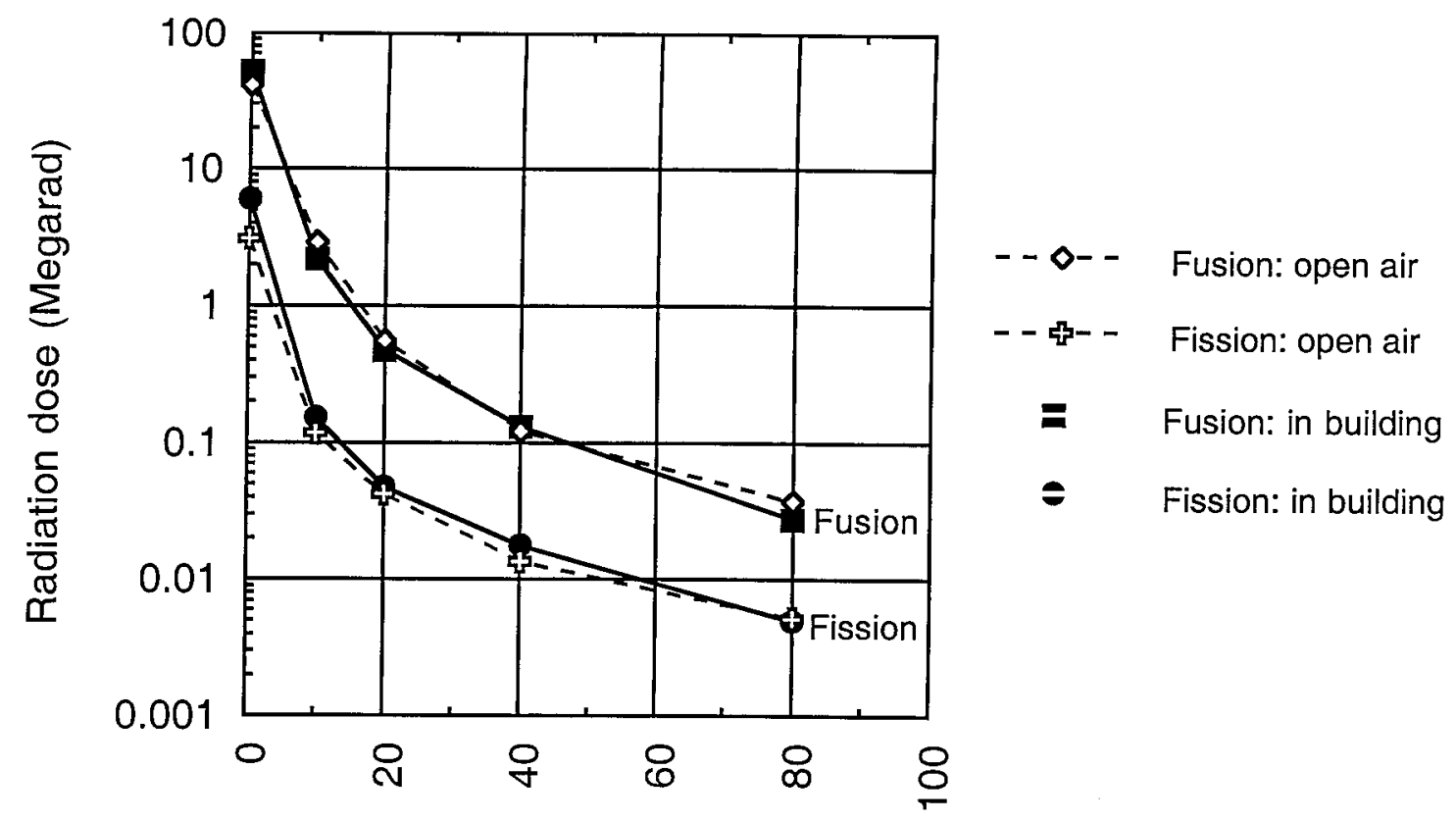

Ground range (meters)

Fig. 28 
Fractional Neutron Dose in a Single-Layer Running Stack of One-Ton Containers on the Ground in Open Air

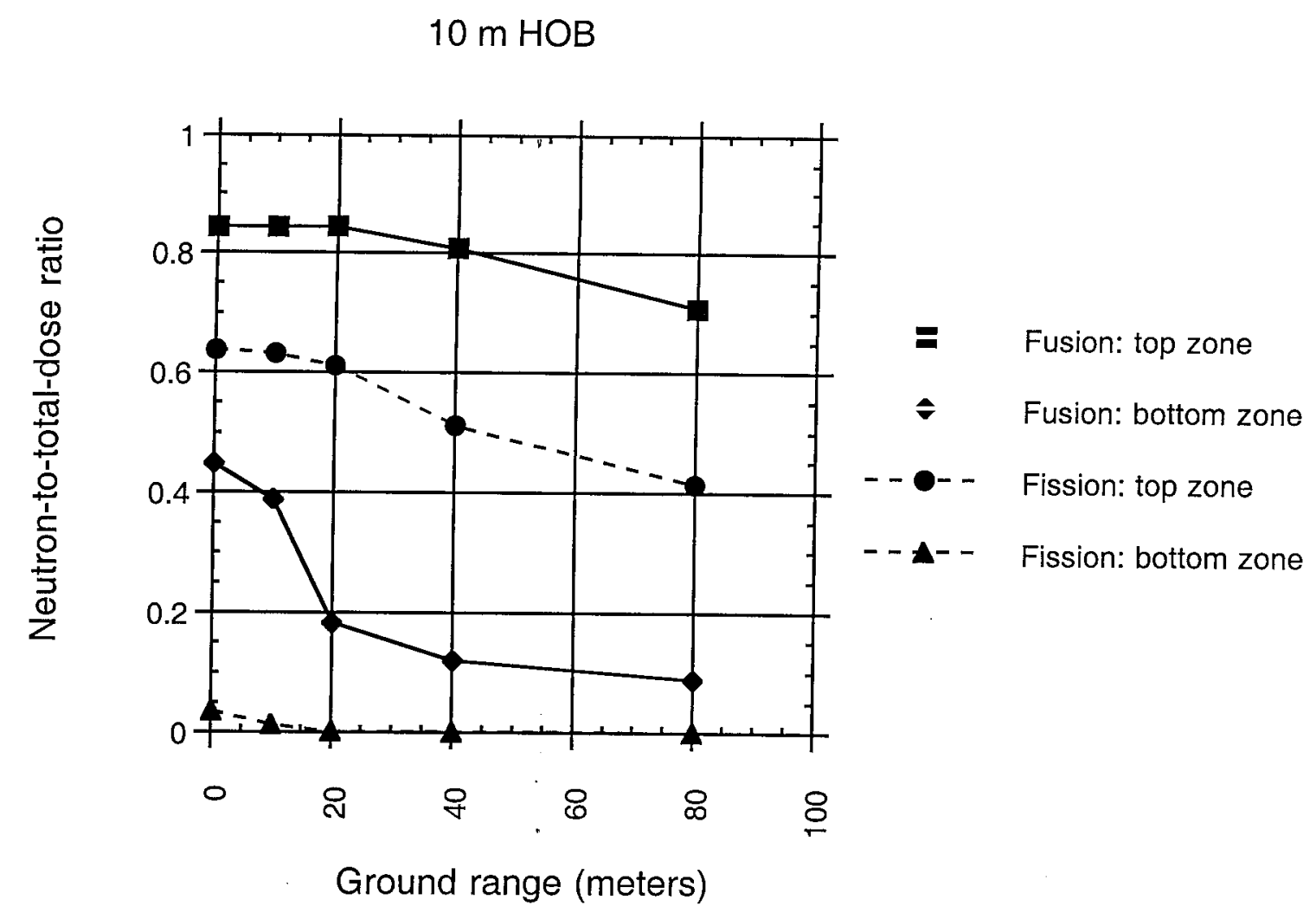

Fig. 27 


\section{Lowest Radiation Dose in Single-Layer Running Stack of One-Ton Agent Containers from $10 \mathrm{kT}$ at $10 \mathrm{~m} \mathrm{HOB}$}

Containers on the ground in open air or in a concrete block building

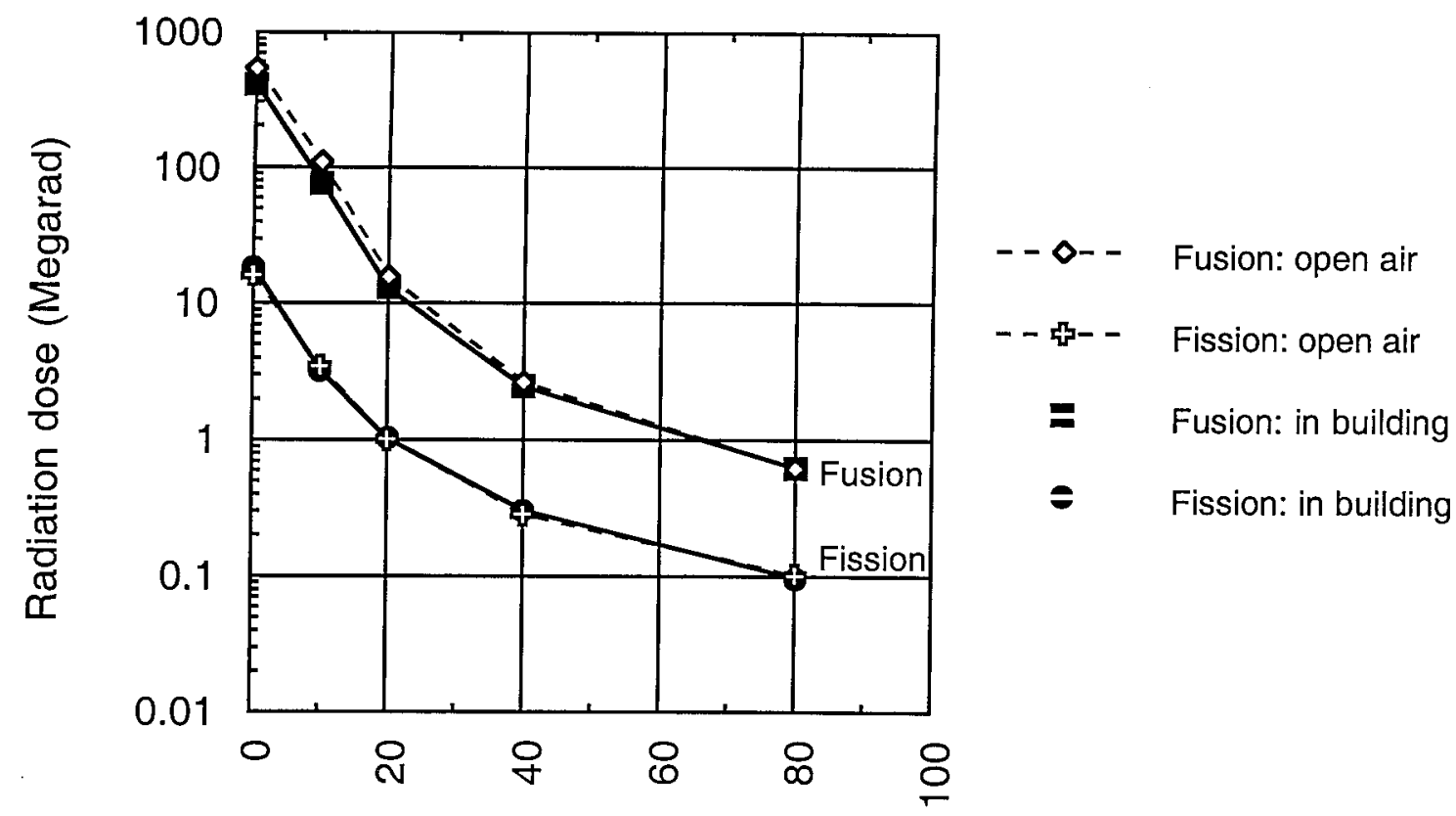

Ground range (meters)

Fig. 26 
MCNP Code Geometry for Double-Layered Running Stack of One-Ton Agent Containers in a Storage Building

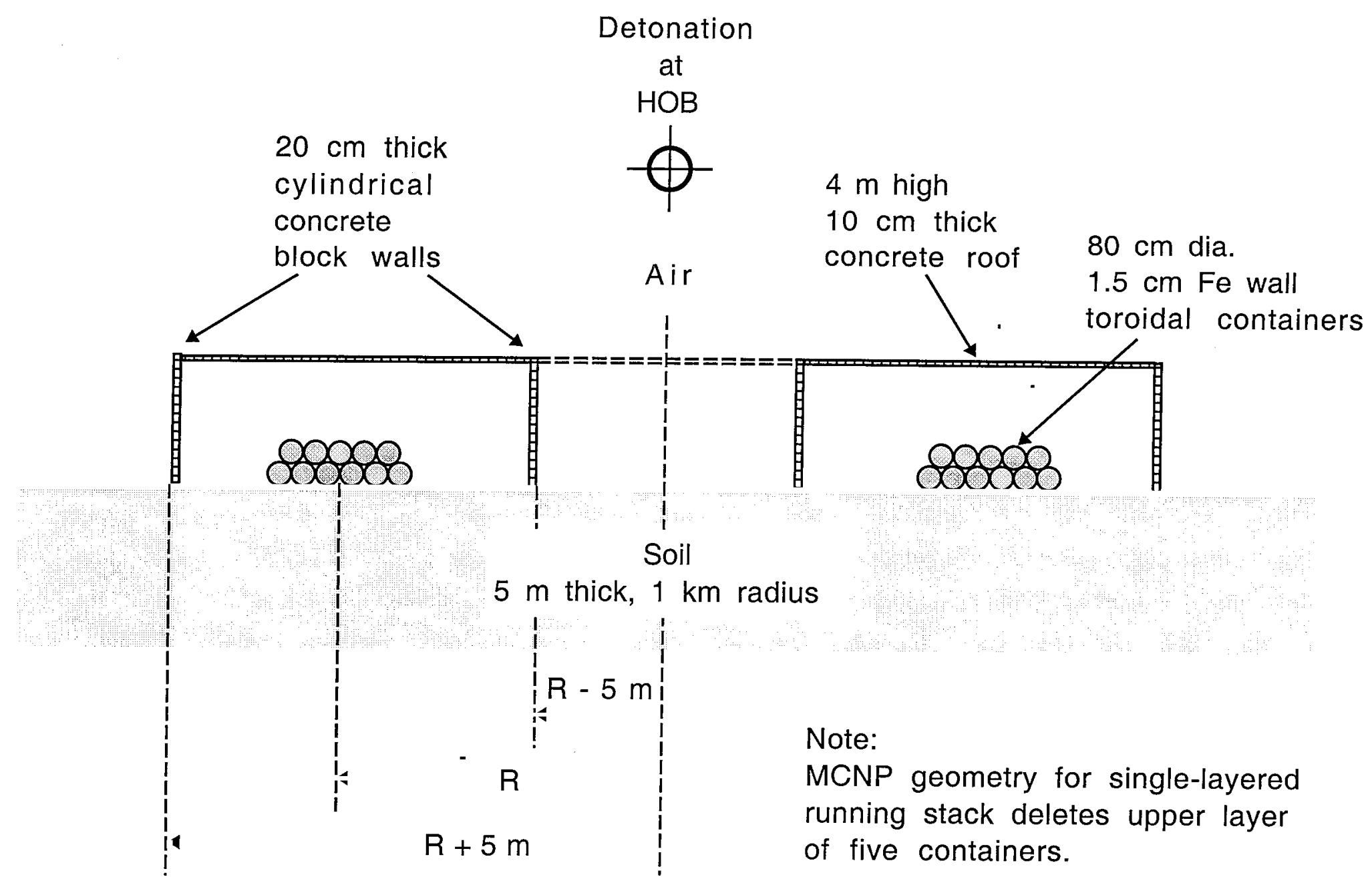

Fig. 25 


\section{Neutron Energy Dependence of Lowest Radiation Dose in Barrel Stack}

at a $10 \mathrm{~m}$ Ground Range from a Burst at $10 \mathrm{~m} \mathrm{HOB}$

Adjacent pyramids of ten 200 liter barrels on the ground in open air

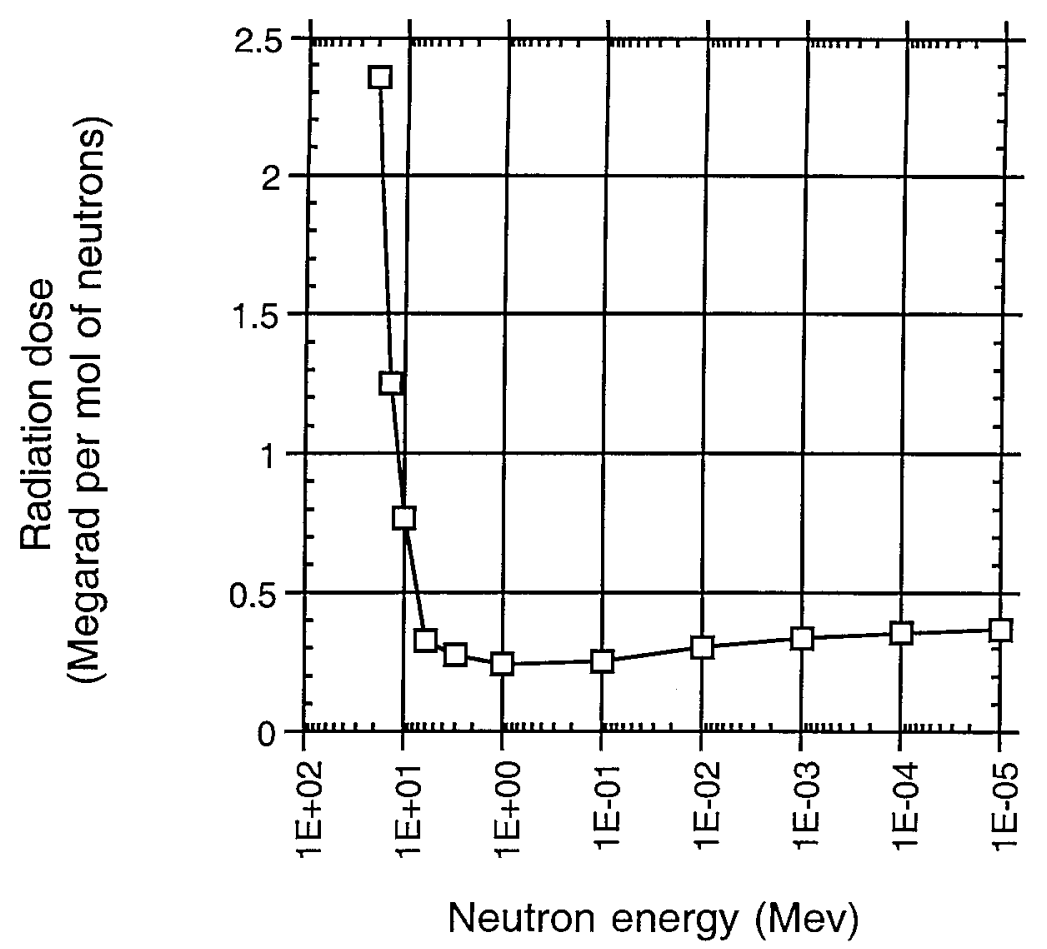

Fig. 24 
Radiation Dose in 200-liter Drums inside a Concrete Block Building at a $20 \mathrm{~m}$ Ground Range

(Megarad)

Yield: $10 \mathrm{kT}$

Neutron spectrum: Fission

Fig. A43

$2.5 \mathrm{~m} \mathrm{HOB}$

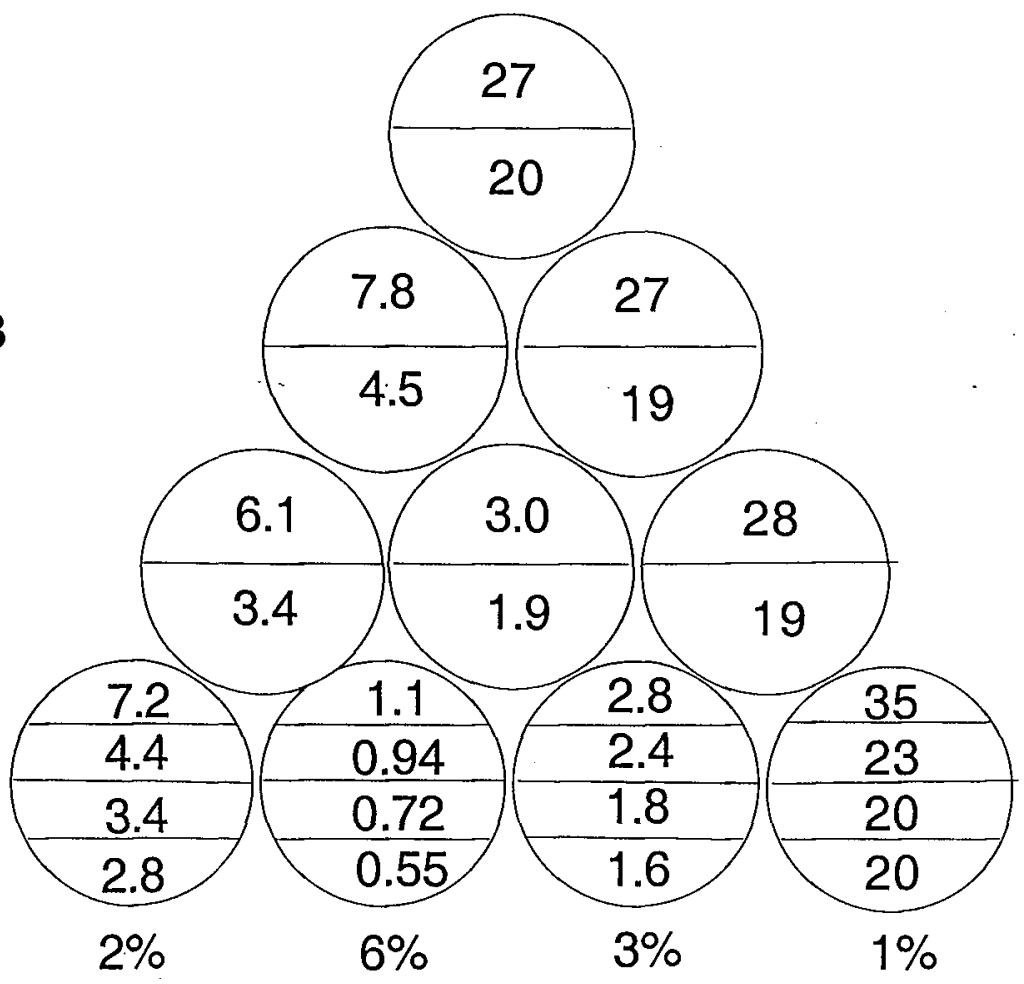

Statistical uncertainty of bottom zones

Fig. A44

$20 \mathrm{~m} \mathrm{HOB}$

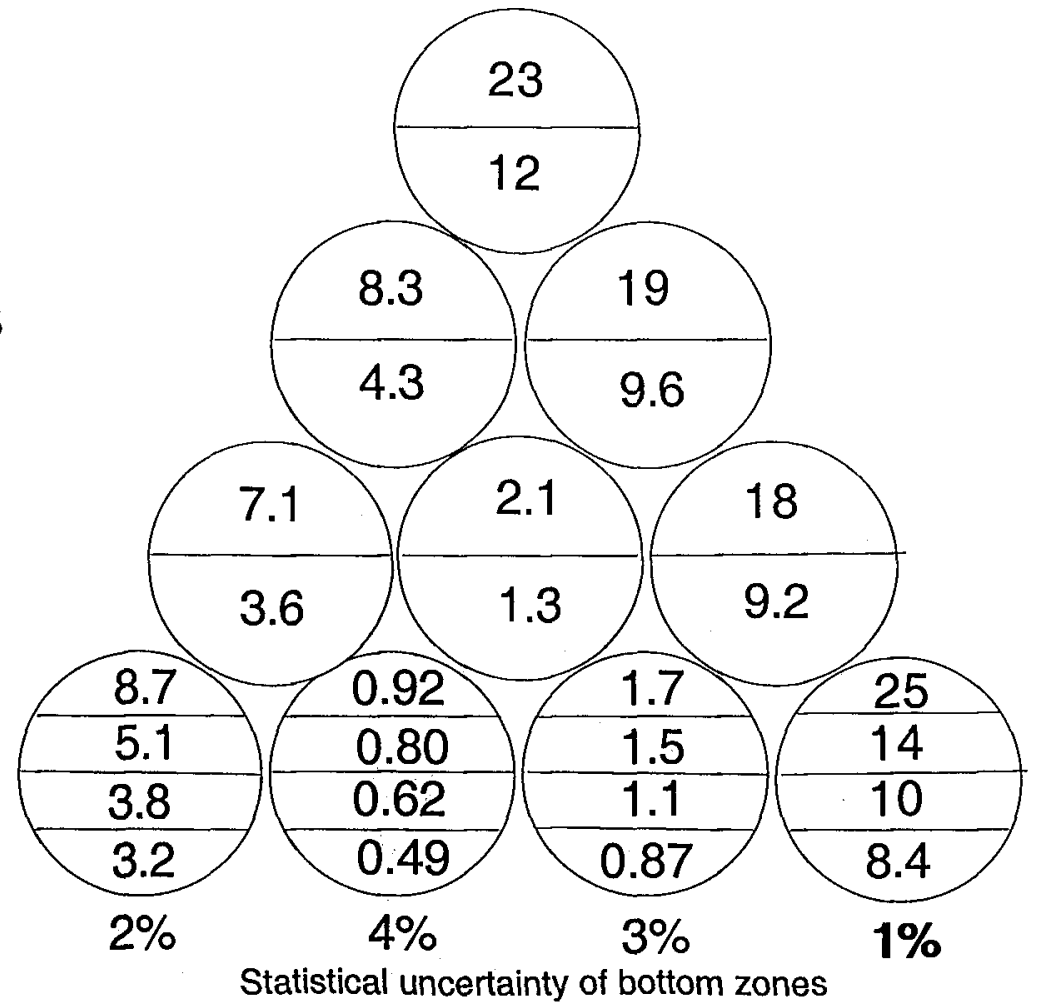


Radiation Dose in 200-liter Drums inside a Concrete Block Building at a $20 \mathrm{~m}$ Ground Range (Megarad)

Yield: $10 \mathrm{kT}$

Neutron spectrum: Fission

Fig. A45

$55 \mathrm{~m} \mathrm{HOB}$

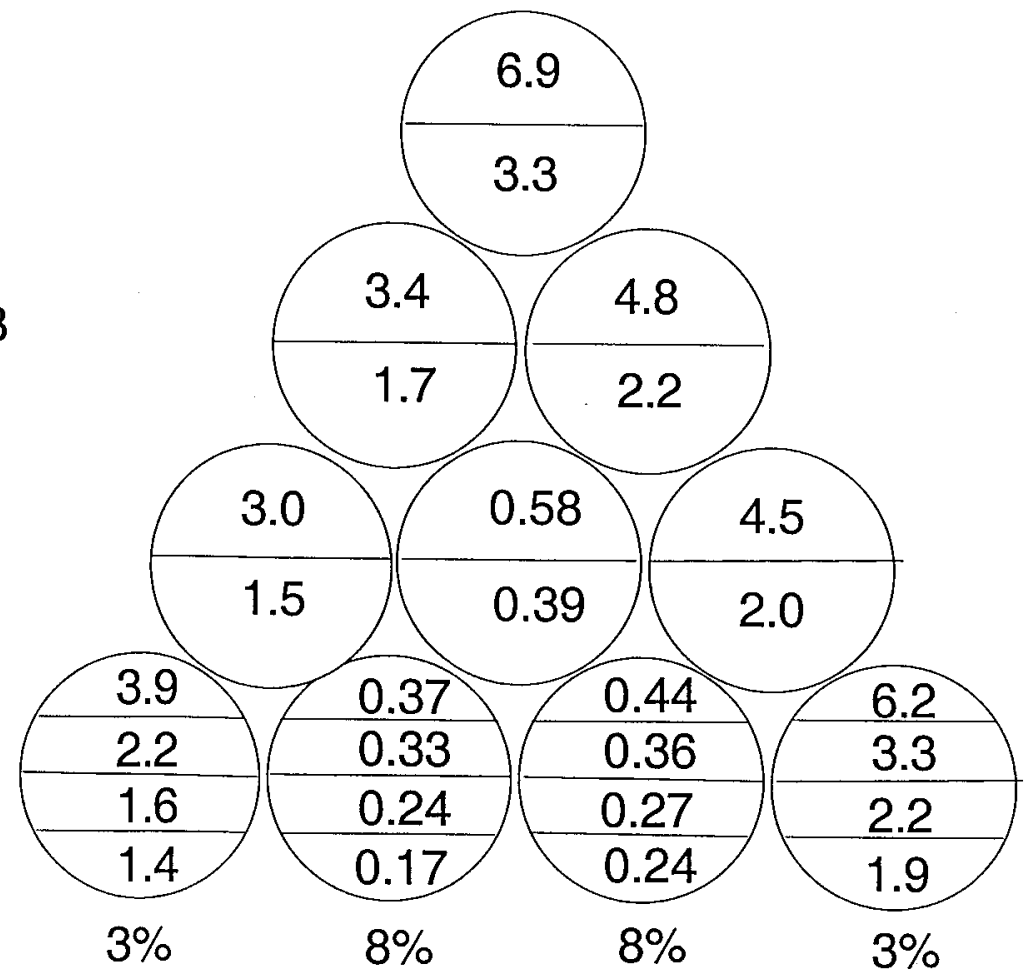

Statistical uncertainty of bottom zones

Fig. A46 $138 \mathrm{~m} \mathrm{HOB}$

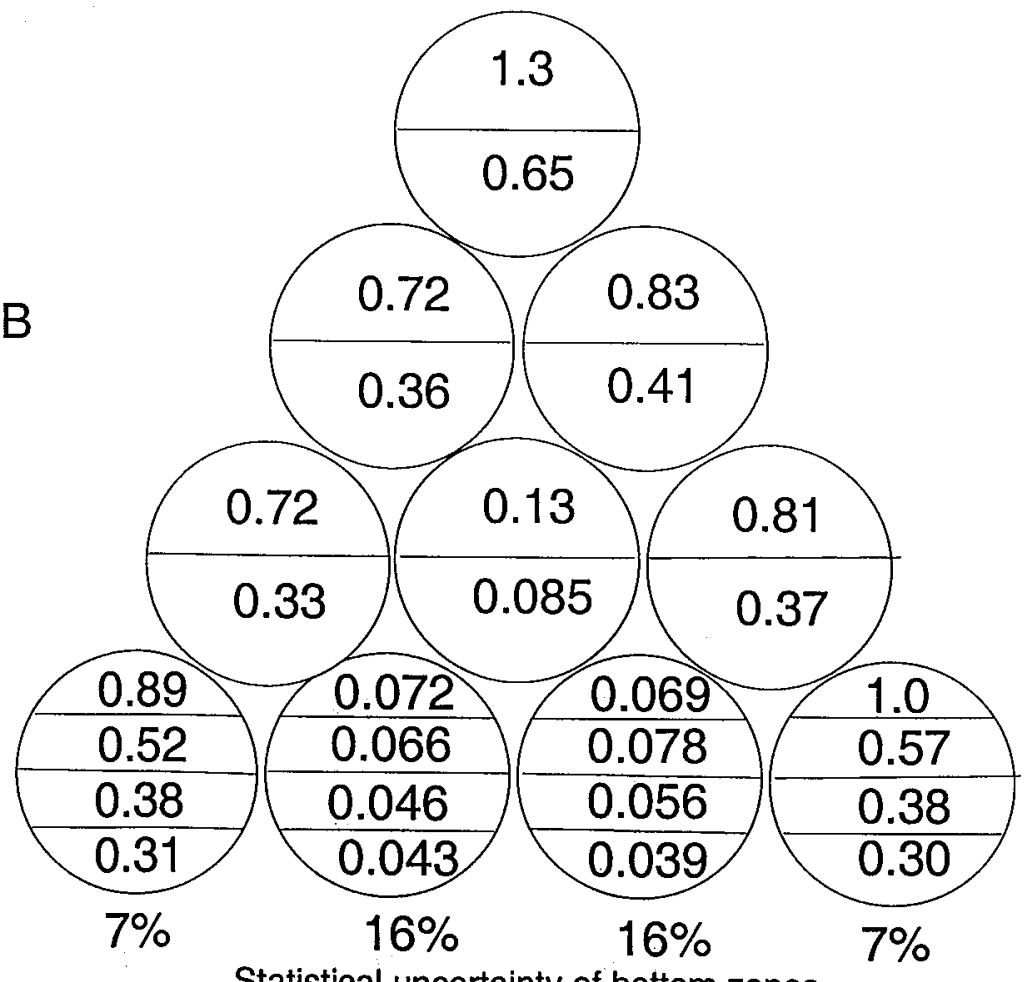

Statistical uncertainty of bottom zones 
Radiation Dose in One-Ton Containers on the Ground in Open Air underneath the Burst Point

(Megarad)

Yield: $10 \mathrm{kT}$

HOB: $10 \mathrm{~m}$

$14 \mathrm{Mev}$ neutrons

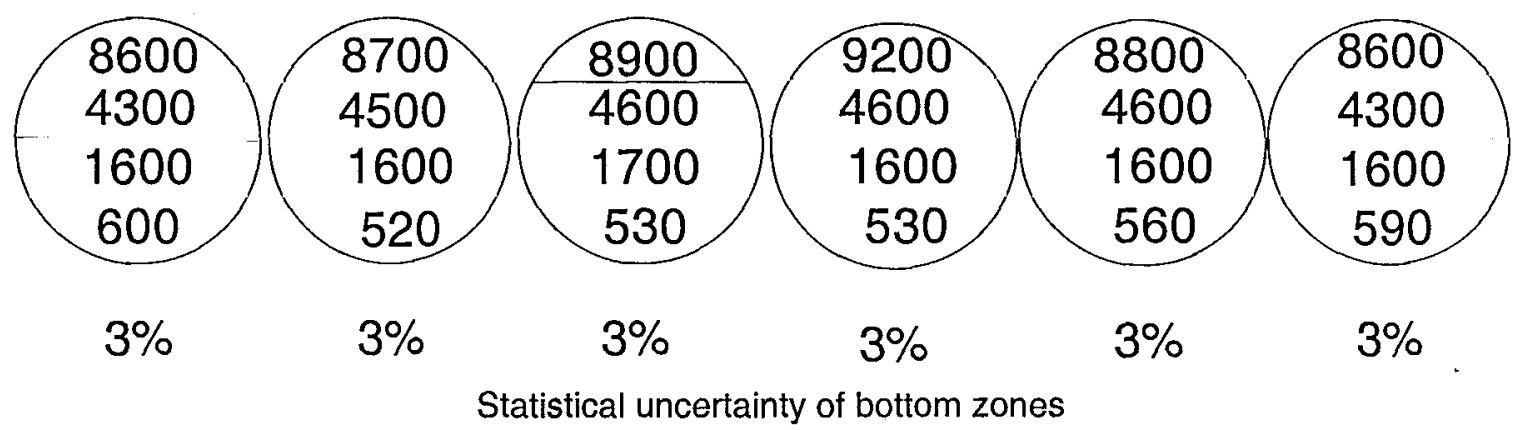

Fig. A47

Fission neutrons

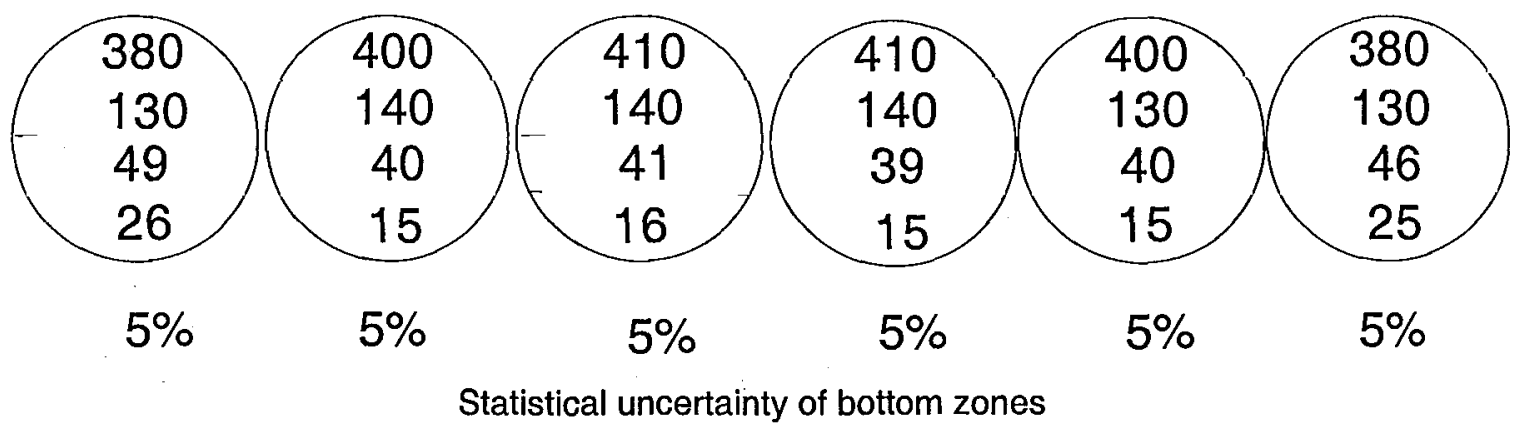

Fig. A48 
Radiation Dose in One-Ton Containers on the Ground in Open Air at a $10 \mathrm{~m}$ Ground Range

(Megarad)

Yield: $10 \mathrm{kT}$

HOB: $10 \mathrm{~m}$

14 Mev neutrons

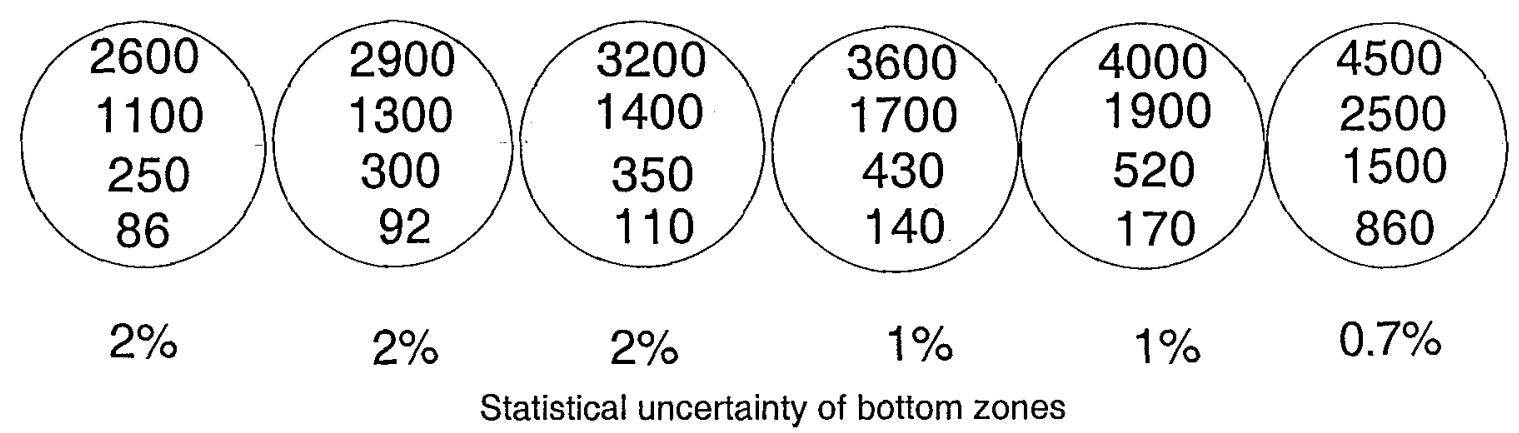

Fig. A49

Fission neutrons

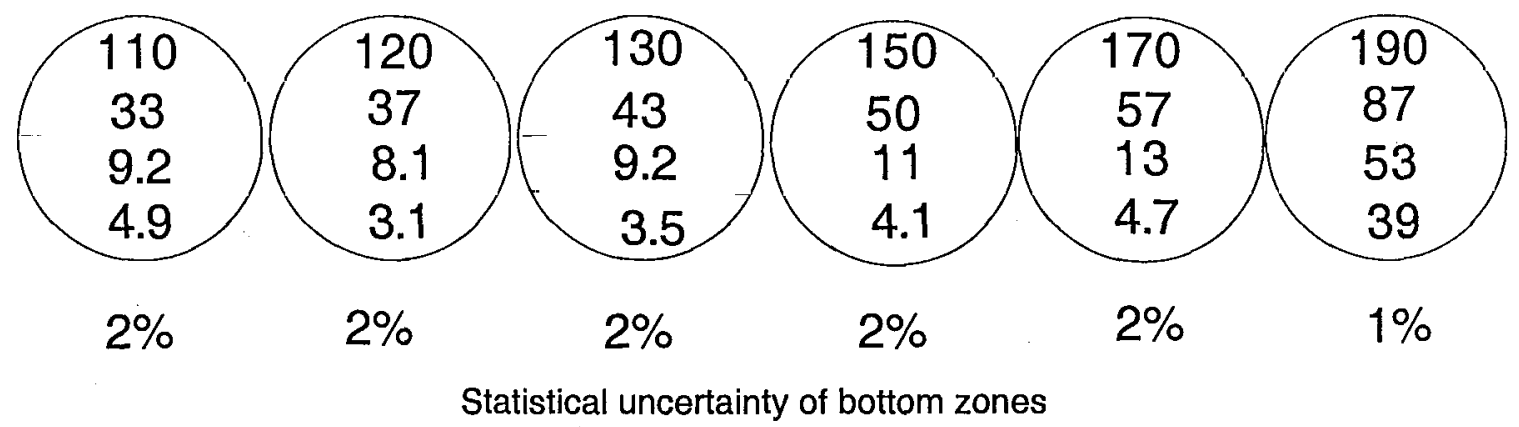

Fig. A50 
Radiation Dose in One-Ton Containers on the Ground in Open Air at a $20 \mathrm{~m}$ Ground Range

(Megarad)

Yield: $10 \mathrm{kT}$

HOB: $10 \mathrm{~m}$

14 Mev neutrons

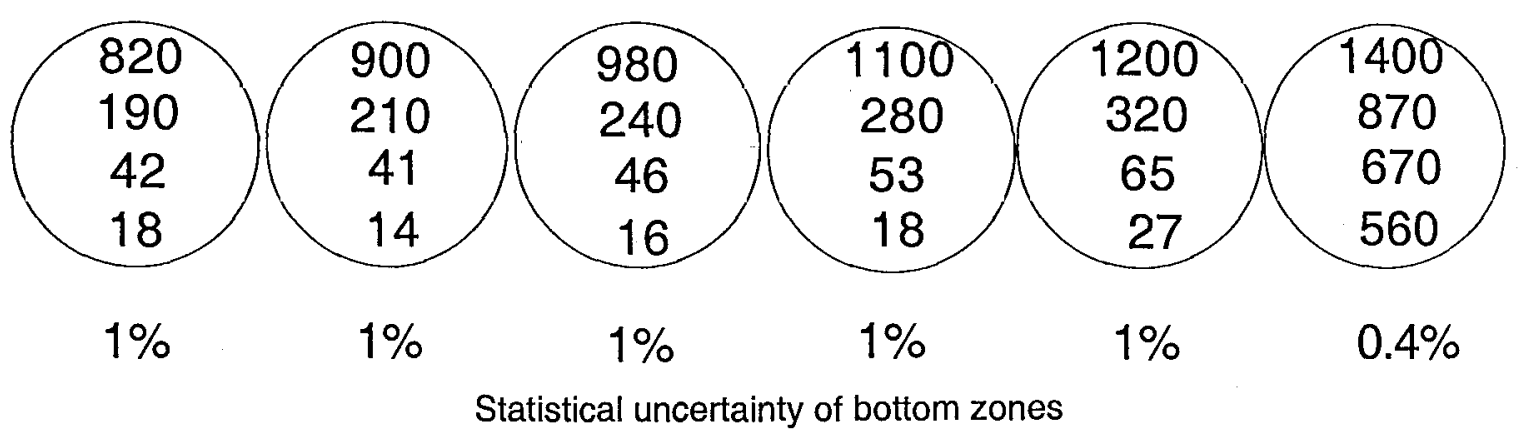

Fig. A51

Fission neutrons

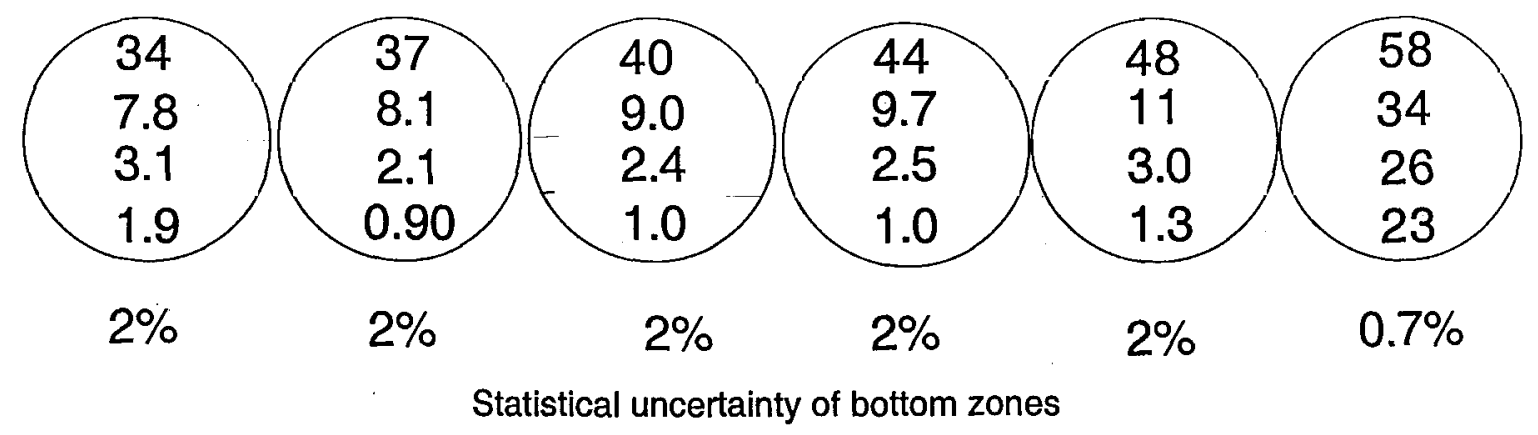

Fig. A52 
Radiation Dose in One-Ton Containers on the Ground in Open Air at a $40 \mathrm{~m}$ Ground Range (Megarad)

Yield: $10 \mathrm{kT}$

HOB: $10 \mathrm{~m}$

14 Mev neutrons

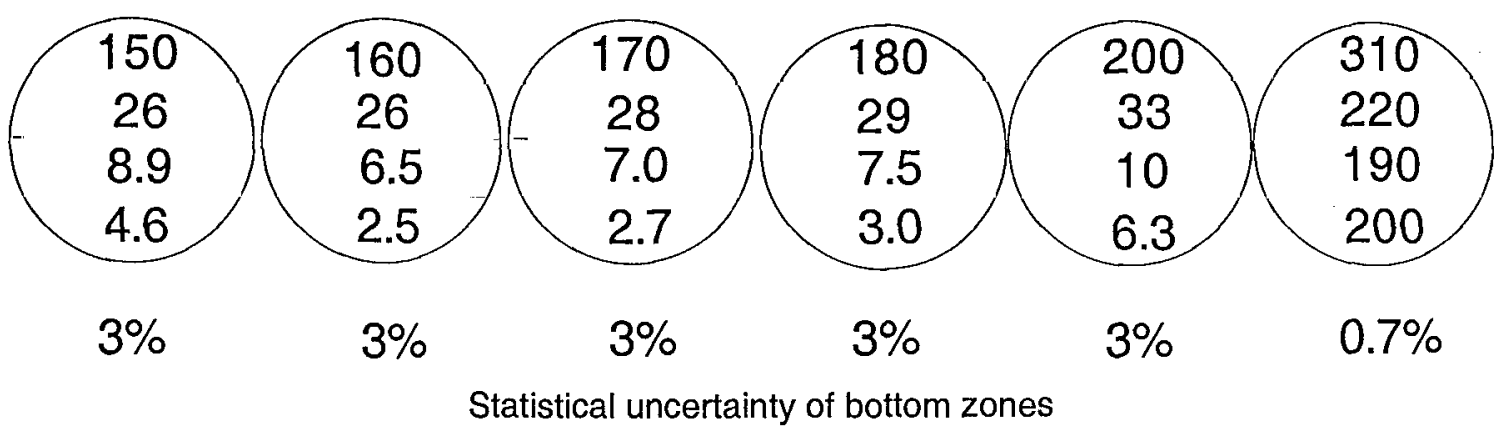

Fig. A53

Fission neutrons

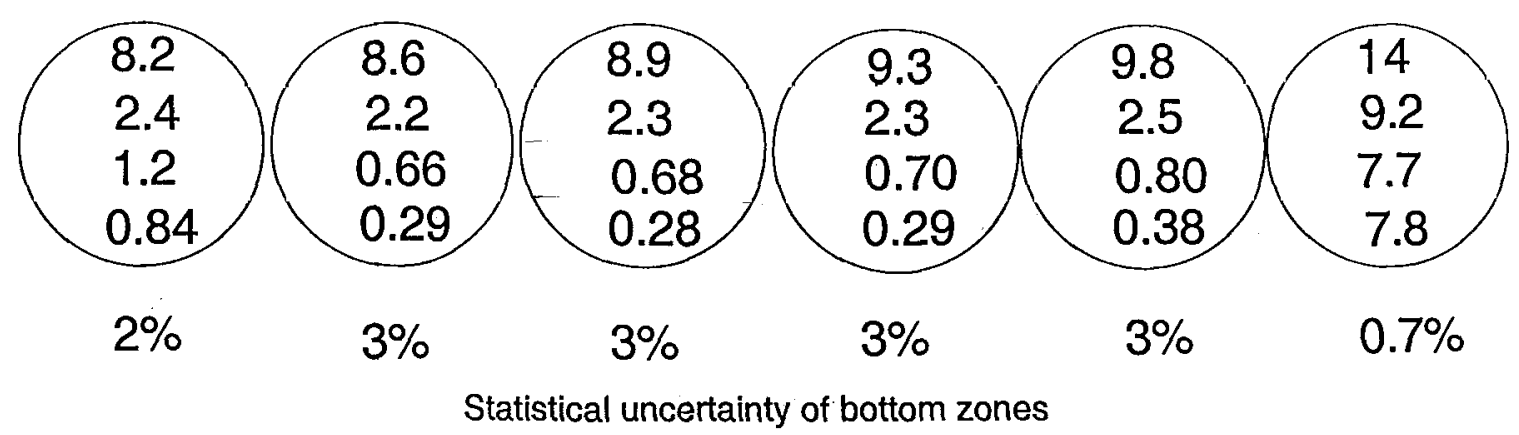

Fig. A54 


\section{Radiation Dose in One-Ton Containers on the Ground in Open Air at a $80 \mathrm{~m}$ Ground Range (Megarad)}

Yield: $10 \mathrm{kT}$

HOB: $10 \mathrm{~m}$

14 Mev neutrons

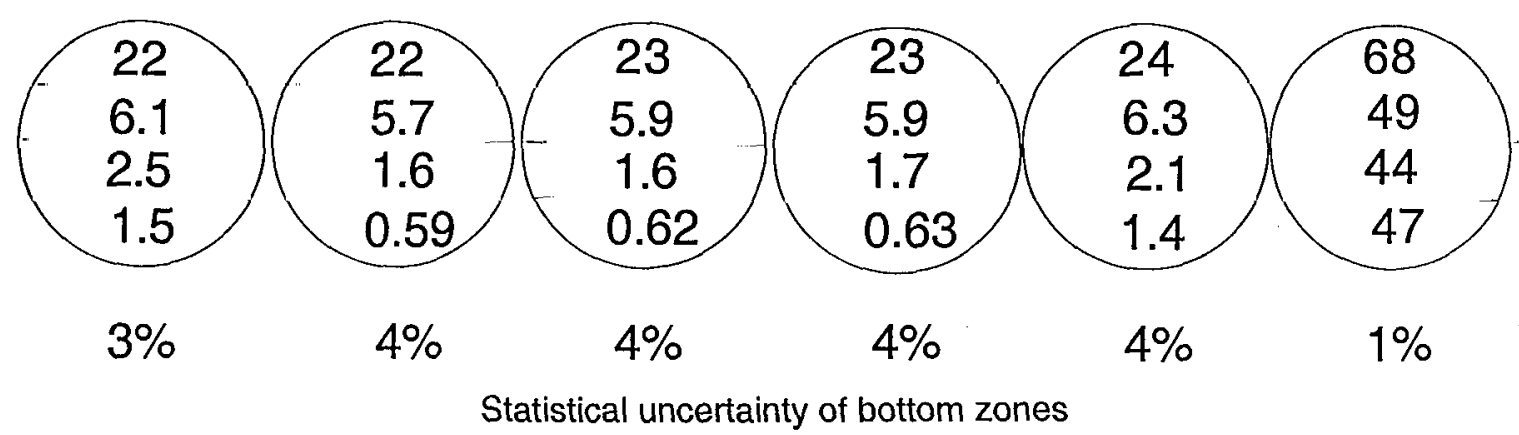

Fig. A55

Fission neutrons

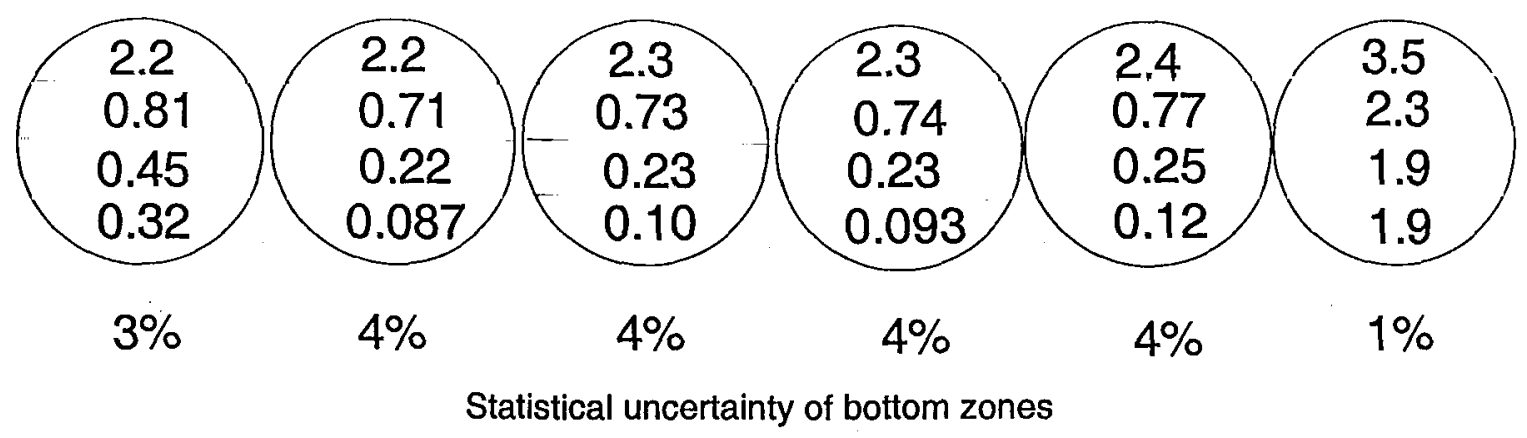

Fig. A56 
Radiation Dose in One-Ton Containers inside a Concrete Block Building underneath the Burst Point (Megarad)

Yield: $10 \mathrm{kT}$

HOB: $10 \mathrm{~m}$

14 Mev neutrons

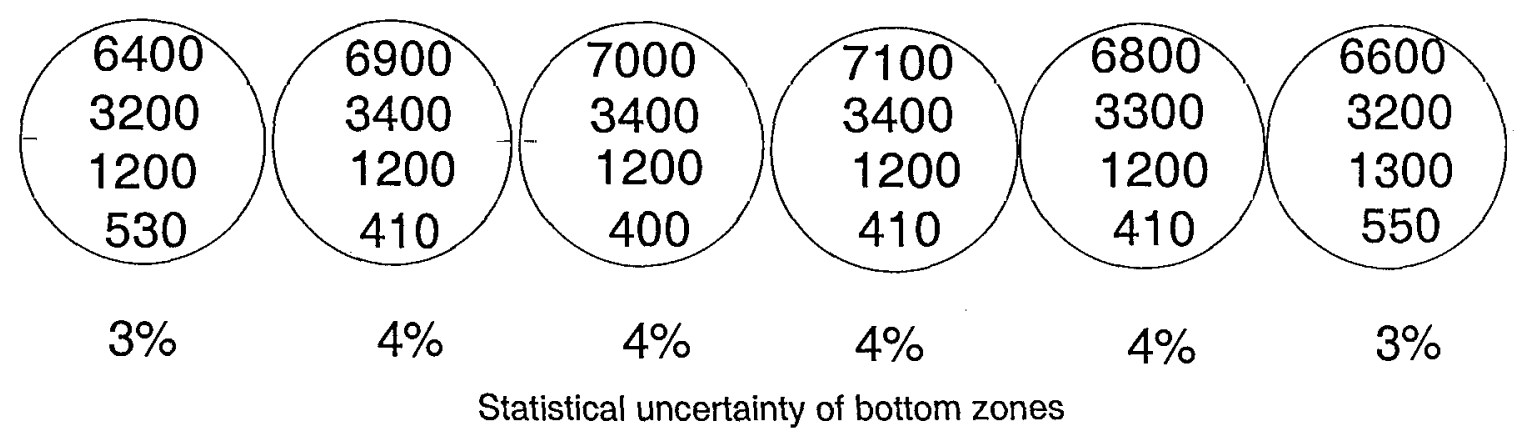

Fig. A57

Fission neutrons

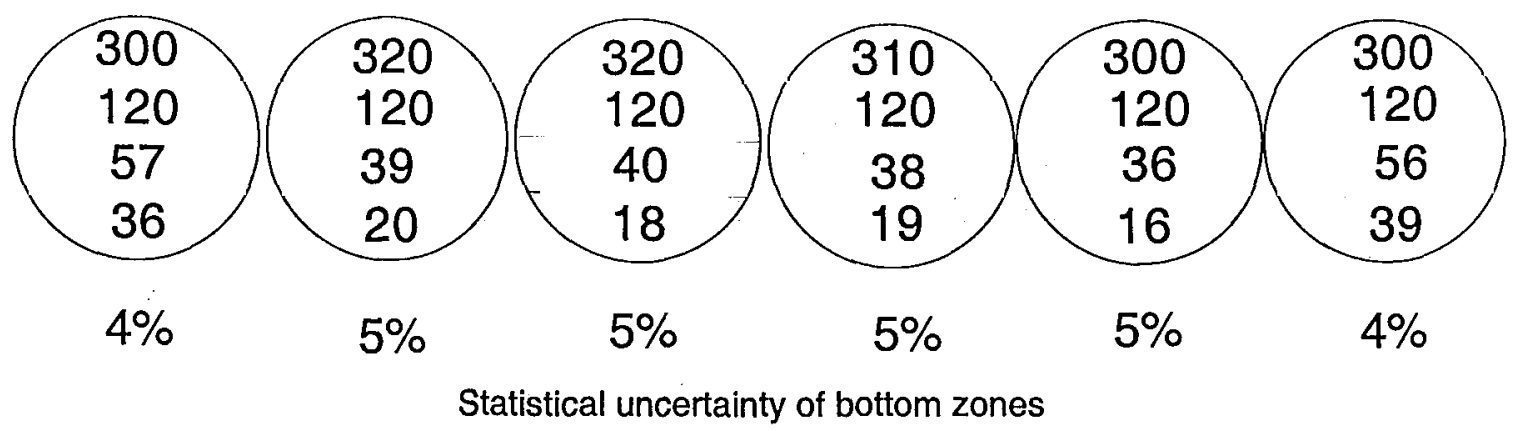

Fig. A58 
Radiation Dose in One-Ton Containers inside a Concrete Block Building at a $10 \mathrm{~m}$ Ground Range

(Megarad)

Yield: $10 \mathrm{kT}$

HOB: $10 \mathrm{~m}$

14 Mev neutrons

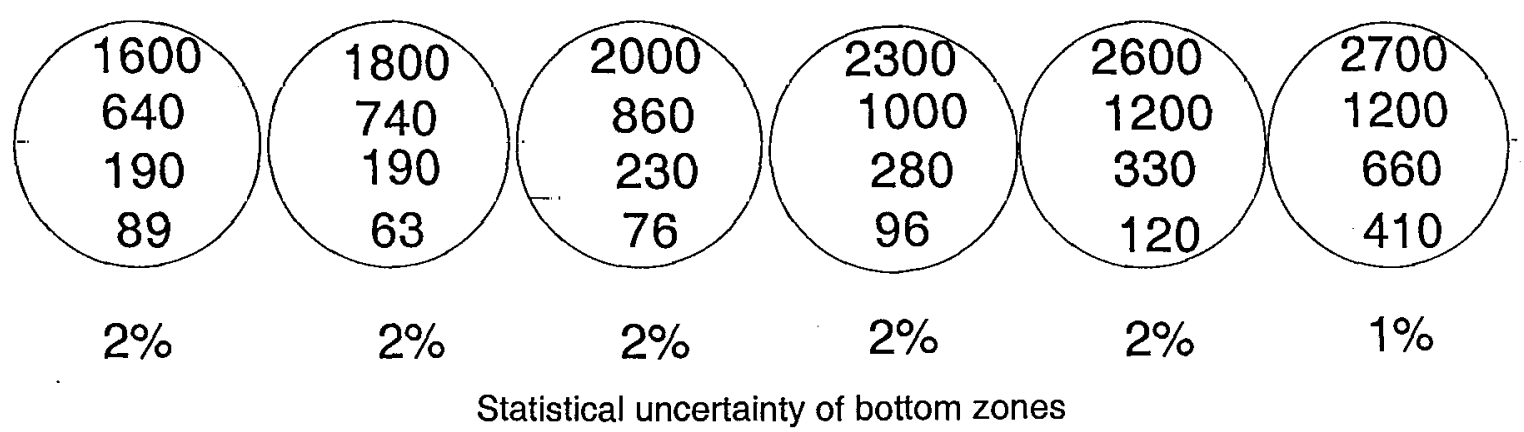

Fig. A59

Fission neutrons

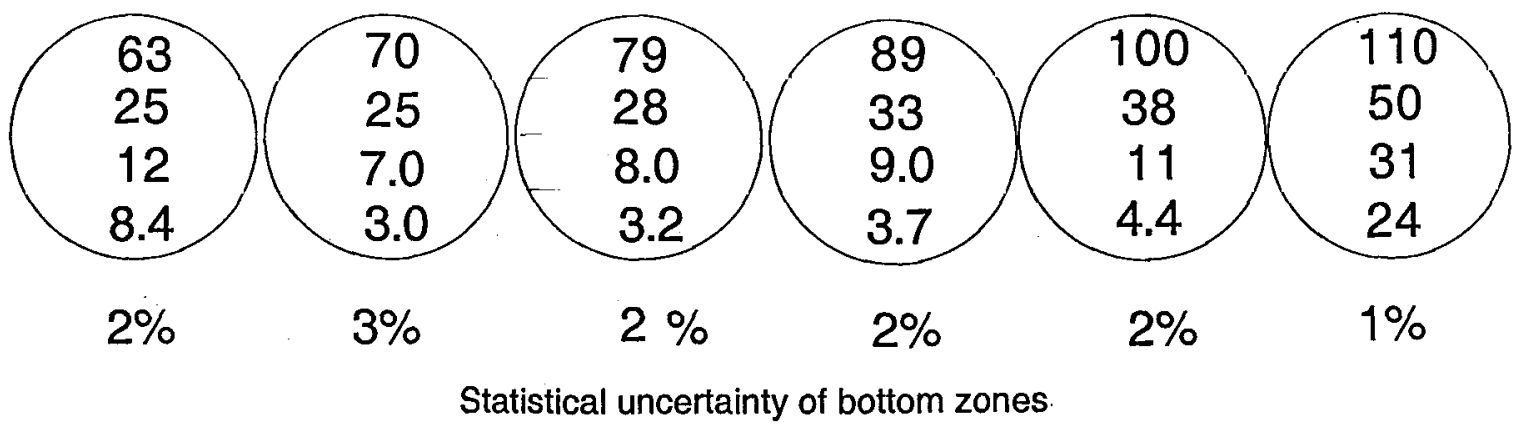

Fig. A60 
Radiation Dose in One-Ton Containers inside a Concrete Block Building at a $20 \mathrm{~m}$ Ground Range (Megarad)

Yield: $10 \mathrm{kT}$

HOB: $10 \mathrm{~m}$

$14 \mathrm{Mev}$ neutrons

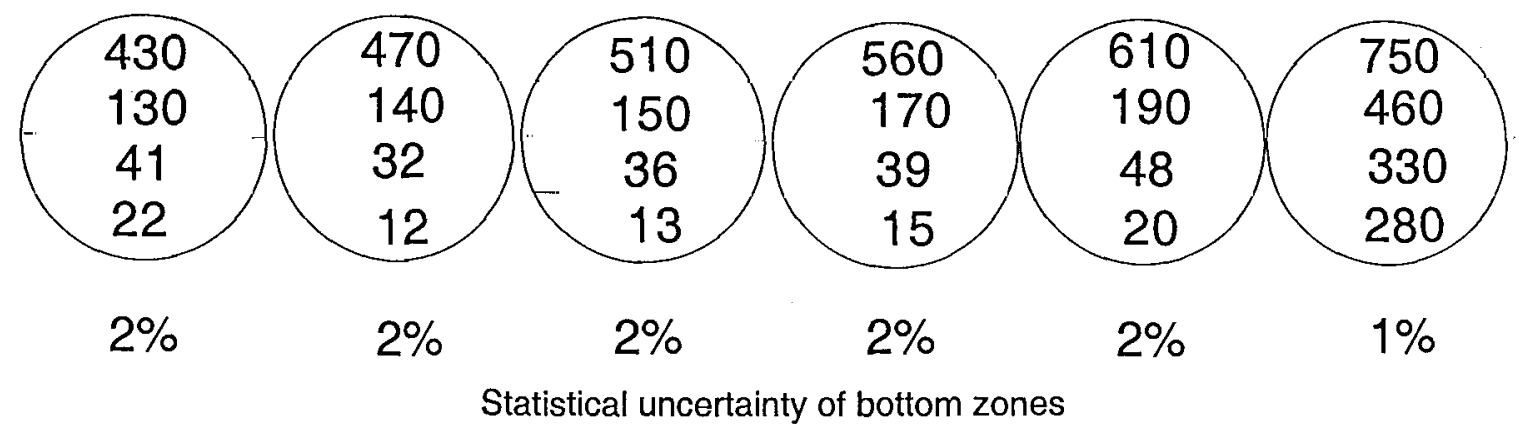

Fig. A61

Fission neutrons

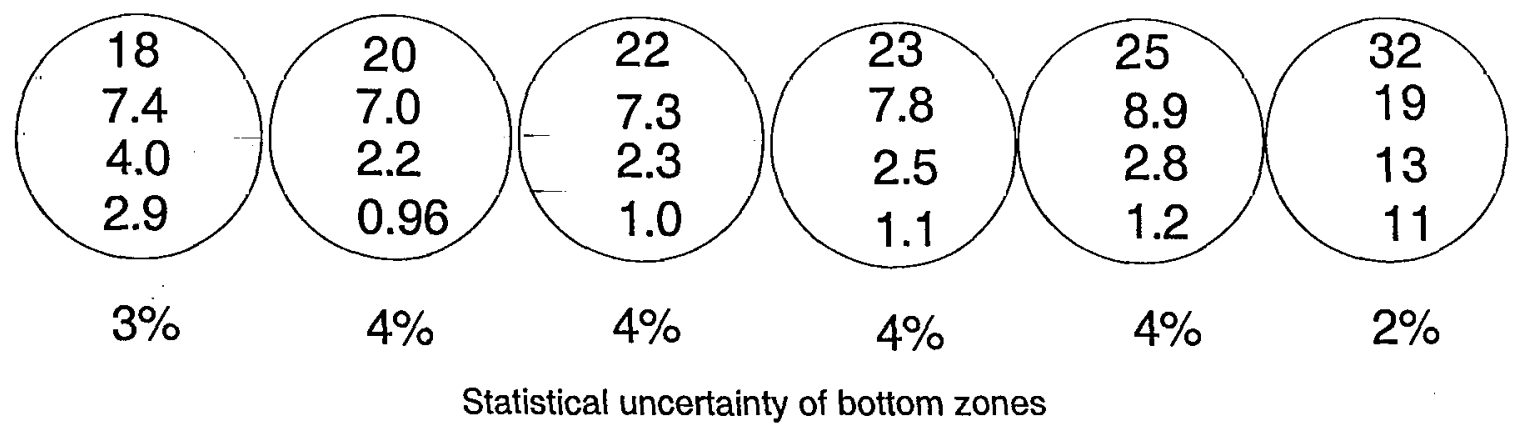

Fig. A62 
Radiation Dose in One-Ton Containers inside a Concrete Block Building at a $40 \mathrm{~m}$ Ground Range (Megarad)

Yield: $10 \mathrm{kT}$ HOB: $10 \mathrm{~m}$

14 Mev neutrons

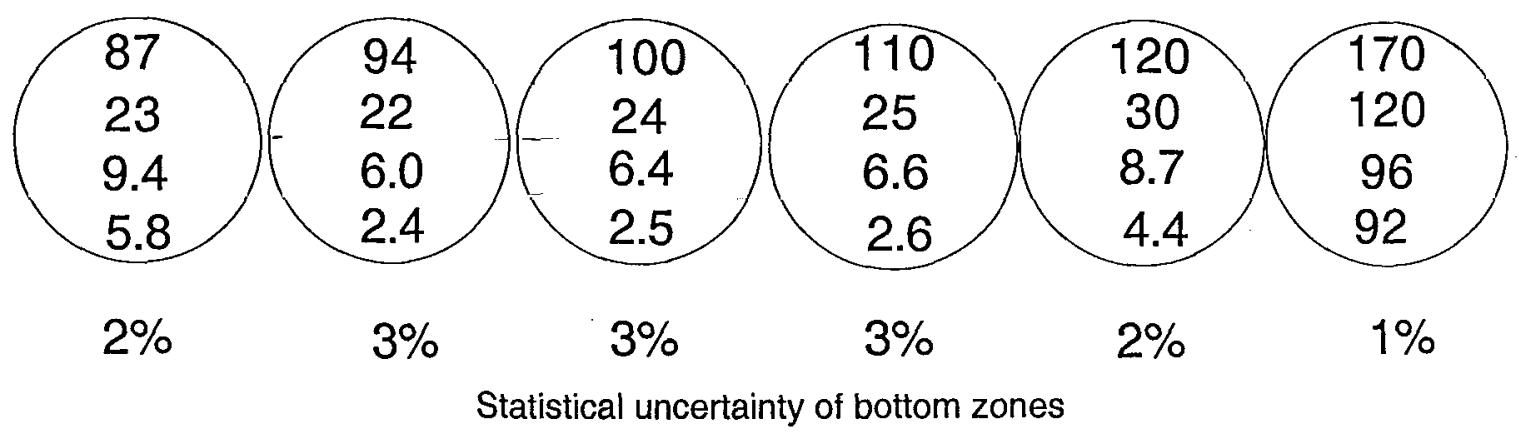

Fig. A63

Fission neutrons

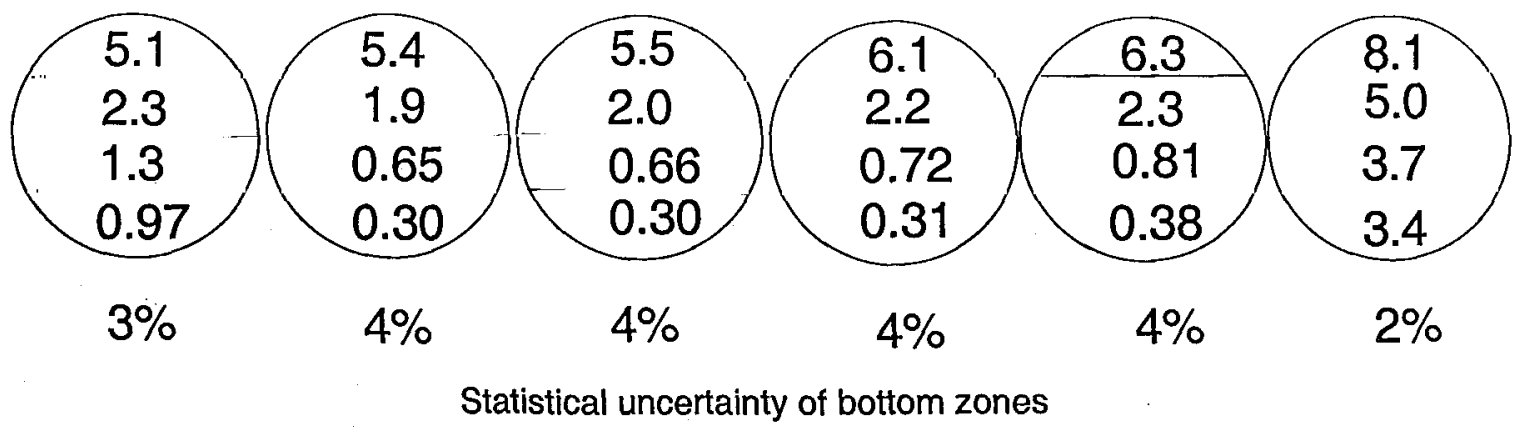

Fig. A64 
Radiation Dose in One-Ton Containers inside a Concrete Block Building at a $80 \mathrm{~m}$ Ground Range

(Megarad)

Yield: $10 \mathrm{kT}$

HOB: $10 \mathrm{~m}$

$14 \mathrm{Mev}$ neutrons

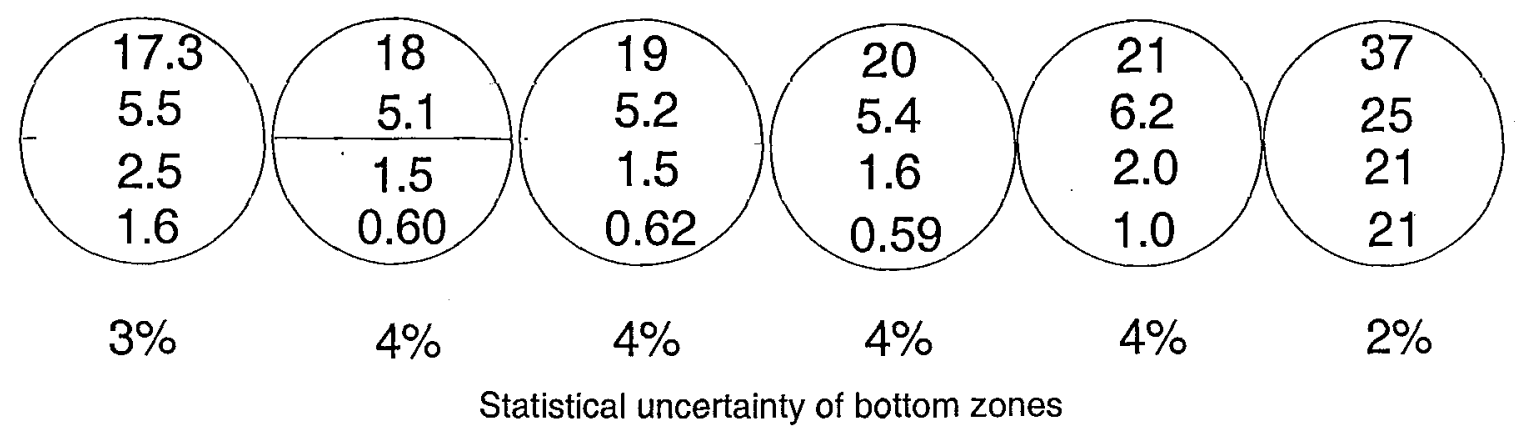

Fig. A65

Fission neutrons

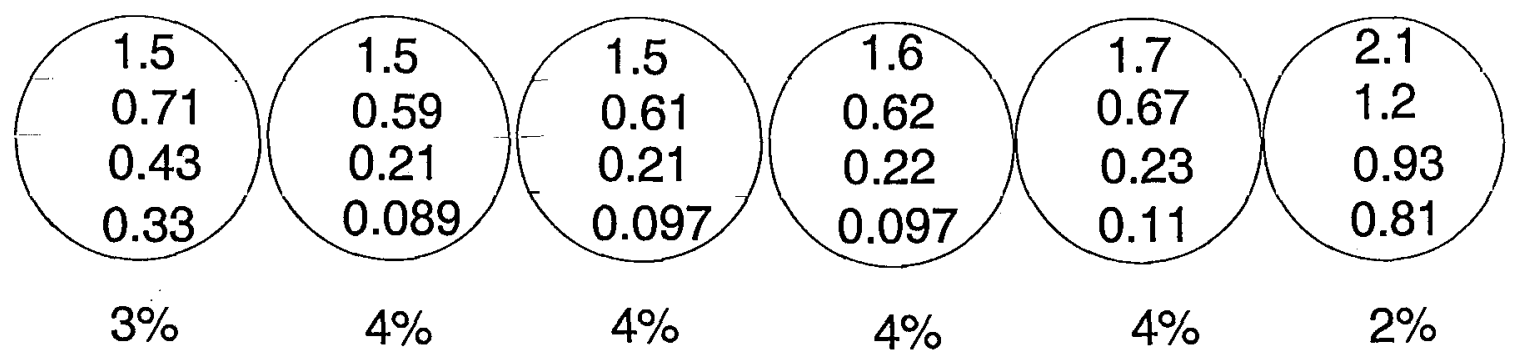

Statistical uncertainty of bottom zones

Fig. A66 
Radiation Dose in One-Ton Containers on the Ground in Open Air underneath the Burst Point

(Megarad)

Yield: $10 \mathrm{kT}$

HOB: $10 m$

14 Mev neutrons

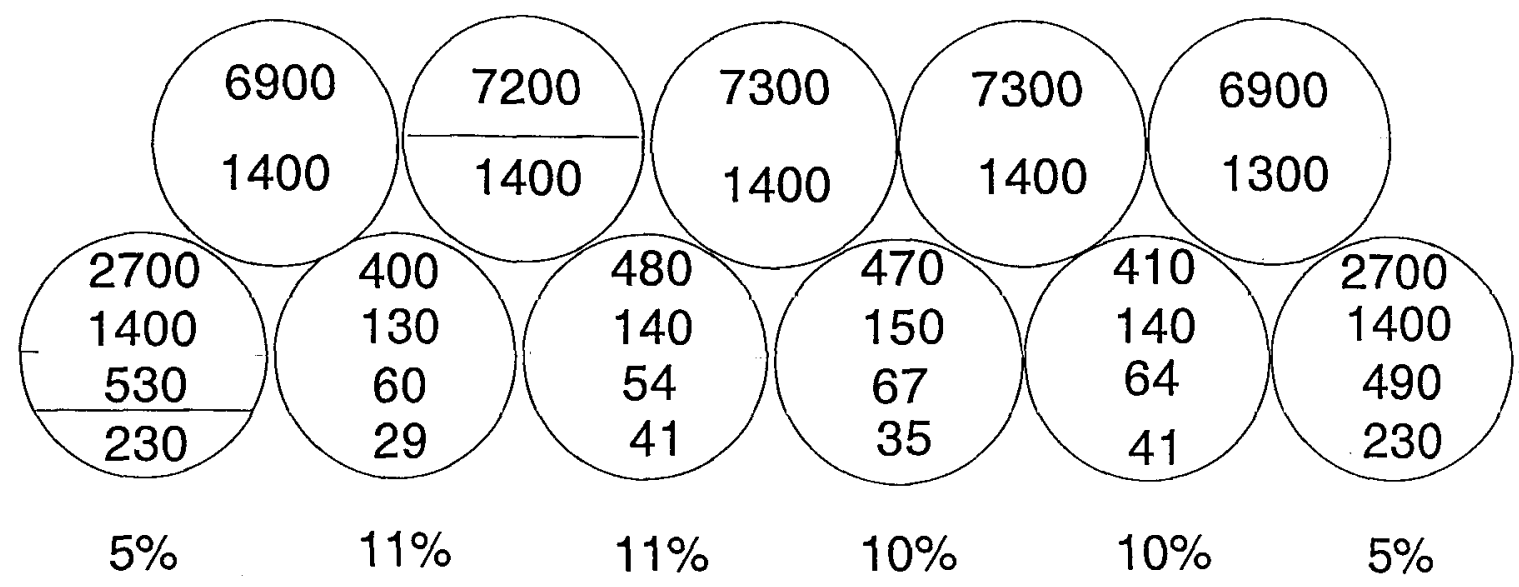

Statistical uncertainty of bottom zones

Fig. A67

Fission neutrons

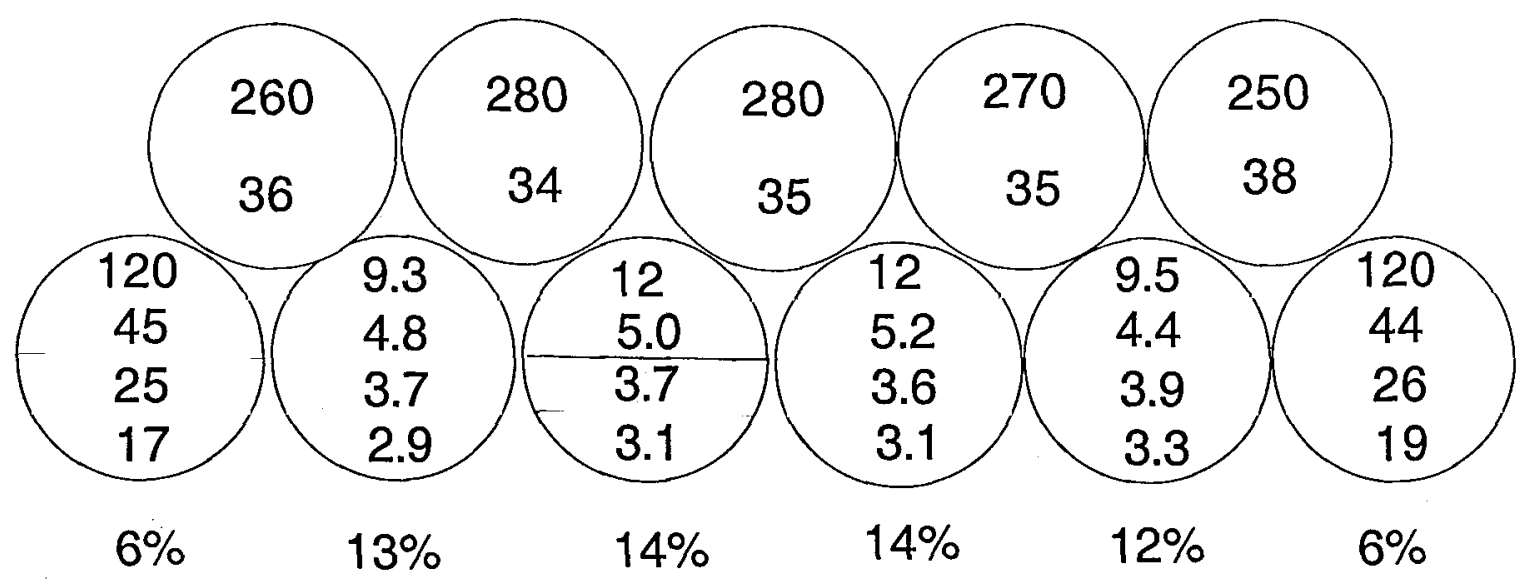

Statistical uncertainty of bottom zones

Fig. A68 
Radiation Dose in One-Ton Containers on the Ground in Open Air at a $10 \mathrm{~m}$ Ground Range

(Megarad)

Yield: $10 \mathrm{kT}$

HOB: $10 \mathrm{~m}$

$14 \mathrm{Mev}$ neutrons

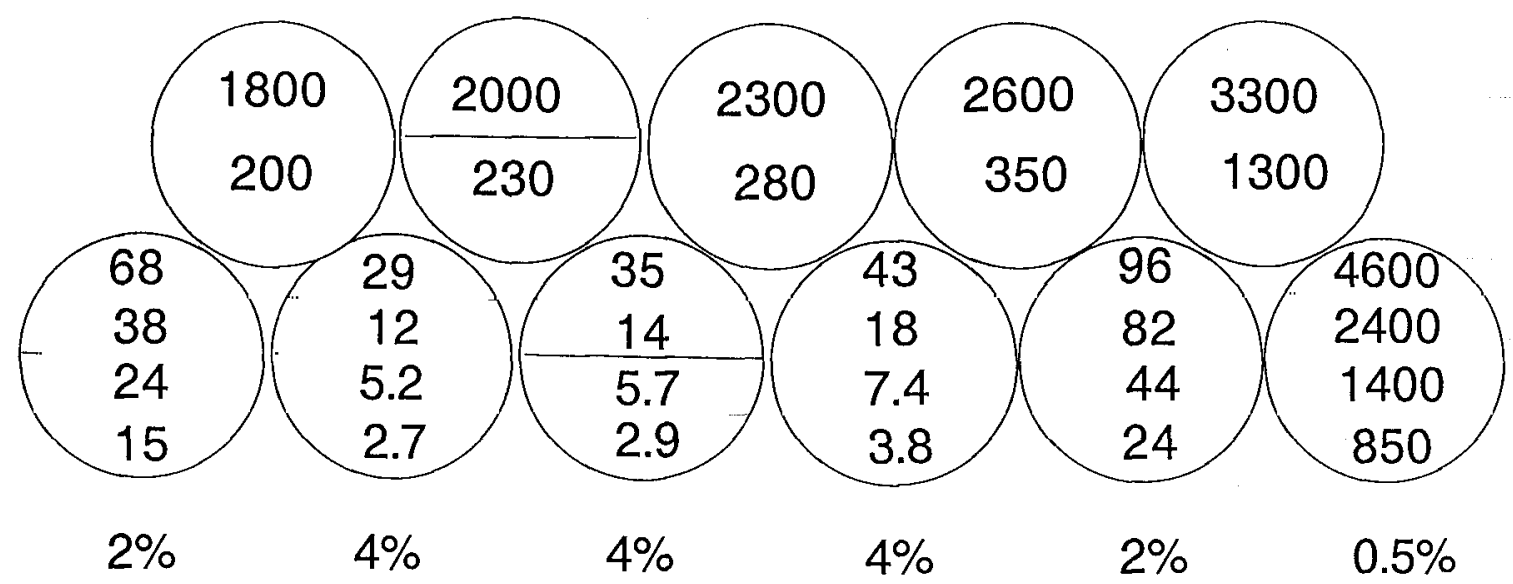

Statistical uncertainty of bottom zones

Fig. A69

Fission neutrons

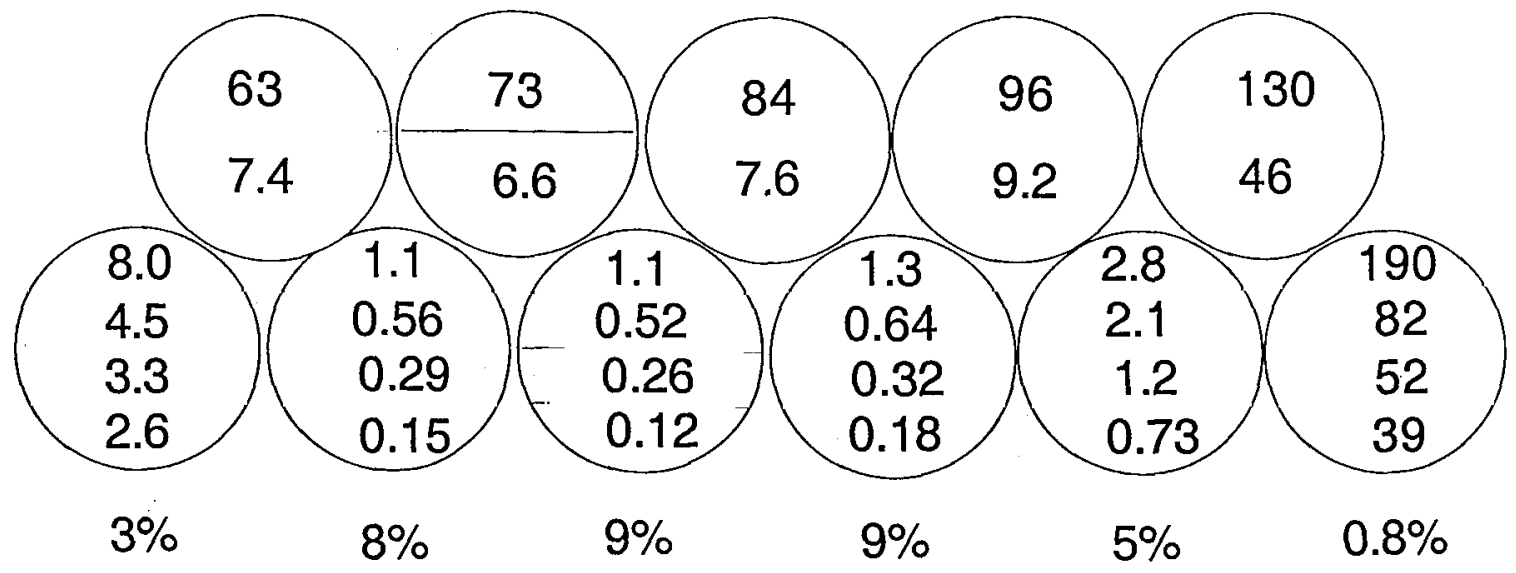

Statistical uncertainty of bottom zones

Fig. A70 
Radiation Dose in One-Ton Containers on the Ground in Open Air at a $20 \mathrm{~m}$ Ground Range

(Megarad)

Yield: $10 \mathrm{kT}$

HOB: $10 \mathrm{~m}$

14 Mev neutrons

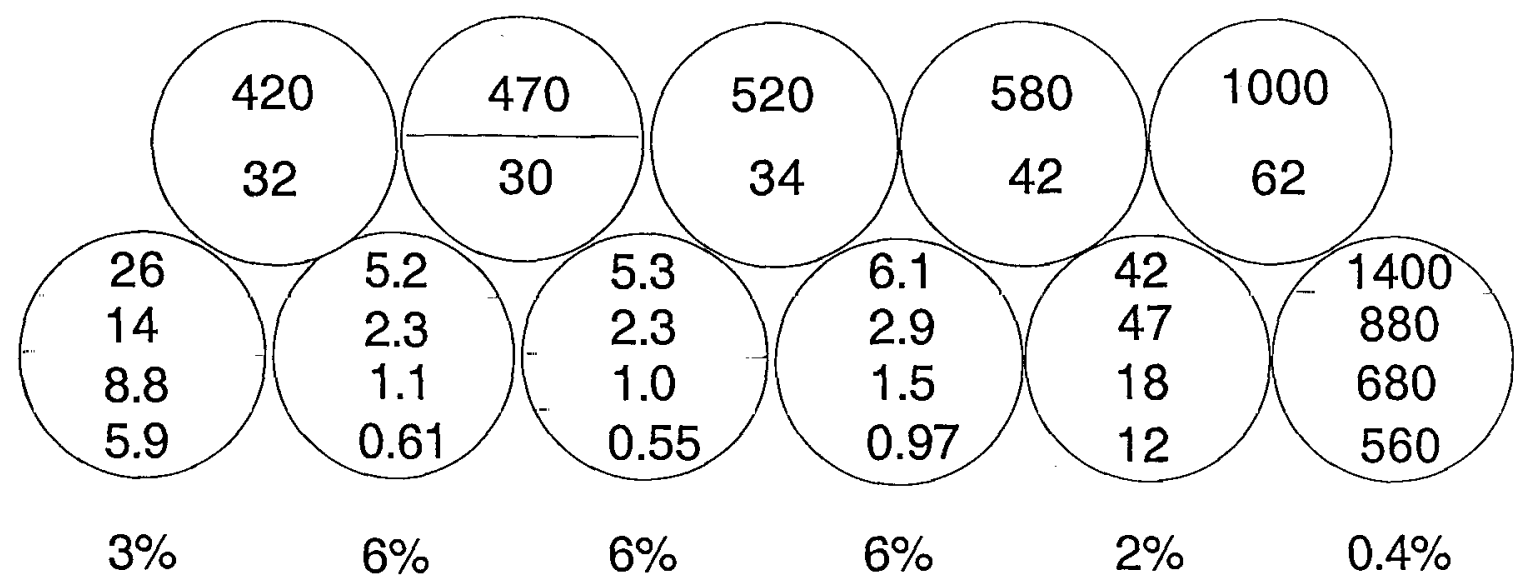

Statistical uncertainty of bottom zones

Fig. A71

Fission neutrons

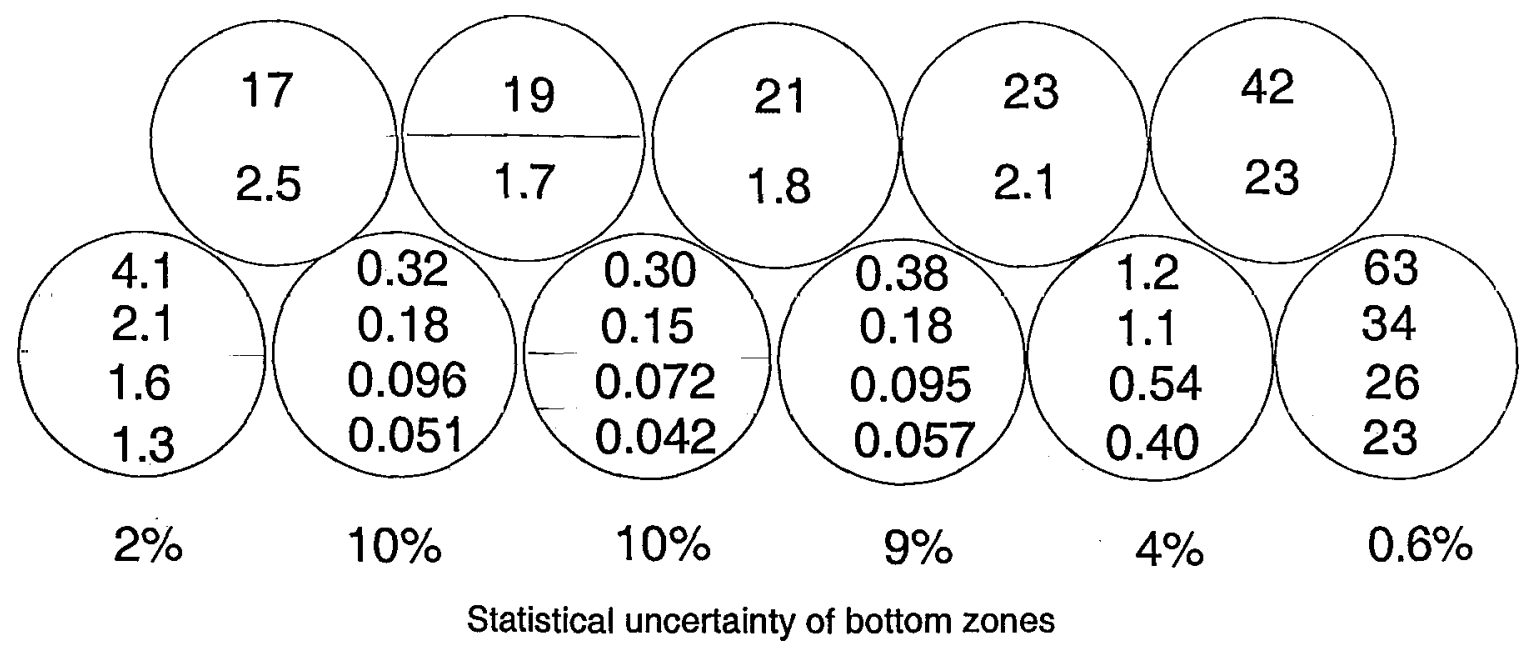

Fig. A72 
Radiation Dose in One-Ton Containers on the Ground in Open Air at a $40 \mathrm{~m}$ Ground Range

(Megarad)

Yield: $10 \mathrm{kT}$

HOB: $10 \mathrm{~m}$

$14 \mathrm{Mev}$ neutrons

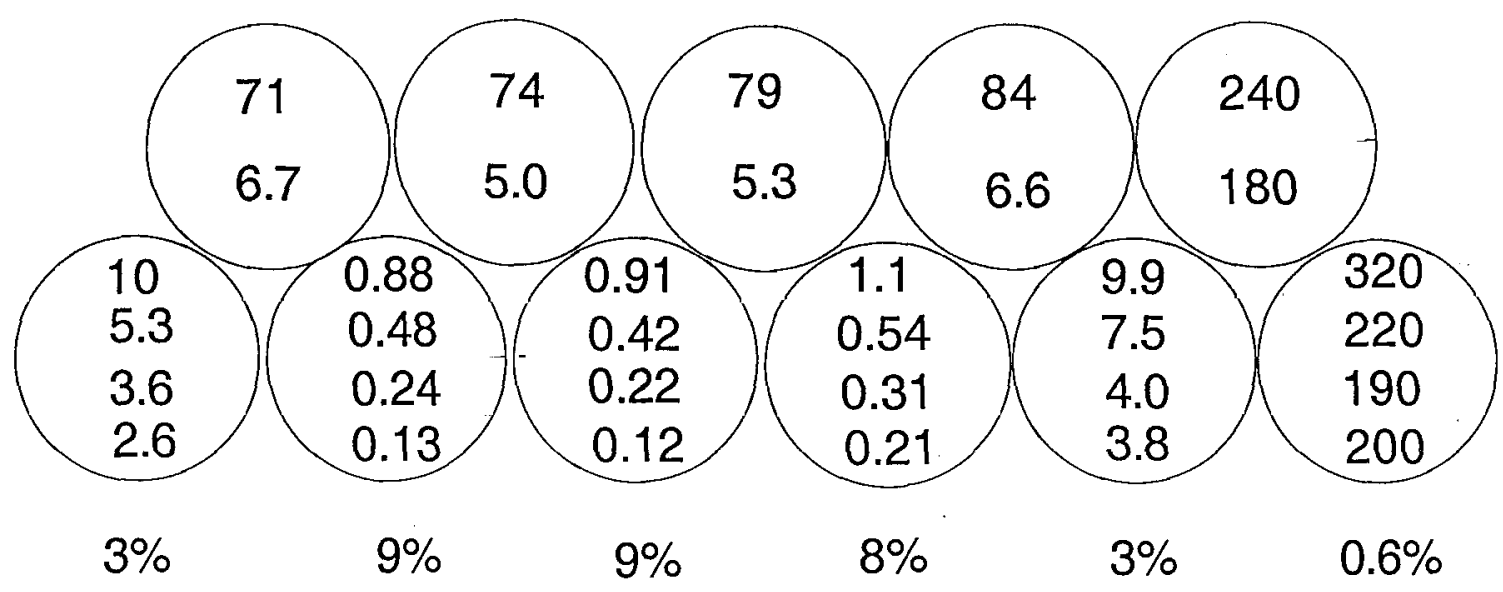

Statistical uncertainty of bottom zones

Fig. A73

Fission neutrons

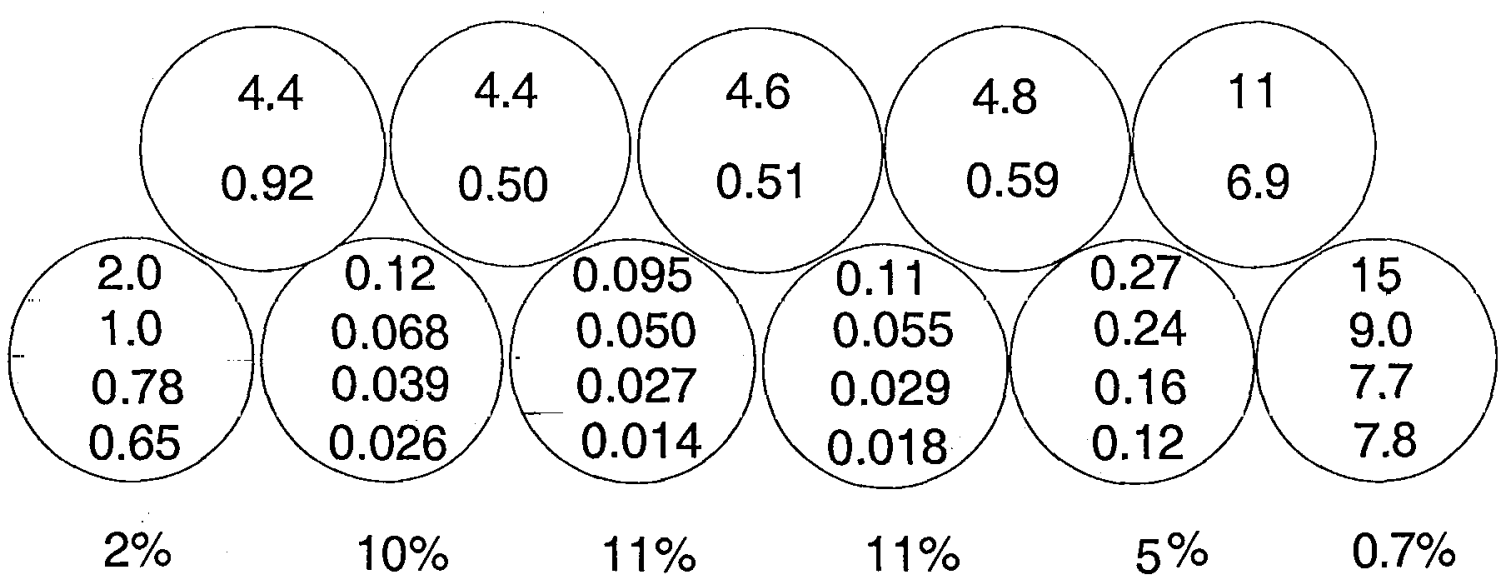

Statistical uncertainty of bottom zones

Fig. A74 
Radiation Dose in One-Ton Containers on the Ground in Open Air at a $80 \mathrm{~m}$ Ground Range

(Megarad)

Yield: $10 \mathrm{kT}$

HOB: $10 \mathrm{~m}$

14 Mev neutrons

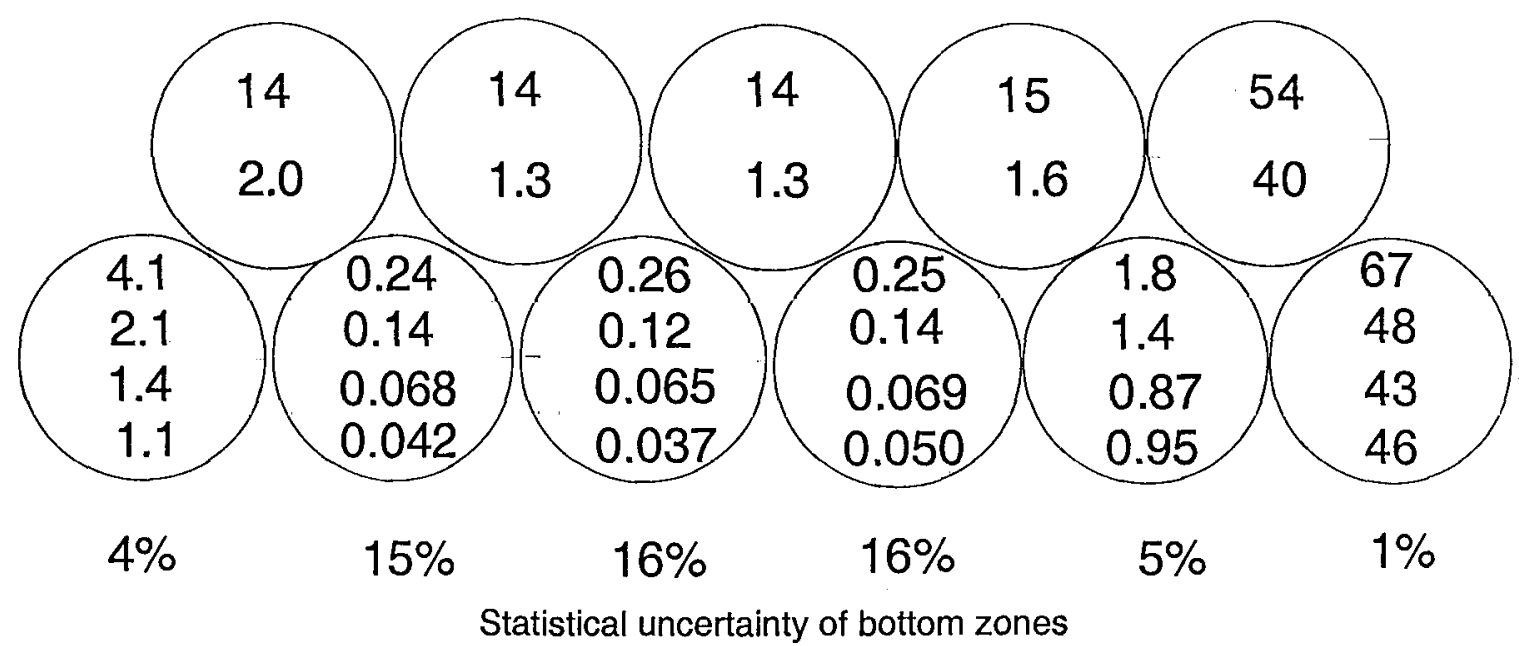

Fig. A75

Fission neutrons

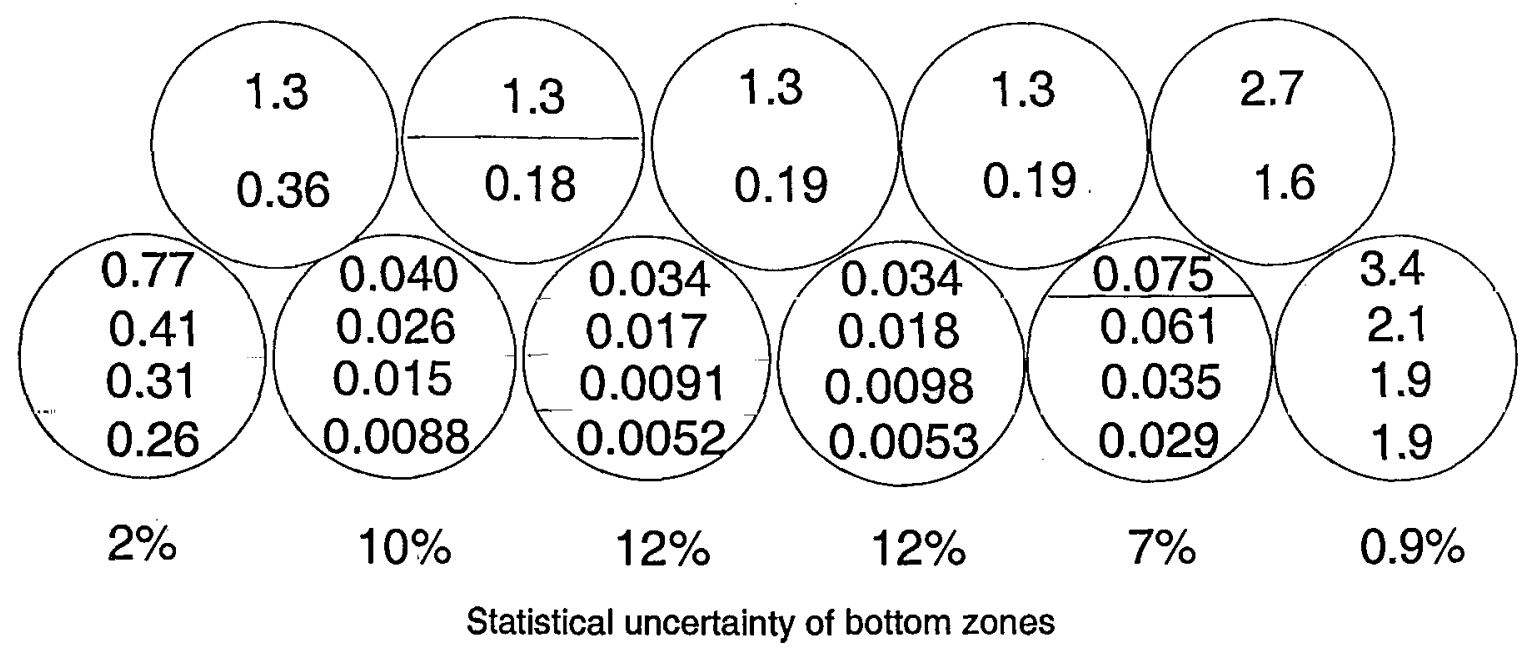

Fig. A76 
Radiation Dose in One-Ton Containers inside a Concrete Block Building underneath the Burst Point (Megarad)

Yield: $10 \mathrm{kT}$

HOB: $10 \mathrm{~m}$

14 Mev neutrons

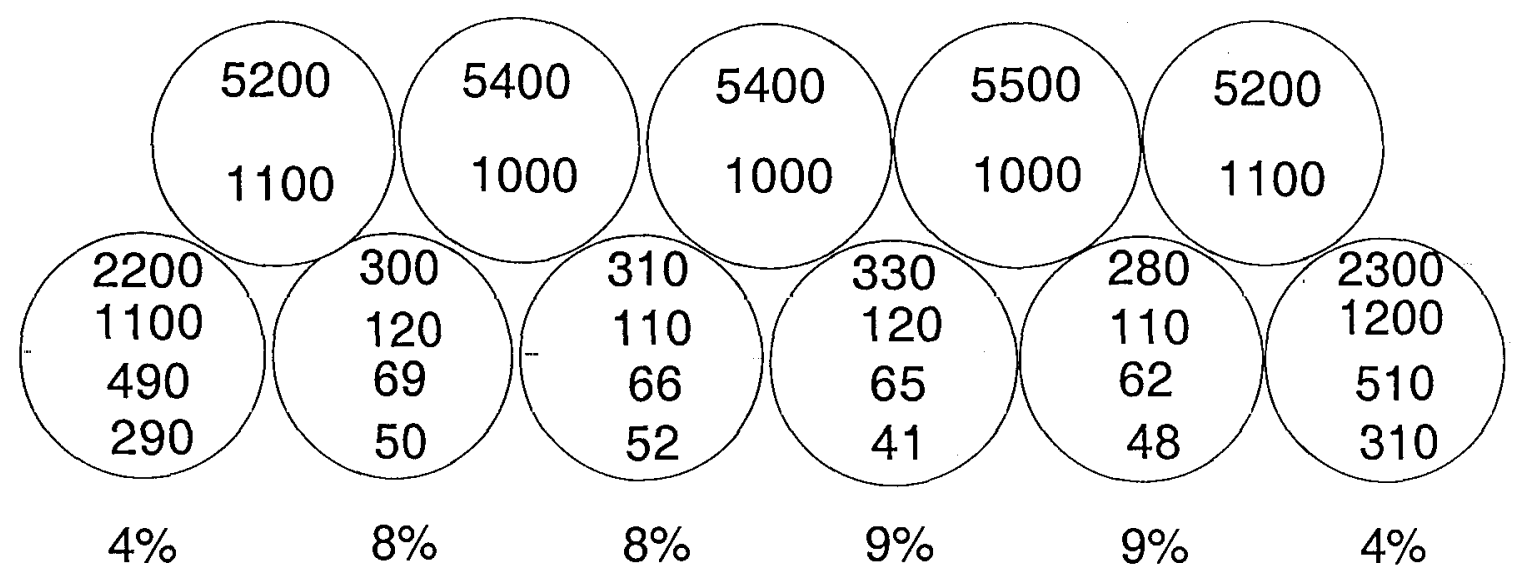

Statistical uncertainty of bottom zones

Fig. A77

Fission neutrons

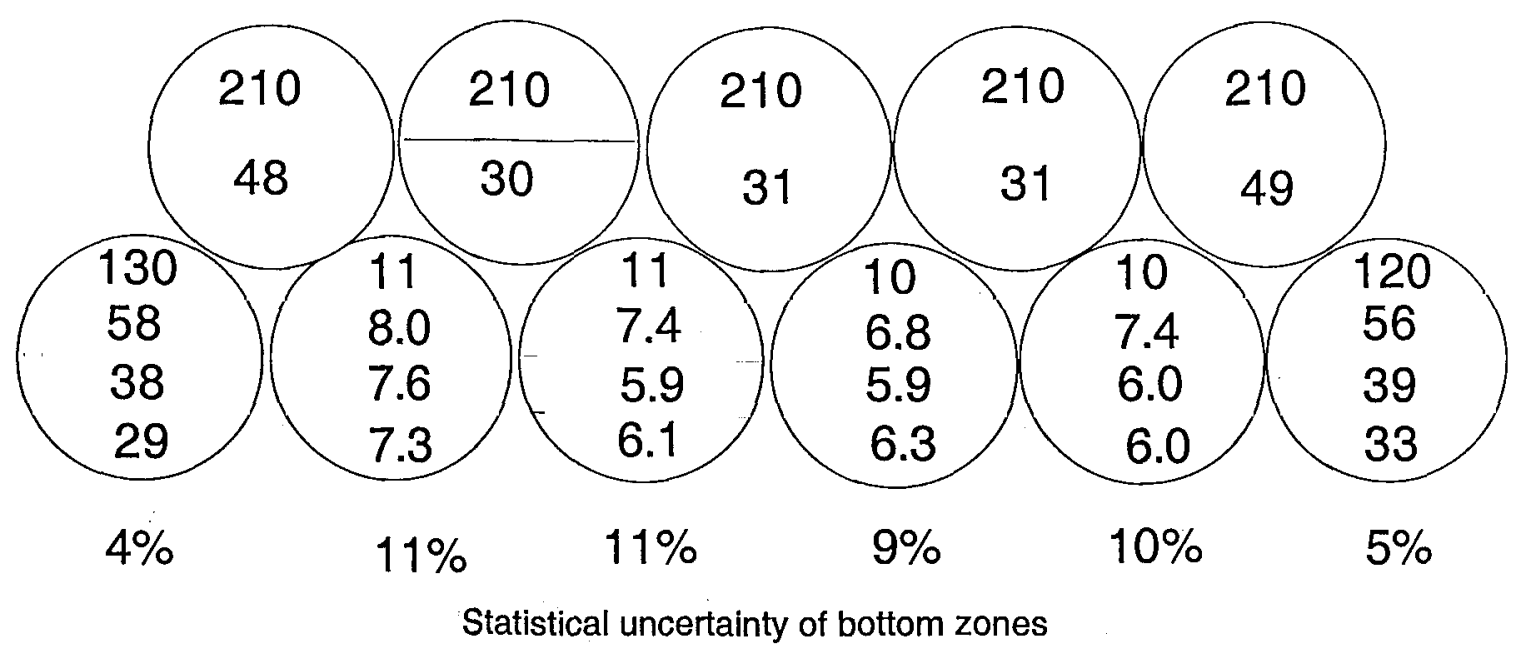

Fig. A78 


\section{Radiation Dose in One-Ton Containers inside a Concrete Block Building at $10 \mathrm{~m}$ Ground Range (Megarad)}

Yield: $10 \mathrm{kT}$

HOB: $10 m$

14 Mev neutrons

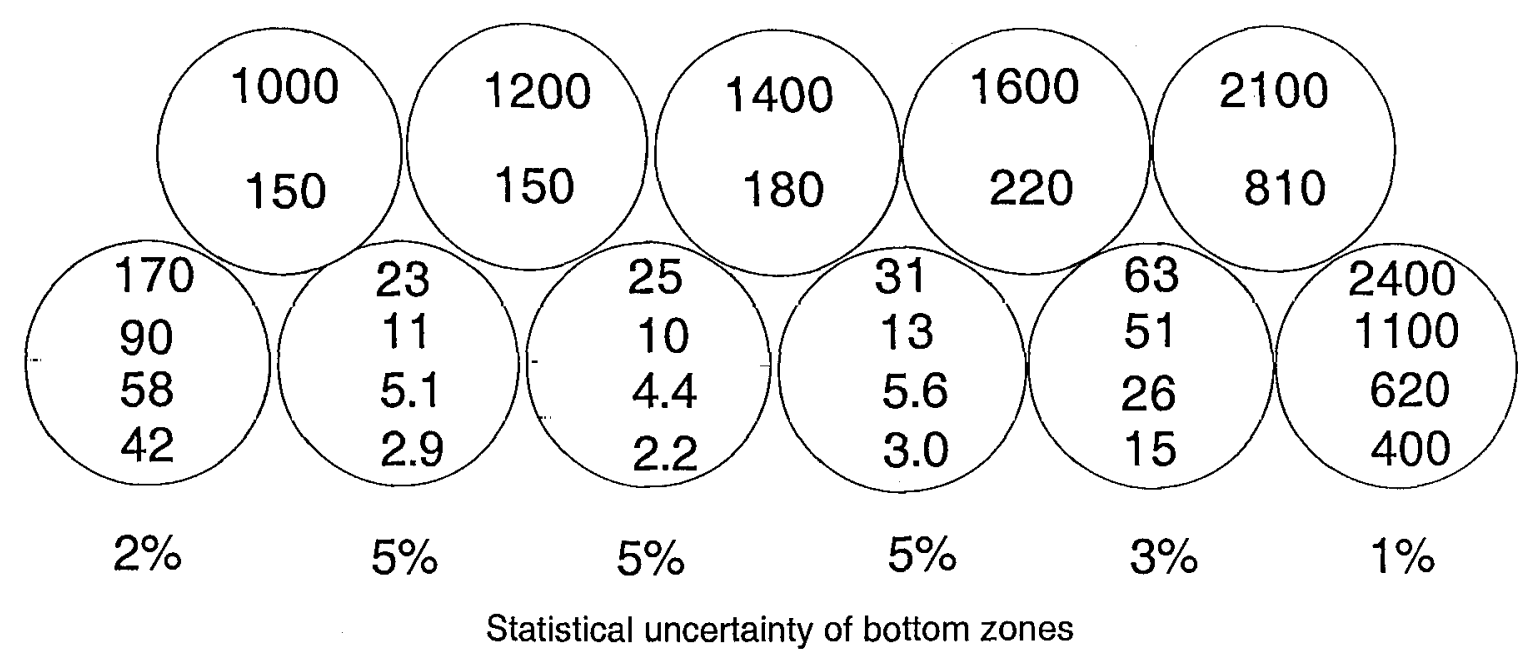

Fig. A79

Fission neutrons

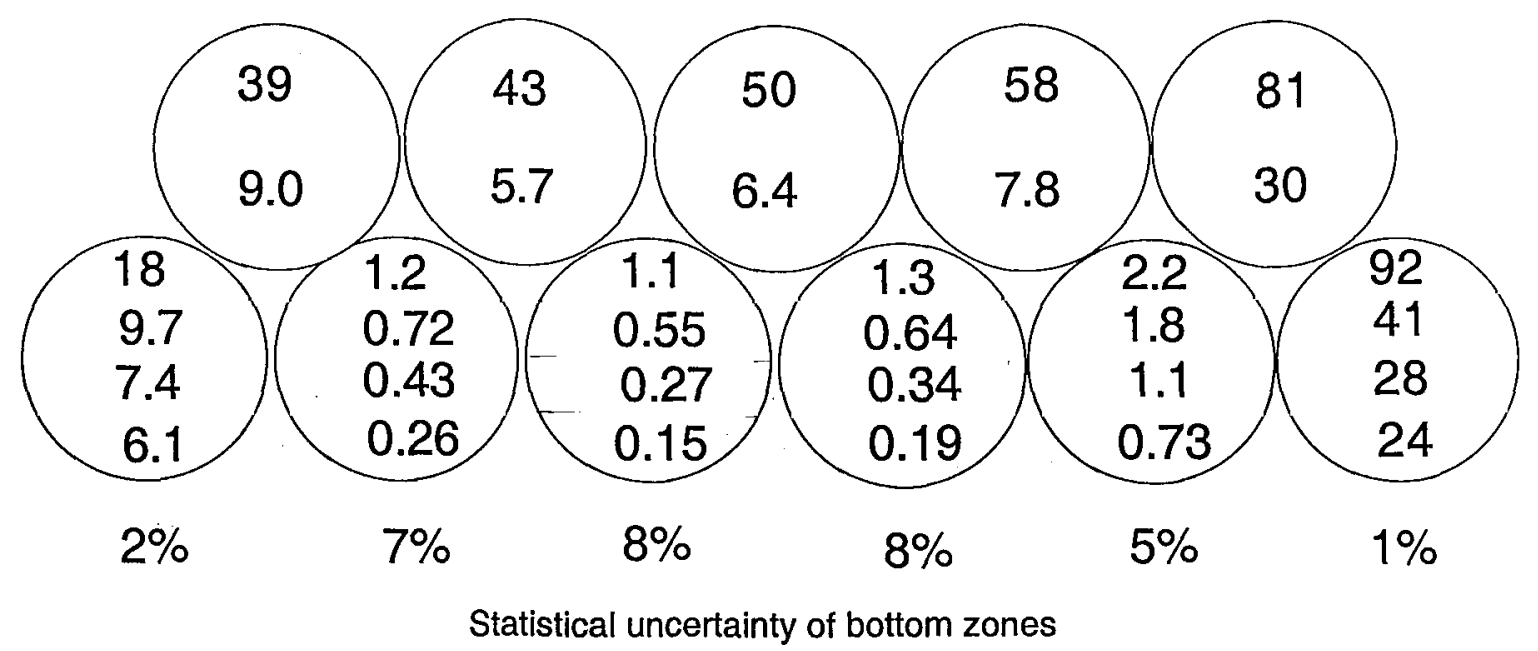

Fig. A80 
Radiation Dose in One-Ton Containers inside a Concrete Block Building at $20 \mathrm{~m}$ Ground Range

(Megarad)

.Yield: $10 \mathrm{kT}$

HOB: $10 m$

14 Mev neutrons

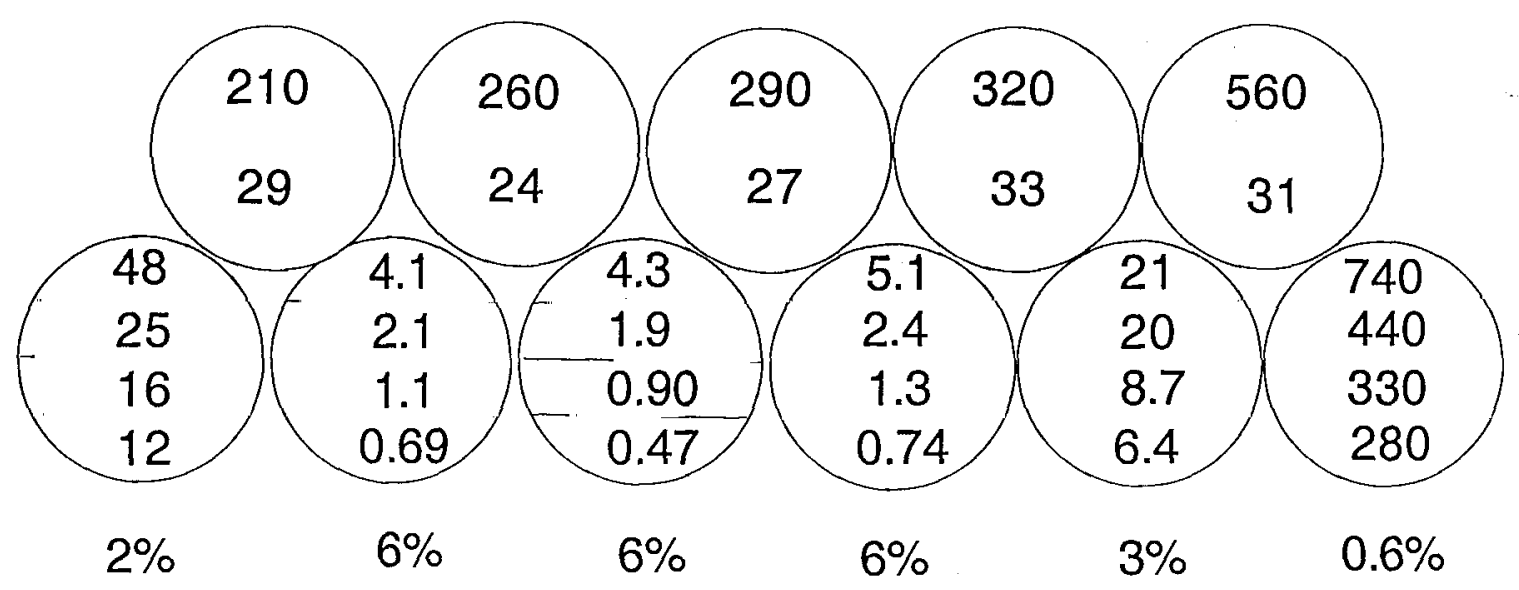

Statistical uncertainty of bottom zones

Fig. A81

Fission neutrons

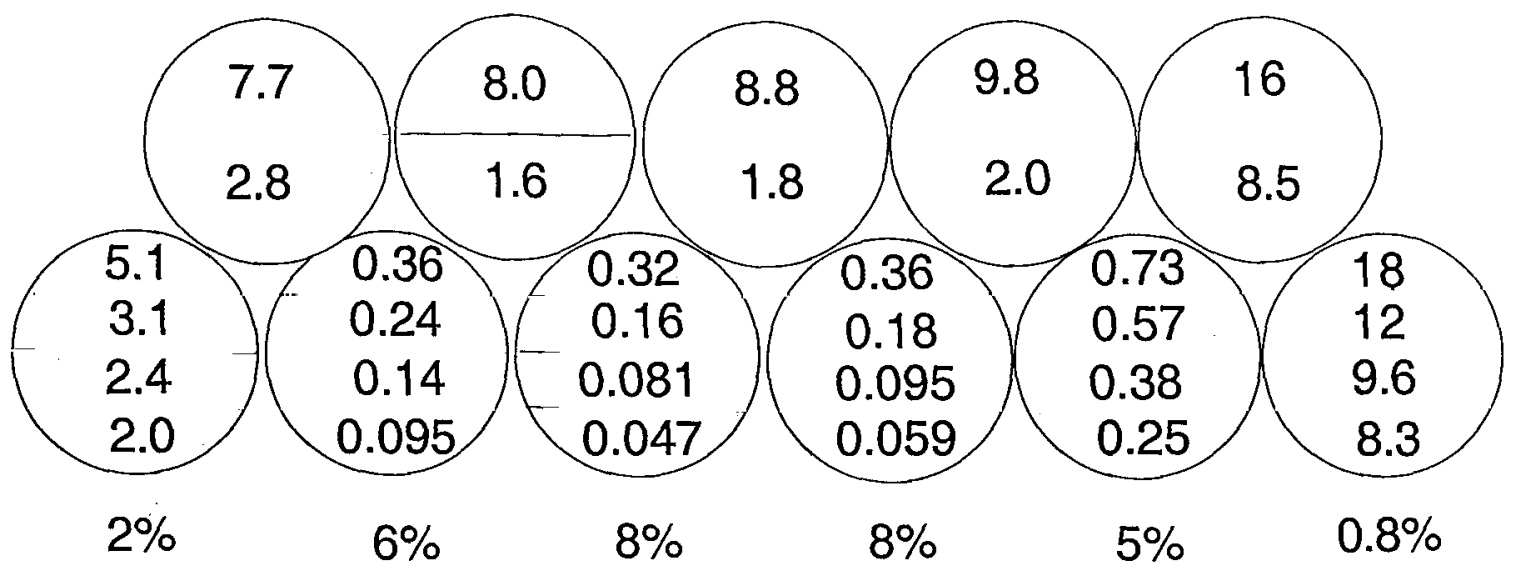

Statistical uncertainty of bottom zones

Fig. A82 
Radiation Dose in One-Ton Containers inside a Concrete Block Building at $40 \mathrm{~m}$ Ground Range

(Megarad)

Yield: $10 \mathrm{kT}$

HOB: $10 \mathrm{~m}$

14 Mev neutrons

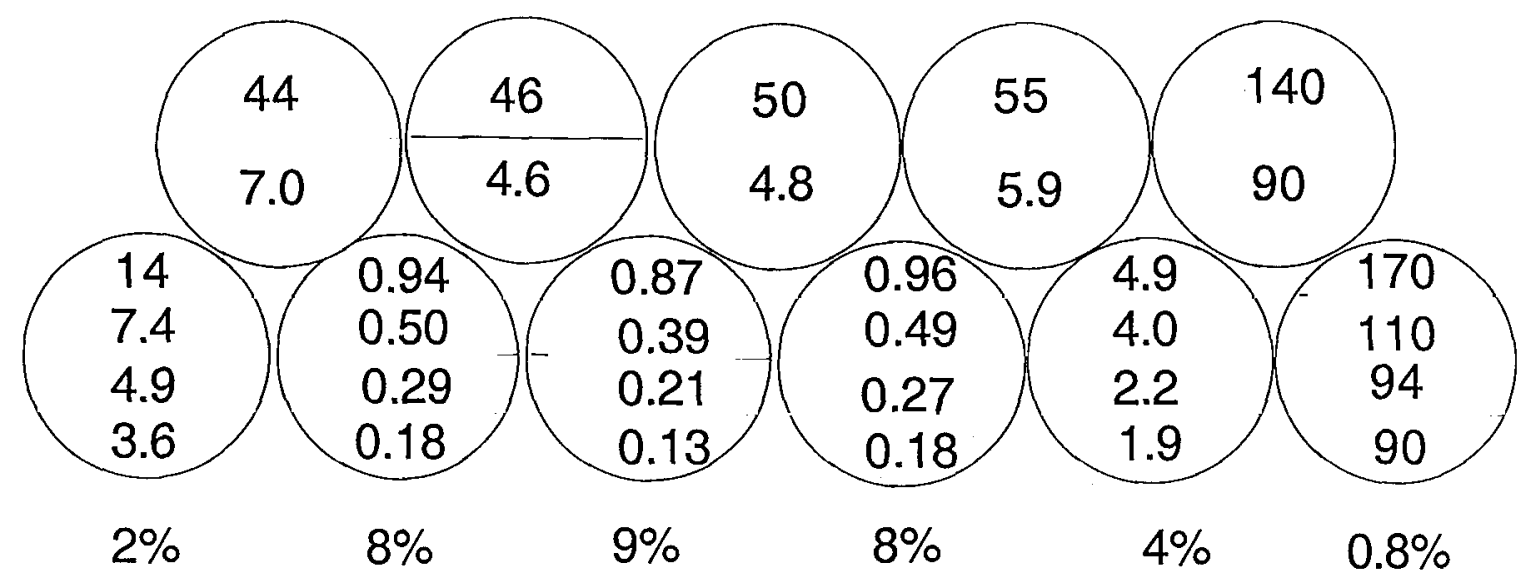

Statistical uncertainty of bottom zones

Fig. A83

Fission neutrons

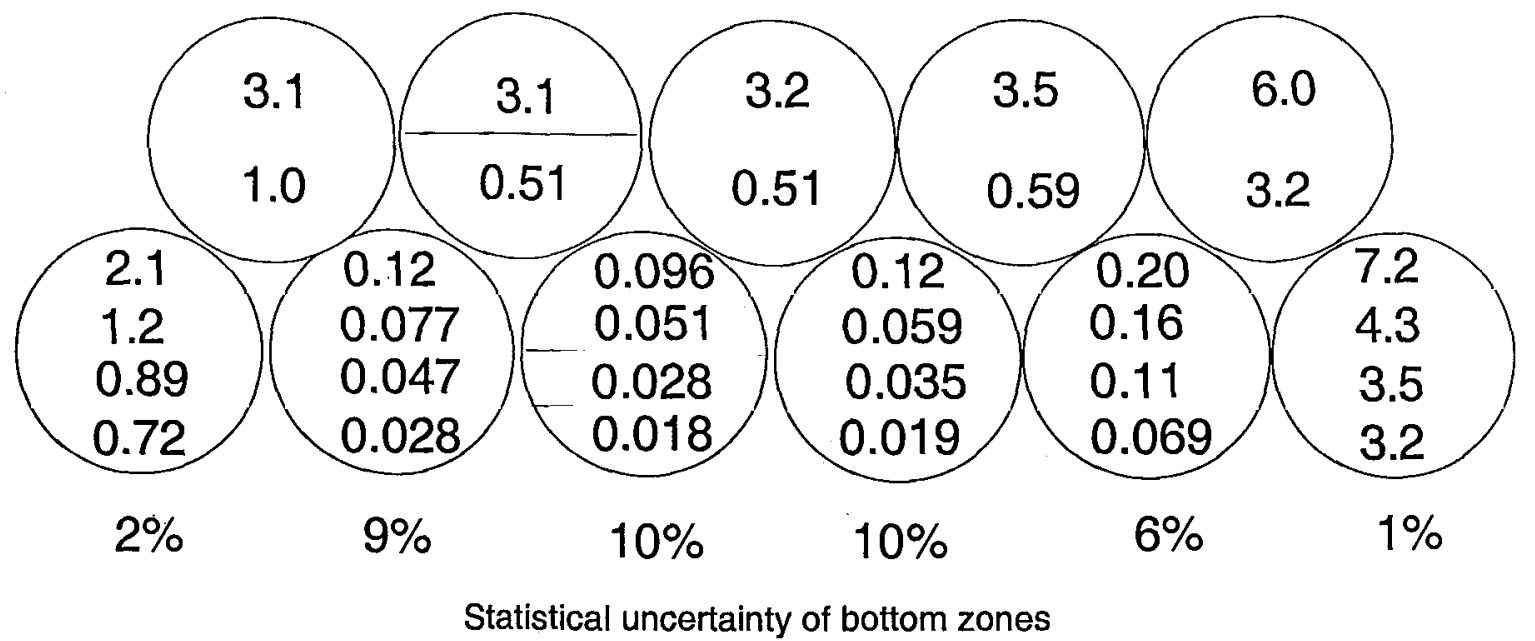

Fig. A84 


\section{Radiation Dose in One-Ton Containers inside a Concrete Block Building at $80 \mathrm{~m}$ Ground Range (Megarad)}

Yield: $10 \mathrm{kT}$

HOB: $10 m$

14 Mev neutrons

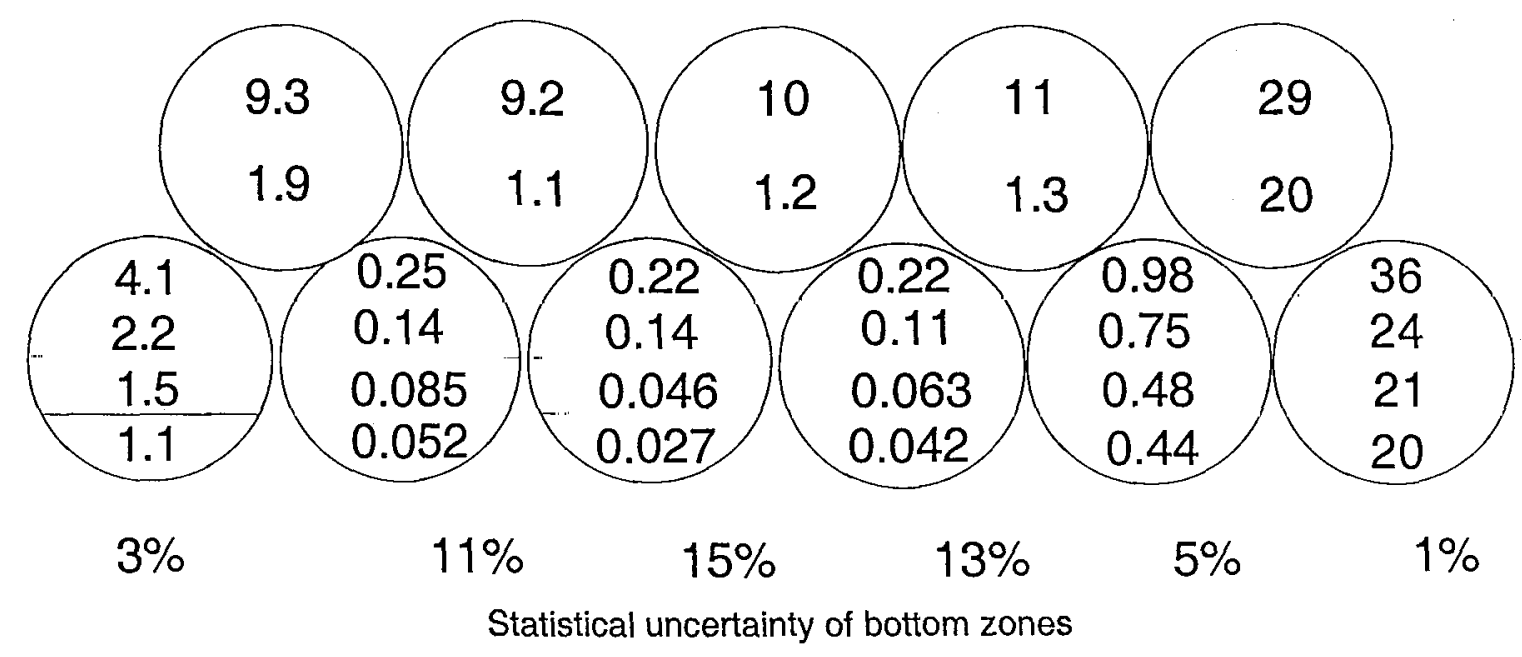

Fig. A85

Fission neutrons

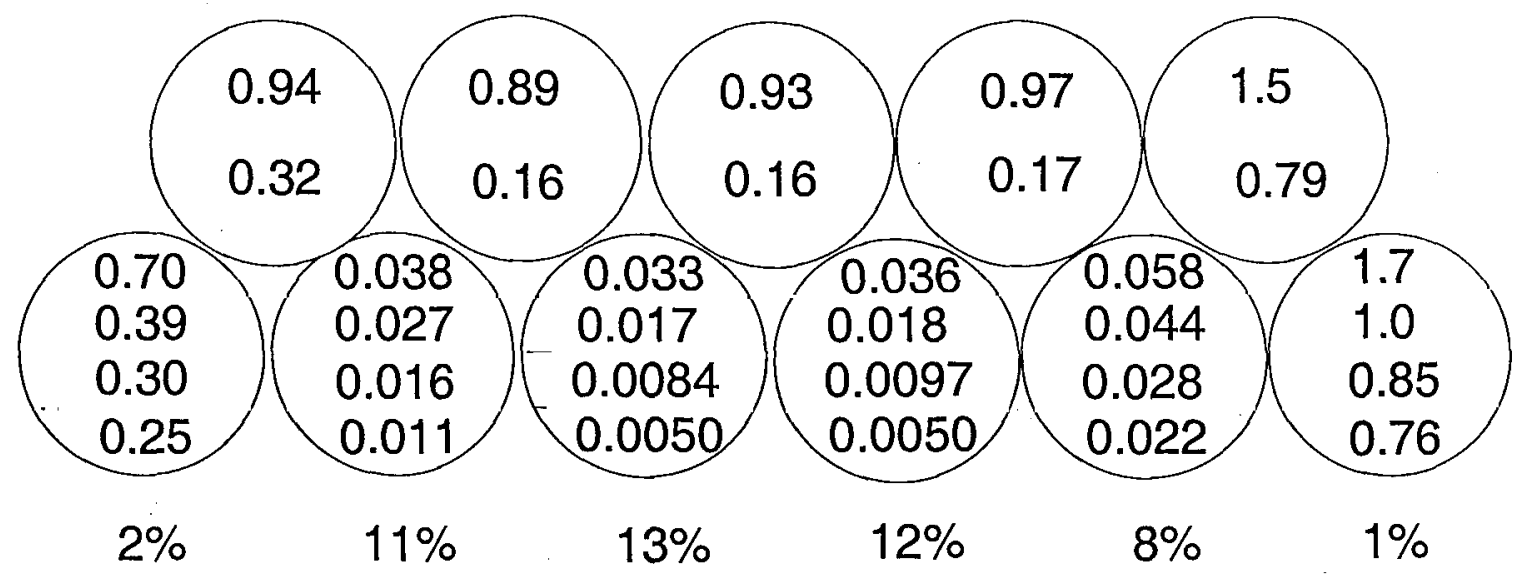

Statistical uncertainty of bottom zones

Fig. A86 
Radiation Dose in 200-liter Drums inside a Metal Roof Building with $R=10$ meters (Megarad)

Yield: 10kT HOB: $10 \mathrm{~m}$

\section{Mev neutrons}

In drums

Next to

drums

Under

burst

point

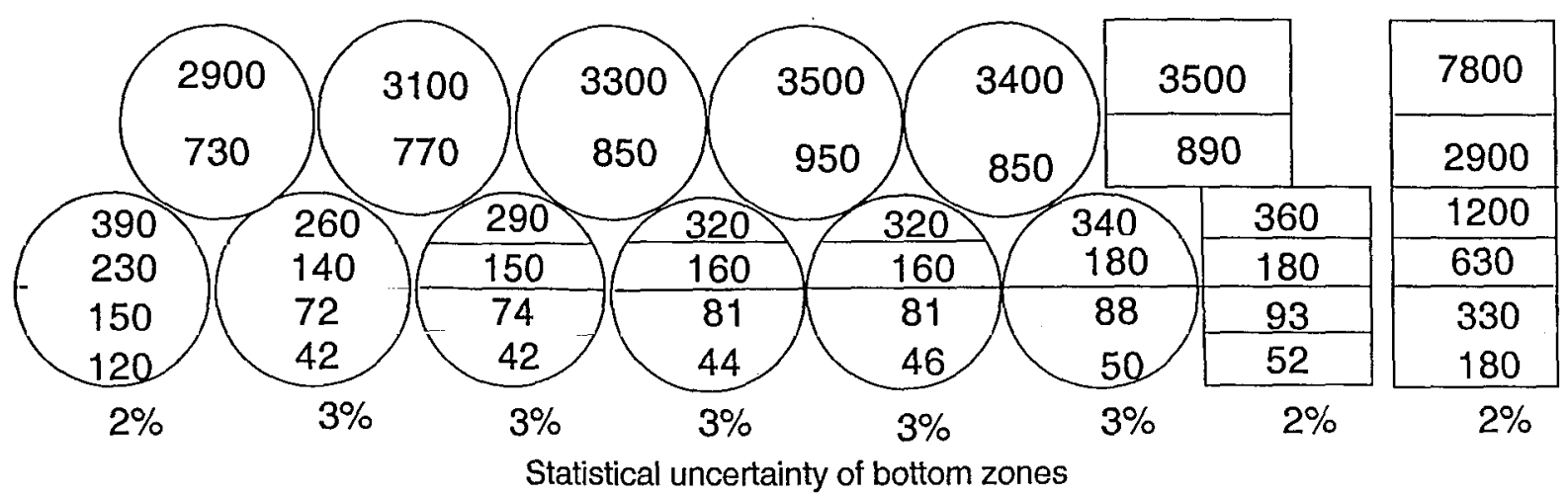

Fig. A87

Fission neutrons

In drums

Next to

drums

Under

burst

point
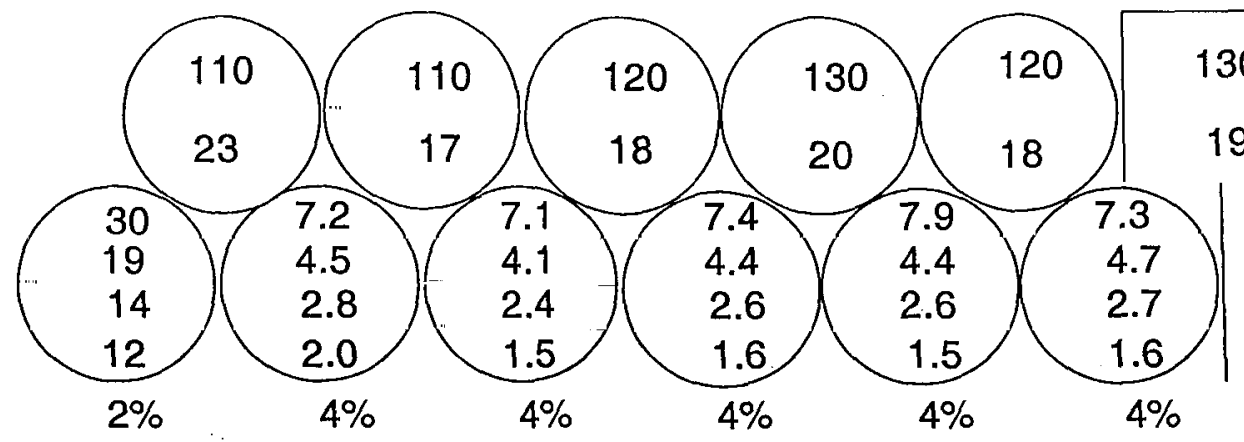

30
19

8.5

4.8

2.9

1.8

$3 \%$

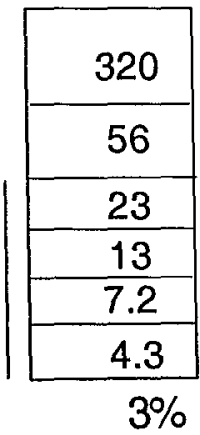

Statistical uncertainty of bottom zones

Fig. A88 


\section{Radiation Dose in 200-liter Drums inside a Metal Roof Building with $\mathrm{R}=20$ meter (Megarad)}

Yield: 10kT HOB: $10 \mathrm{~m}$

\section{$14 \mathrm{Mev}$ neutrons}

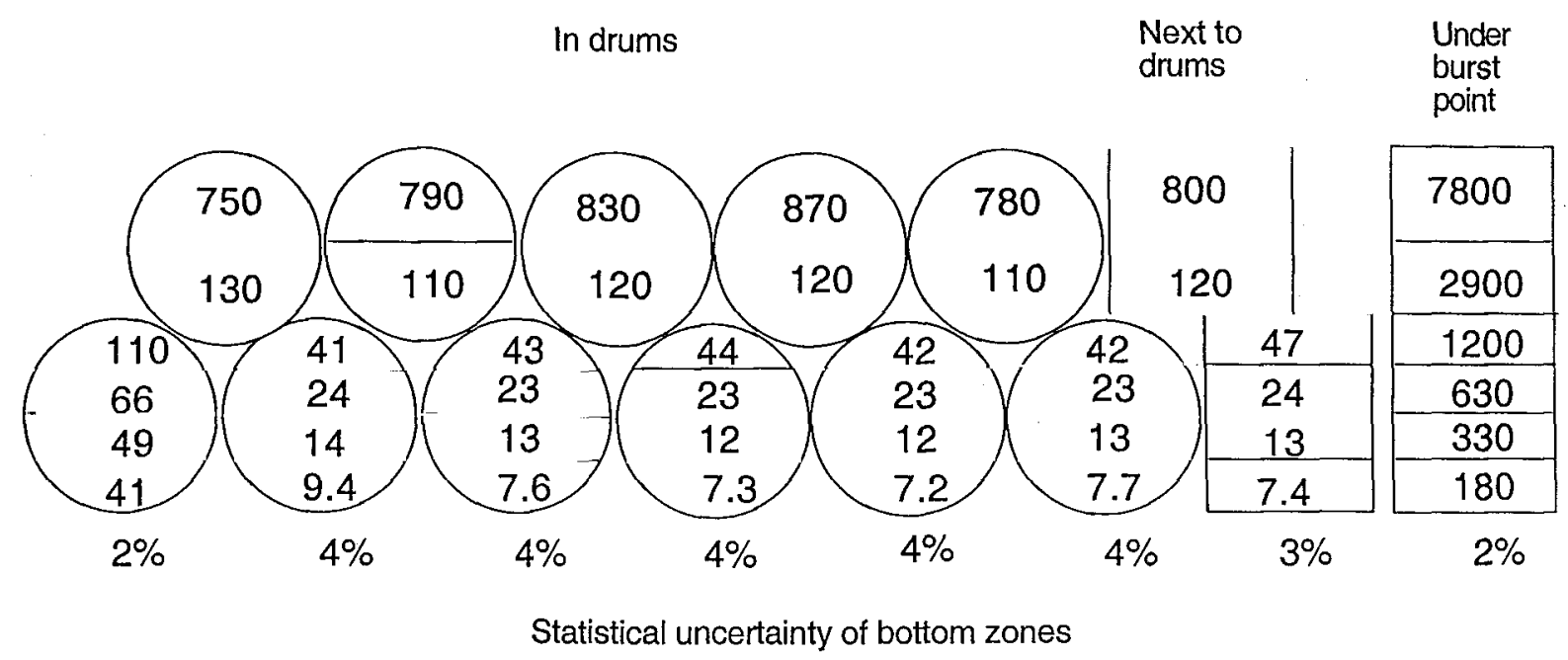

Fig. A89

Fission neutrons

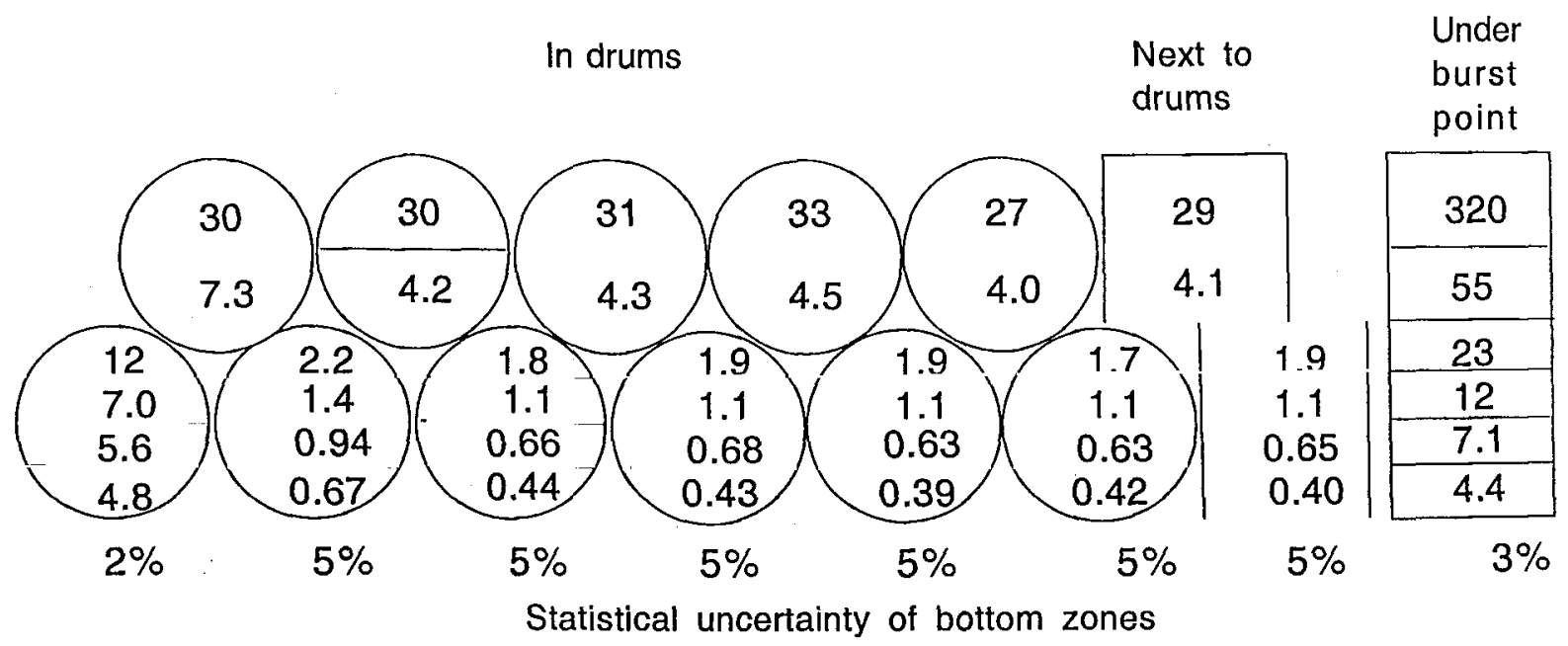

Fig. A90 
Radiation Dose in 200-liter Drums inside a Metal Roof Building with $R=40$ meter (Megarad)

Yield: $10 \mathrm{kT} \quad$ HOB: $10 \mathrm{~m}$

\section{$14 \mathrm{Mev}$ neutrons}

In drums

Next to

drums

Under

burst
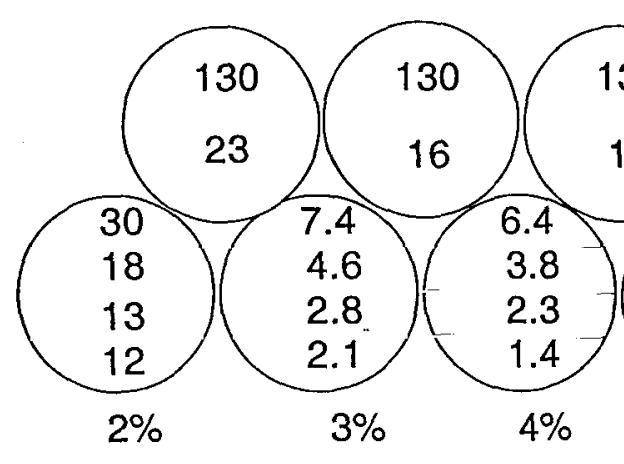

130
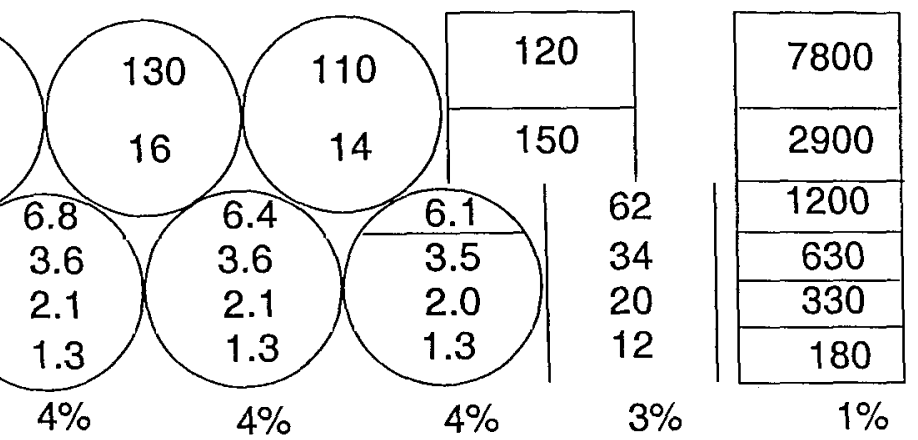

Statistical uncertainty of bottom zones

Fig. A91

\section{Fission neutrons}

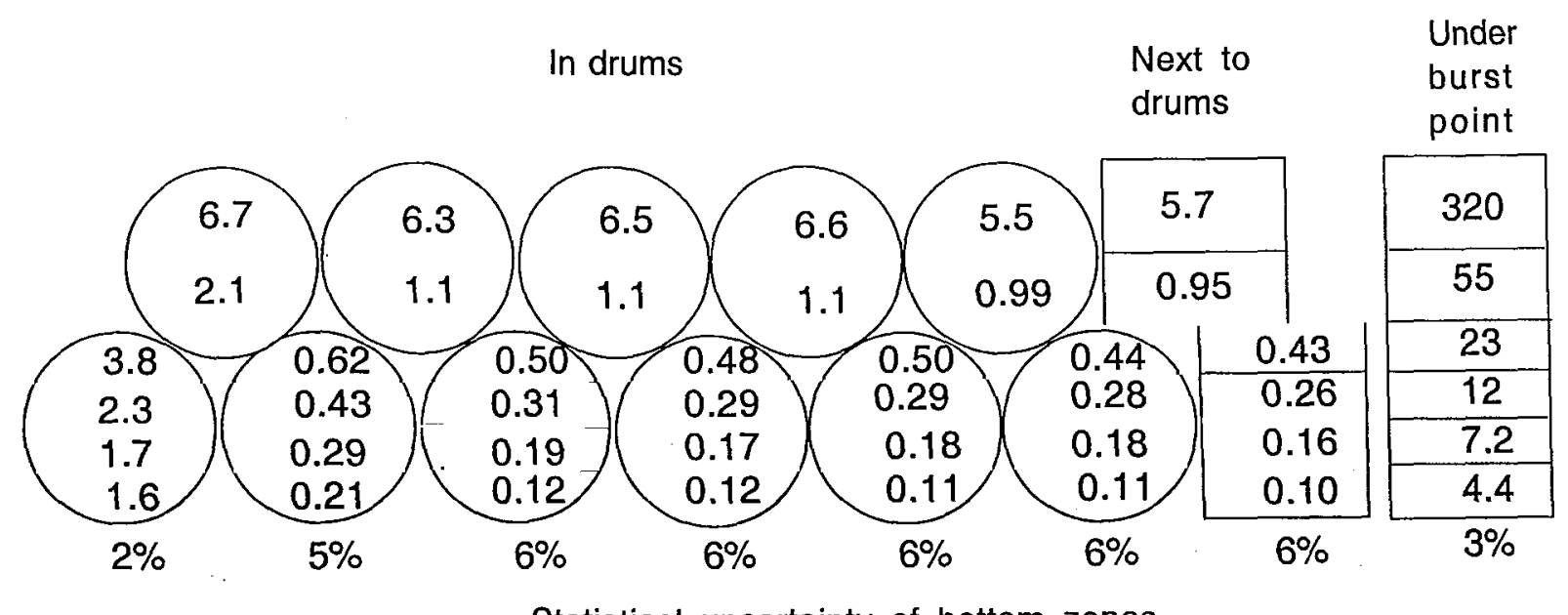

Statistical uncertainty of bottom zones

Fig. A92 
Radiation Dose in 200-liter Drums inside a Metal Roof Building with $\mathrm{R}=80$ meter (Megarad)

Yield: 10kT HOB: $10 \mathrm{~m}$

$14 \mathrm{Mev}$ neutrons

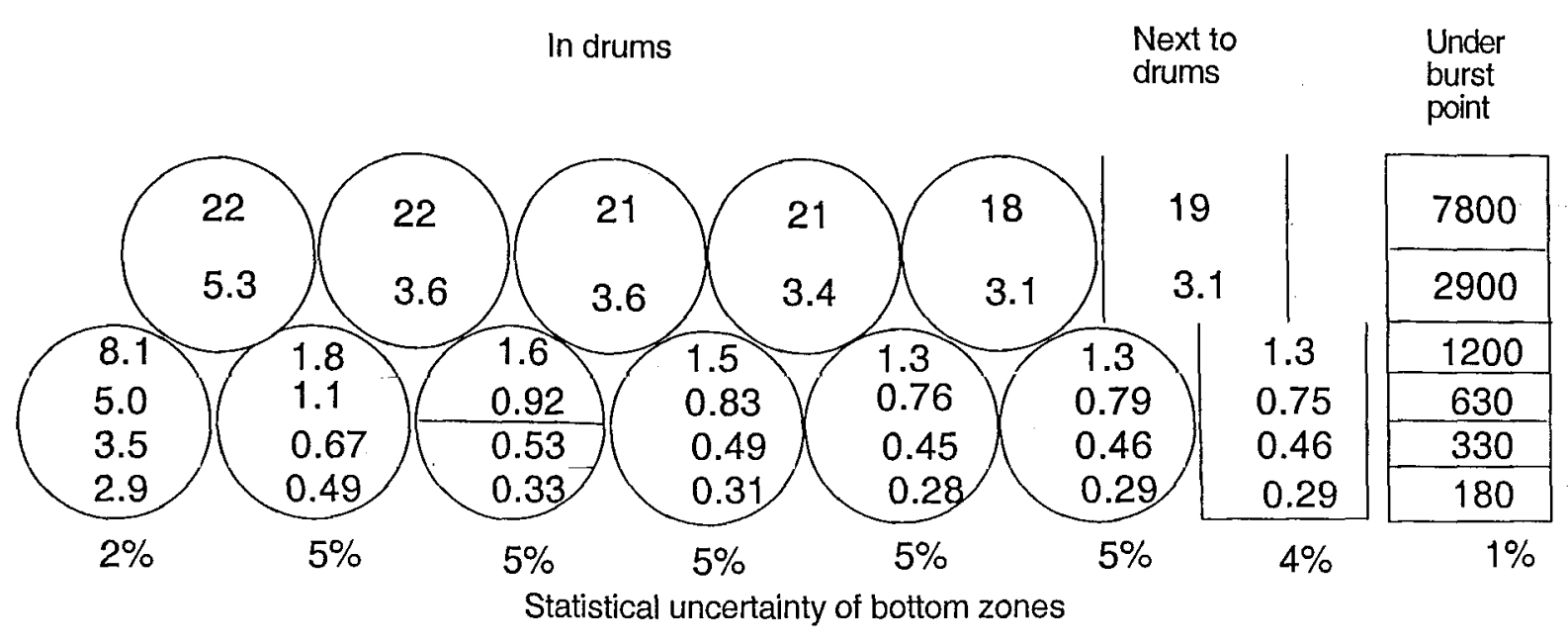

Fig. A93

Fission neutrons

In drums

Next to

Under

drums

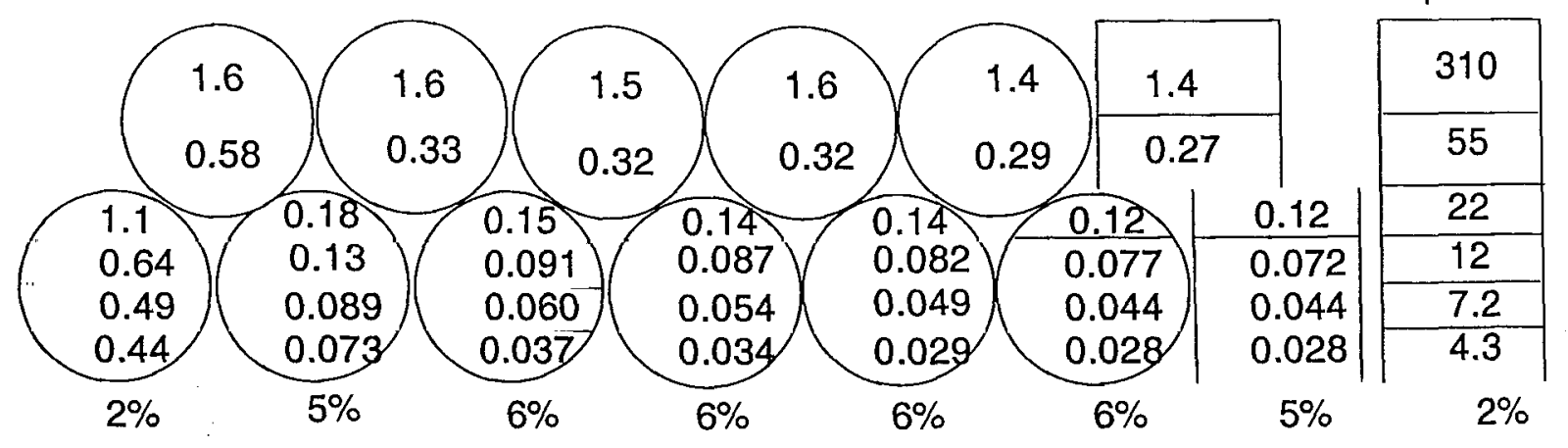

Statistical uncertainty of bottom zones

Fig. A94 


\section{Radiation Dose in 200-liter Drums inside a Metal Roof Building with $\mathrm{R}=20$ meter (Megarad)}

Yield: 10kT Neutron spectrum: $14 \mathrm{Mev}$

\section{$5 \mathrm{~m} \mathrm{HOB}$}

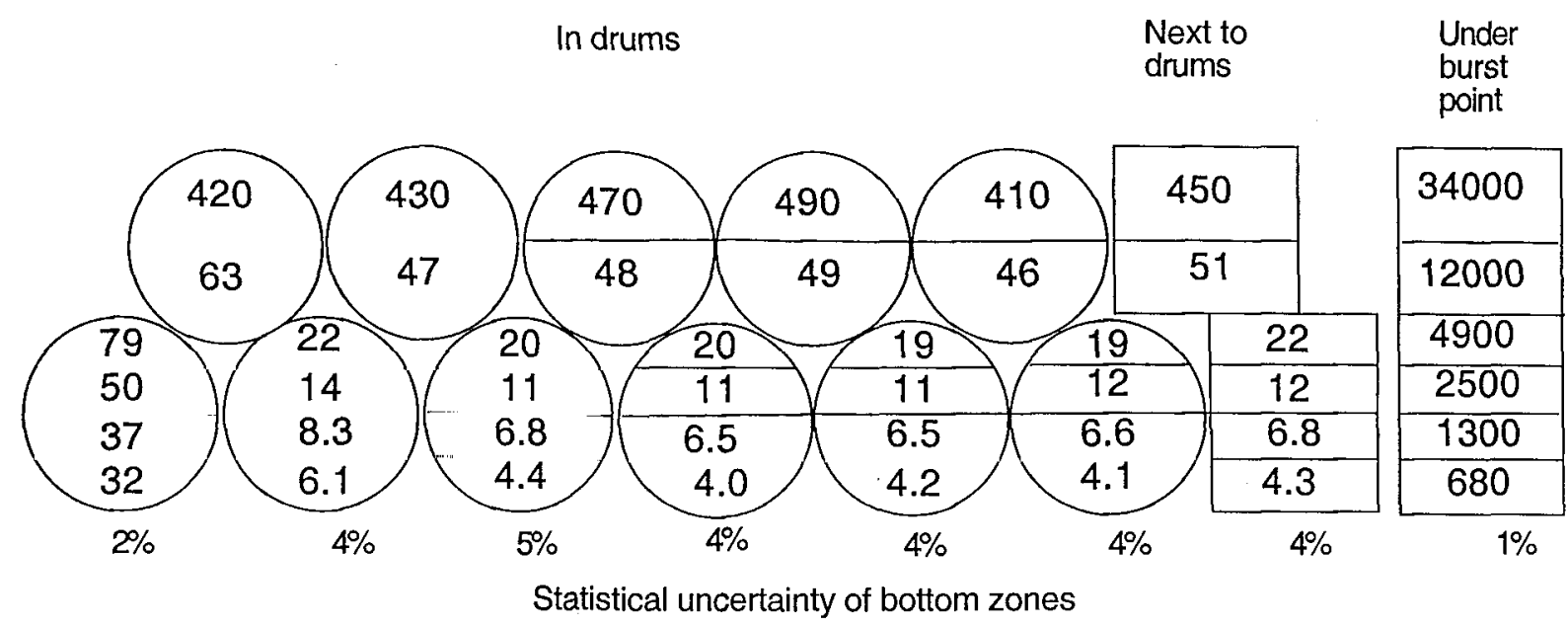

Fig. A95

$20 \mathrm{~m} \mathrm{HOB}$

In drums

Next to

Under

drums

burst

point

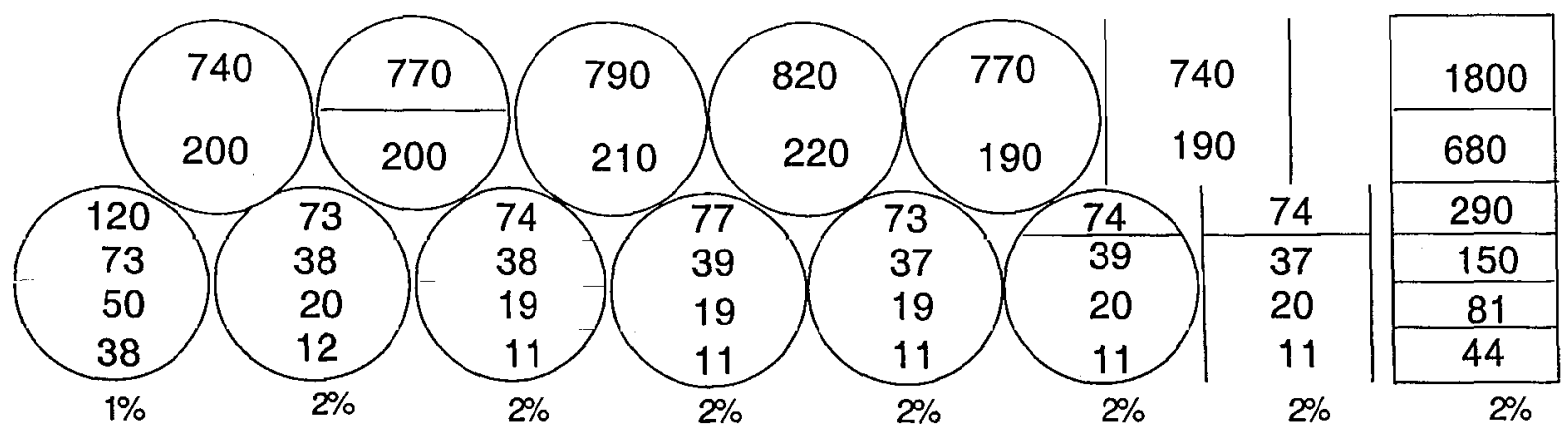

Statistical uncertainty of bottom zones

Fig. A96 
Radiation Dose in 200-liter Drums inside a Metal Roof Building with $R=20$ meter (Megarad)

Yield: 10kT Neutron spectrum: $14 \mathrm{Mev}$

\section{$55 \mathrm{~m} \mathrm{HOB}$}

In drums

Next to

Under

burst
point

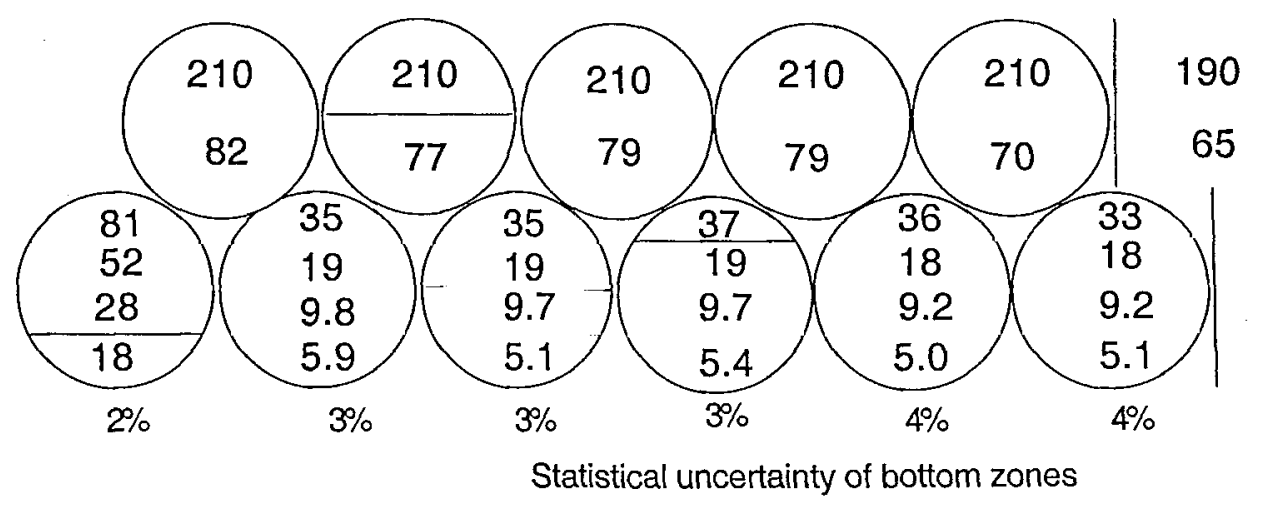

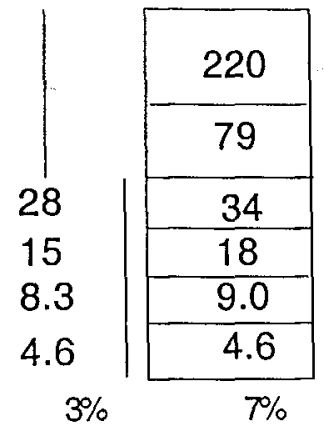

Fig. A97

\section{$138 \mathrm{~m} \mathrm{HOB}$}

In drums

Next to

Under

drums

burst

point

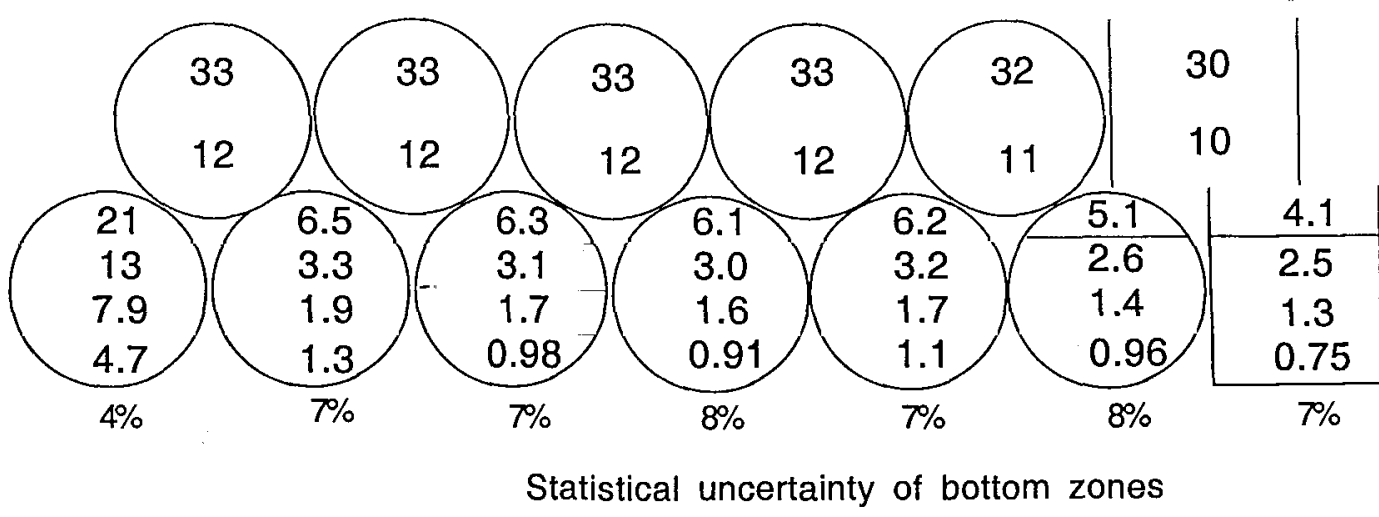

\begin{tabular}{|c|}
\hline 29 \\
\hline 10 \\
\hline 4.6 \\
\hline 2.6 \\
\hline 1.5 \\
\hline 0.93 \\
\hline $14 \%$
\end{tabular}

Fig. A98 
Radiation Dose in 200-liter Drums inside a Metal Roof Building with $\mathrm{R}=20$ meter (Megarad)

Yield: 10kT Neutron spectrum: Fission

\section{$5 \mathrm{~m} \mathrm{HOB}$}

Next to
drums

In drums
Under

$$
\text { burst }
$$

point

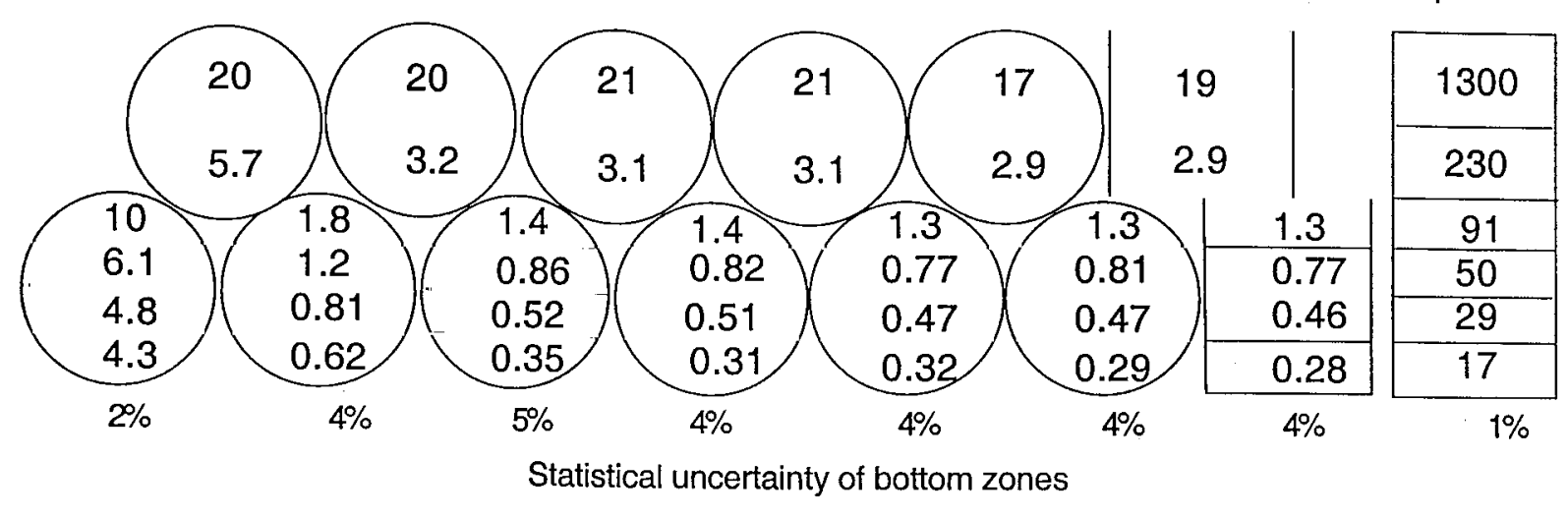

Fig. A99

\section{$20 \mathrm{~m} \mathrm{HOB}$}

In drums

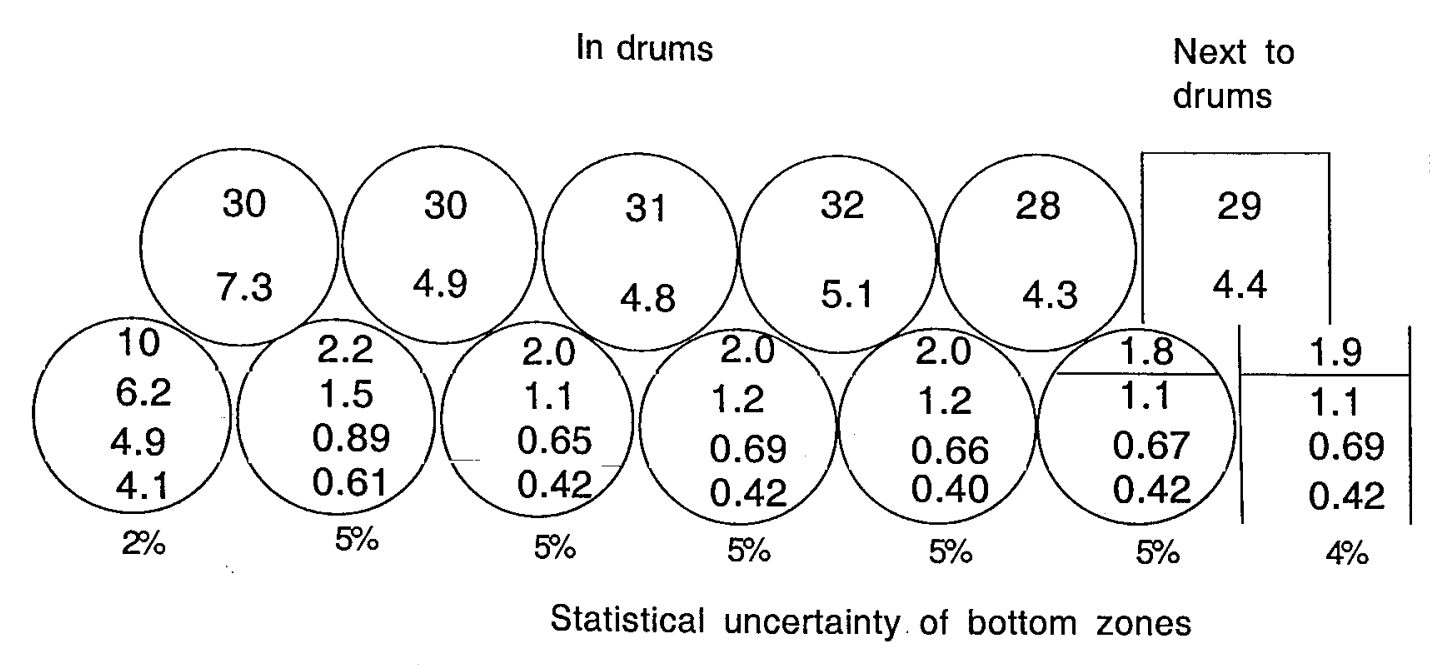

Fig. A100 


\title{
Radiation Dose in 200-liter Drums inside a Metal Roof Building with $\mathrm{R}=20$ meter (Megarad)
}

Yield: 10kT Neutron spectrum: Fission

\section{$55 \mathrm{~m} \mathrm{HOB}$}

\author{
In drums
}

Next to

drums

Under

burst

point
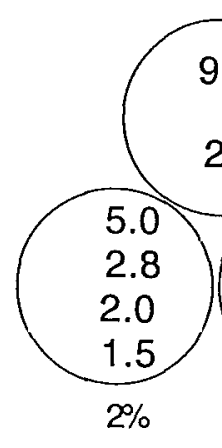

\section{5 \\ 2.6}
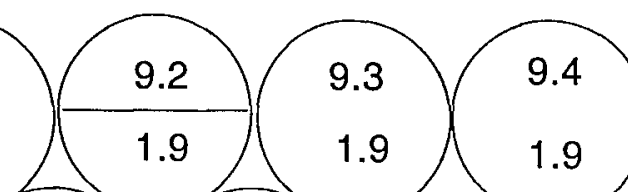

0.89

0.55

0.35

0.25

1.9

0.81
0.44

0.27

0.17

$5 \%$

Statistical uncertainty of bottom zones

Fig. A101

$138 \mathrm{~m} \mathrm{HOB}$

In drums

Next to

drums
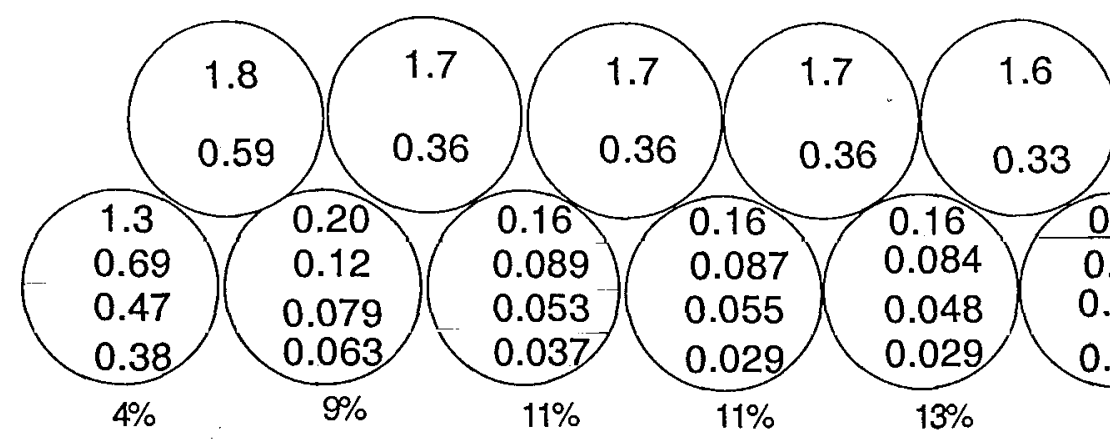

0.087

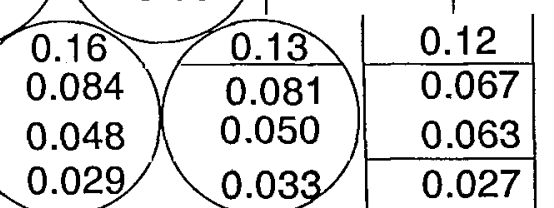

0.055

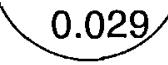

$13 \%$

$13 \%$

$12 \%$

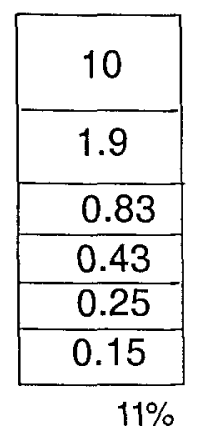

Statistical uncertainty of bottom zones

Fig. A102 